Claremont Colleges

Scholarship@Claremont

KGI Theses and Dissertations

KGI Student Scholarship

$12-16-2016$

\title{
Multiplex Drug Screenings to Discover Host Oriented Therapies Against Infectious Diseases
}

William Leonardi

\section{Recommended Citation}

Leonardi, William. (2016). Multiplex Drug Screenings to Discover Host Oriented Therapies Against Infectious Diseases. KGI Theses and Dissertations, 5. https://scholarship.claremont.edu/kgi_theses $/ 5$. doi: 10.5642/kgitd $/ 5$

This Open Access Dissertation is brought to you for free and open access by the KGI Student Scholarship at Scholarship @ Claremont. It has been accepted for inclusion in KGI Theses and Dissertations by an authorized administrator of Scholarship @ Claremont. For more information, please contact scholarship@cuc.claremont.edu. 


\section{Multiplex Drug Screenings to Discover Host Oriented Therapies Against Infectious Diseases}

A Dissertation submitted to the Faculty of Keck Graduate Institute of Applied Life Sciences in partial fulfillment of the requirements for the degree of Doctor of Philosophy in Applied Life Sciences, Claremont, California, 2016 


\section{Copyright by William Leonardi 2016}

All rights Reserved

We, the undersigned, certify that we have read this dissertation of William Leonardi and approve it as adequate in scope and quality for the degree of Doctor of Philosophy.

Dissertation Committee:

Dr. Mikhail Martchenko, Chair

Dr. Animesh Ray, Member

Dr. M. Ian Phillips, Member

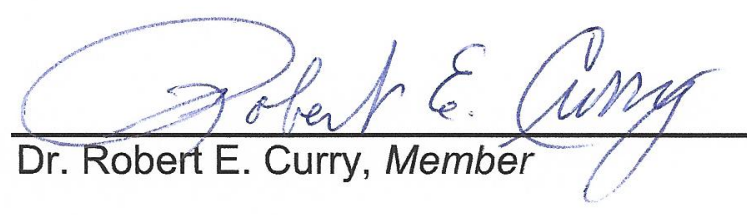

Dr. John L. Krstenansky, PhD Program Director 


\section{Dedication:}

To my parents Rifai Leonardi and Linda Tjahja 


\section{Acknowledgement}

I would like to express my deepest gratitude to all persons who have supported to finally complete my research and dissertation.

My deepest gratitude goes first to my parents Rifai Leonardi and Linda Tjahja who always gracious support, encouragement, advice, and comfort through ups and downs. Without my parents, I will not be able to stand where I am today. My deepest appreciation also goes to my mentor and advisor, Dr. Mikhail Martchenko who always have a faith and optimism on me to always excel and constantly guided me through my research and graduate studies. I really appreciate your support and trust in me despite ups and downs during the research process.

My sincere gratitude also extends to my dissertation advisory committee, $\mathrm{Dr}$. Animesh Ray, Dr. M. Ian Phillips, and Dr. Robert E. Curry for the valuable advises, comments, and encouragements through my research. Your guidance and advises have provided me with different perspective on to better approach my research.

I would like to also thank Dr. Anastasia Levitin, Leeor Zilbermintz, Kevin Kim, Liz Henderson, Ryan McComb, Kathryn McNevin, KiriLynn Svay, Labmates, KGI Faculties and Staff for making my five years' time at KGI memorable. I really enjoy and treasure the friendships that I made during my time.

Lastly, I would like to thank my brother, Anthony Leonardi and my best friend for life Indah Kusumawardhani for your tireless support and encouragement. 


\title{
Multiplex Drug Screenings to Discover Host Oriented Therapies Against Infectious Diseases
}

\author{
By William Leonardi \\ Keck Graduate Institute of Applied Life Sciences: 2016
}

Drug resistance is a longstanding and still-increasing threat to the effective treatment of infectious diseases. Discovering drugs that target host proteins involved in pathogenicity is a strategy that could address this problem. Unfortunately, there are currently no FDA-approved infectious disease therapies that specifically target host proteins. Our goal is to develop a method to i) quickly discover new drugs for the treatment infectious diseases, ii) identify the specific host protein target of the drugs, iii) investigate the broad spectrum application of the drugs. To find these types of drugs, we employed a novel multiplex drug screening method in which we used disease pathway knowledge to more effectively screen a library of FDA-approved drugs. We utilized a cell-based survival assay to determine safety and efficacy and a biochemical-based assay to determine the host protein target of the drugs. This methodology led to the discovery of two approved drugs and their host protein targets. In addition, these drugs were shown to be safe and effective in animal models. These results suggest that our novel multiplex drug screening method can be used to address the drug resistance problem. 


\section{Table of Contents}

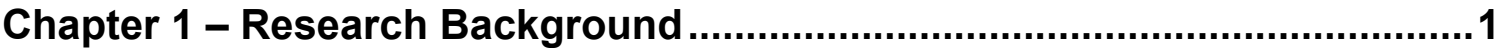

Major Probem with Current Infectious Disease Therapies ................................... 1

Anti-microbials as Frontline Therapeutics for Infectious Diseases ...................... 2

The Development of Antimicrobial Resistance ................................................... 2

Host-Oriented Therapies as a Solution ............................................................. 4

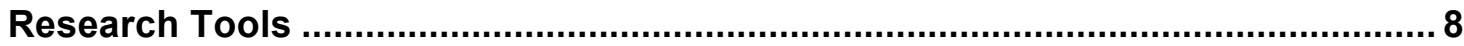

Research Approach and Strategy ............................................................... 8

William Leonardi Contributions .................................................................11

Chapter 2 - Identification of agents effective against multiple toxins and viruses by host-oriented cell targeting .....................................................12

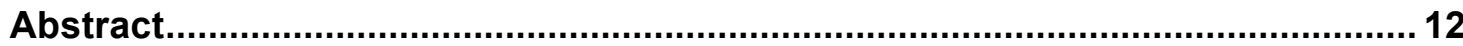

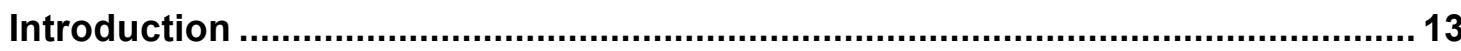

Results …........................................................................................... 14

Screening of FDA approved drugs for inhibitors of toxin - induced cell death ........ 14

Amodiaquine and its metabolite are potent inhibitors of LF-PA induced death in vitro

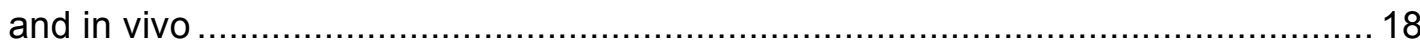

Amodiaquine Inhibits Cytosolic Entry of LF ................................................ 20

Amodiaquine binds to and inhibits host cathepsin B ........................................... 23

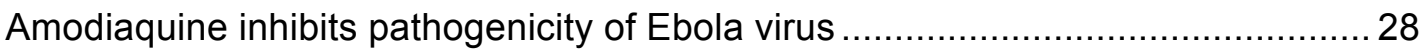

Amodiaquine inhibits pathogenicity of other Category A, B, and C pathogenic agents that enter into host cytoplasm from acidified endosomes ......................... 30

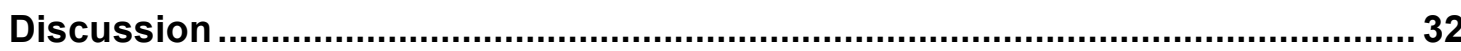

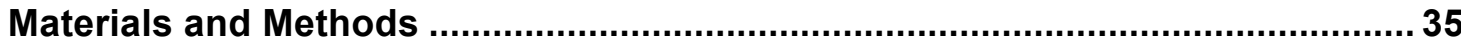

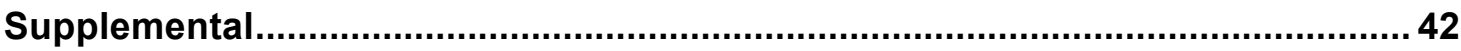

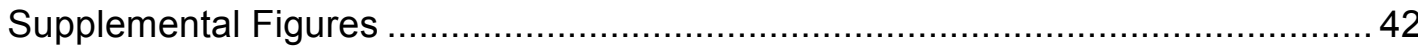

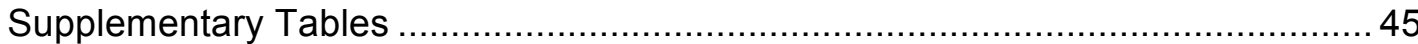

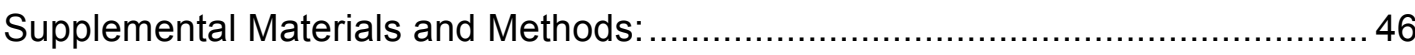

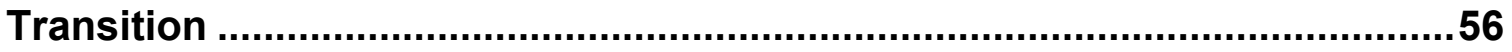

William Leonardi Contributions ...............................................................57

Chapter 3 - Bithionol blocks pathogenicity of bacterial toxins, ricin, and

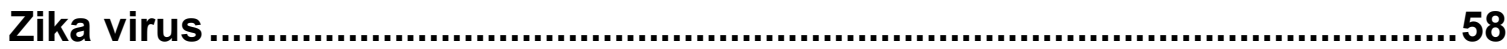

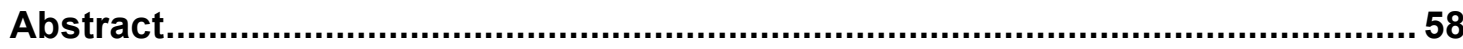

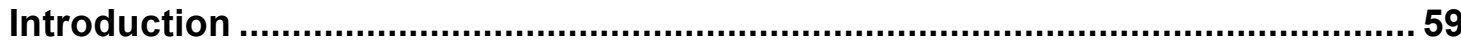

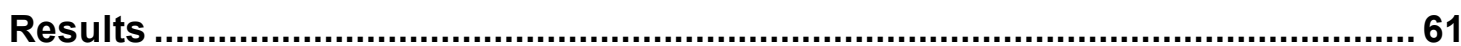

Identification of host hub proteins exploited by multiple pathogenic toxins.............61

The effect of caspase mutations on the sensitivity of human B-cells to P.aeruginosa

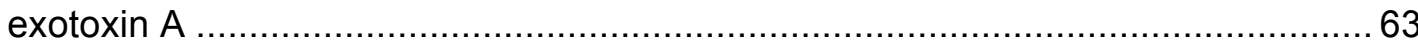

A multiplexed cellular screen for $C C L$ drugs that inhibit cytotoxic activities of bacterial toxins exploiting unique but interconnected host pathways 
A multiplex protein function-based screen for $\mathrm{CCL}$ drugs that inhibit proteolytic activities of host caspase-3, -6 , and -7 .

Bithionol reduces the pathogenicity of a range of toxins by inhibiting host caspases

Bithionol inhibits cytotoxic activity of anthrax toxins.

Bithionol inhibits ricin and Botulinum Neurotoxin A - induced death in vitro and in vivo.

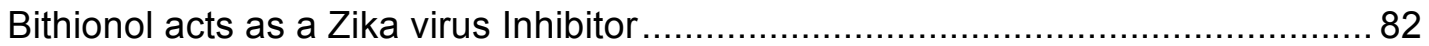

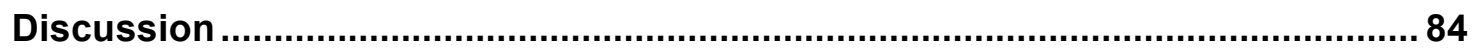

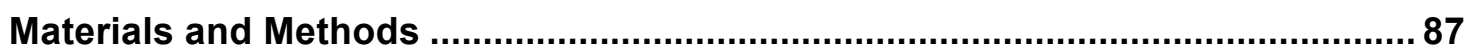

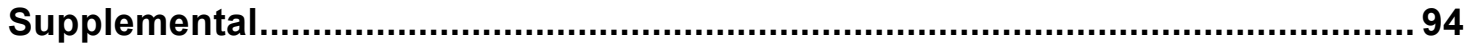

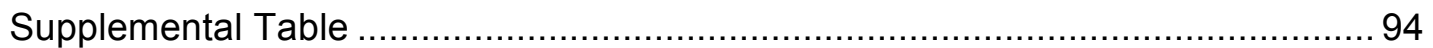

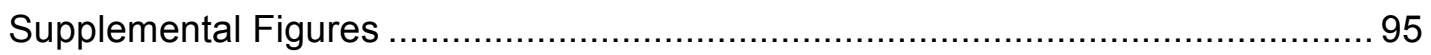

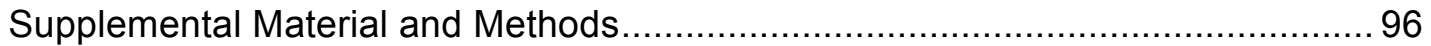

Chapter 4 - Future Directions and Concluding Remarks ..........................100

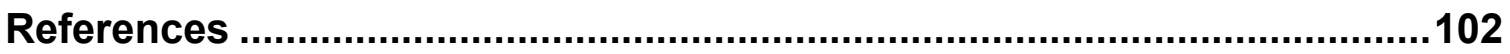




\section{Chapter 1 - Research Background}

\section{Major Probem with Current Infectious Disease Therapies}

Despite the advancement of science and disease treatment, infectious diseases are still the leading cause of mortality in millenial century ${ }^{1}$. Between 1980 and 2013 there were 12,102 outbreaks of 215 human infectious diseases ${ }^{2}$. Infectious diseases contribute to 44 million disease cases a year, occuring in 219 nations ${ }^{2}$. Various efforts have been deployed to manage the outbreak of infectious diseases, the primary methof being prescribing antimicrobial therapies. Unfortunately, the effort of combating infectious diseases by prescribing antimicrobial thereapy also contributed to a three fold increas in infectious

disease outbreaks between 1980 and 2010 (Figure 1)2. The emergence and reemergence of infectious diseases and increasing cases of anti-microbial resistance press the need to discover effective therapies against them.

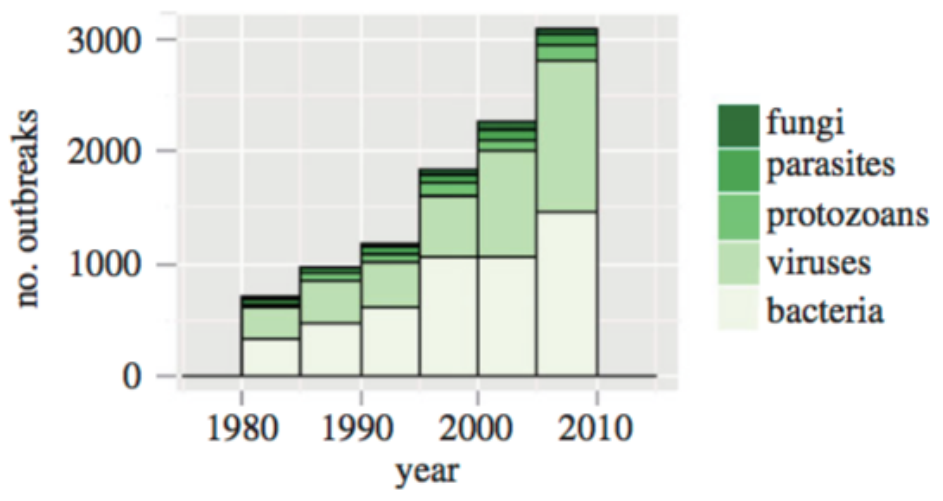

Figure 1: Total number of outbreaks steadily increased between 1980 and 2010 , disease outbreak predominantly caused by bacteria ${ }^{2}$ 


\section{Anti-microbials as Frontline Therapeutics for Infectious Diseases}

The definition of antimicrobials are outlined by American Chemistry Society (ACS), as compounds that are produced by bacteria or fungi which have the ability to inhibit or kill the competing microbial species ${ }^{3}$. Penicillin was the first effective and successful antimicrobial therapy that was used for various of infections such as pneunomia and gonorrhea ${ }^{3}$. Penicillin was first discovered by Alexander Flemming in 1928 when he discovered a halo on one of his petri dishes that contained Staphylococus bacteria. Through this observation, he concluded that the halo was caused by the Penicillium fungus or mold ${ }^{4}$. The discovery of penicillin was further studied by a group of scientists from Oxford University who produced it for use in humans in $1941^{3}$. Later on, multiple pharmaceutical companies developed efforts to scale up the production process. By late 1943 the mass production of penicillin began and was effectively used to fight infections during World War $\|^{3}$. By the end of the 1940s, Penicillin was widely available for humans at an affordable cost. The discovery of penicillin has served as the foundation for the extensive research of discovering various antimicrobial therapies for many years to come.

\section{The Development of Antimicrobial Resistance}

The success of Penicilin served as a foundation for a new era of antimicrobial therapy. Between 1940 and 1960, there was extensive discovery of a new class of anti microbials to fight infections ${ }^{5}$. Understanding the significance and clinical 
benefit of antimicrobials as a therapy, people started to misuse and overuse the then, which are the two main contributing factors that lead to antimicrobial resistance $^{6}$. Due to this fact, antimicrobial resistance developed not long after antimicrobials became widely used (Figure 2). Pathogens started to develop resistance against antimicrobials within a short amount of time and the problems of anti-microbial resistance will remain an issue for many years to come.

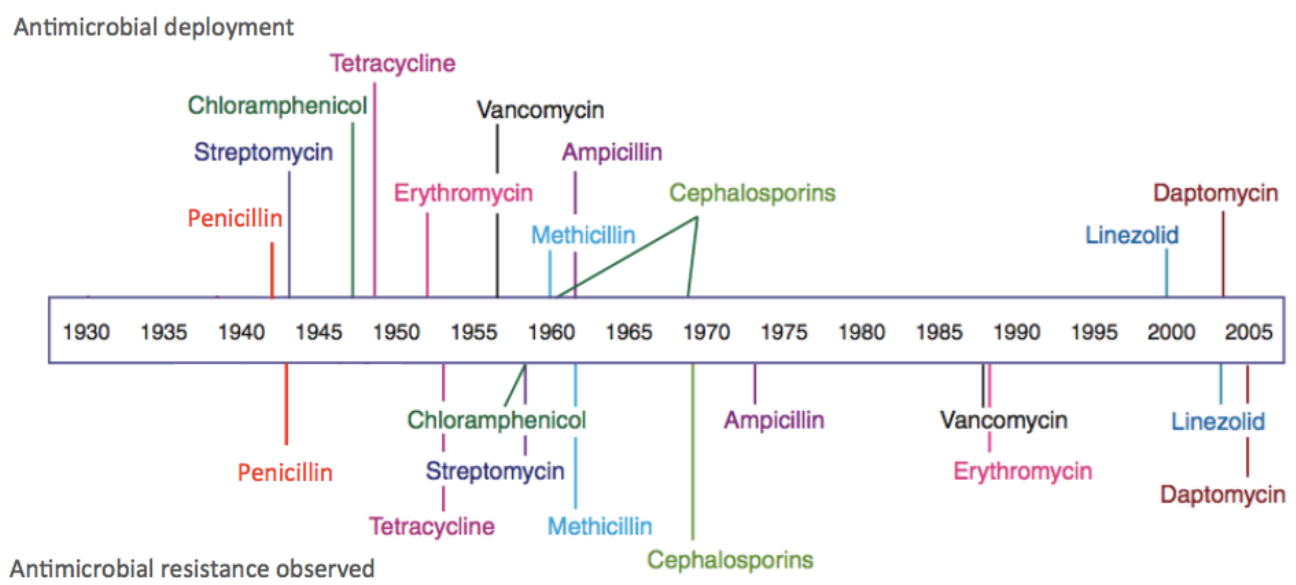

Figure 2: Timeline of antimicrobial first use and development of antimicrobial resistance ${ }^{5}$

The hypothesis underlying the development of antimicrobial resistance is due to its own mechanism of action. Antimicrobials are designed to directly inhibit the function and growth of the pathogen ${ }^{5}$. In short, once the pathogen develops mutatios or evolves, antimicrobial will lose their ability to surpress or inhibit the original targeted function of the pathogens. Mycobacterium tuberculosis is a prominent example of a pathogen that acquired multiple mutations which 
eventually became known as "superbug" due to its propencity for developing resistance against multiple antimicrobial treatments ${ }^{7}$.

Antimicrobial resistance has also emerged as one of the major causes of death worldwide ${ }^{8}$. A publication published by the Review on Antimicrobial Resistance in 2014 concluded that antimicrobial resistance will be the number one cause of death in $2050^{9}$. The study projected that antimicrobial resistance will contribute to more than 10 million deaths, which is much more than the amount of deaths causes by cancer ${ }^{9}$. In addition, globalization also contributes to the spread of antimicrobial-resistance pathogens ${ }^{9}$. Reflecting upon the urgency of antimicrobial resistance, there is a huge need to address the problem by discovering new alternative therapies against infectious diseases.

\section{Host-Oriented Therapies as a Solution}

In order to address the current problems of antimicrobial therapies, having a understanding of host protein and pathogen interactions is important, as it will help to unveil a way to discover and develop new therapies that directly target host proteins or "host oriented therapies". Different than antimicrobial therapy, also known as "pathogen oriented therapies", host oriented therapies aim to directly target host protein(s) that are exploited by the pathogen. This approach is very robust and lucrative, as it has the advantage of circumventing the development of drug resistance due to pathogen mutations. 
Pathogens require the cooperation of host cell proteins to enter, replicate, and exert their toxicity/activity. Once pathogens bind with receptors on the outer cell membrane, the host cell will start the process of cell signalling and eventually internalize pathogens and proteins complexes via endocytosis or phagocytosis. Once it gets into the inner membrane, different proteins will help mediate the release of pathogens into the cytosol. Pathogens will then exert their pathogenic effects through different types of mechanisms which eventually lead to host cell death.

Studies have shown that different types of pathogens may share similar pathogenic pathways in their expolitation of host cells ${ }^{10}$. Viruses such as Leishmania, Chlamydia, HIV, and SV40 share similar entry mechanisms while having different exit mechanisms. Leishmania, Chlamydia, and HIV travel to the endosome before being tranlocated to the cytosol. Meanwhile SV4O will undergo retrogate transport through the Golgi to the Endoplasmic Reticulum (ER) before being translocated into cytosol where it eventually kills the host cell ${ }^{10}$. Similar to viruses, bacterial toxins such as Diphtheria, Anthrax, Botulinum, Cholera, Shiga, and Ricin toxins also share similar entry mechanism pathways. Diphtheria, Anthrax, and Botulinum toxins bind with receptors before being internalized, and travel into endosomes prior their release into cytosol; Cholera and Shiga toxins, as well as Ricin all undergo retrogate transport through the Golgi to the 
Endoplasmic Reticulum (ER) before being translocated into the cytosol where they eventually kill the host cells ${ }^{10}$.

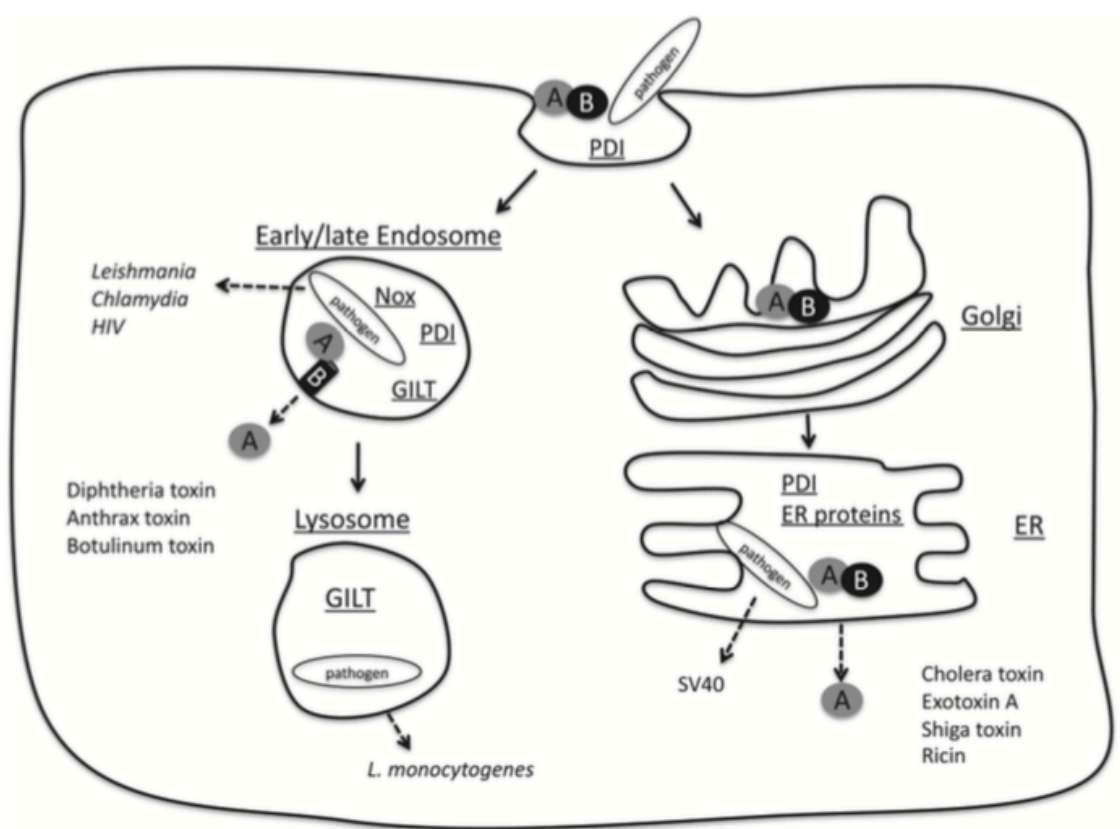

Figure 3: Different pathogens may share similar pathways of introducing their pathogenicity ${ }^{10}$.

As it has been previously described, different pathogens may share similar pathways of introducing their pathogenicity into the host. In addition, there are multiple host proteins that mediate the entry and exit mechanisms of the pathogens (Table 1). Therefore, the hypothesis of host oriented therapies may offer additional benefits to be used as potential broad specturm therapies, as multiple pathogens exploit similar host proteins to mediate their pathogenicity. 


\begin{tabular}{|c|c|c|}
\hline \multirow{2}{*}{$\begin{array}{l}\text { Exploited Host } \\
\text { Proteins }\end{array}$} & \multicolumn{2}{|c|}{ Pathogenic Agents } \\
\hline & Bacterial Toxins & Viruses \\
\hline Furin & $\begin{array}{c}\text { Anthrax }^{11}, \text { Diphtheria } \\
\text { P. aeruginosa exotoxin } A^{13}\end{array}$ & $\begin{array}{l}\text { HIV-1 } \\
\text { Ebola }^{14}\end{array}$ \\
\hline Calpain & Anthrax $^{11}$ & $\begin{array}{c}\text { HIV-1 }^{16} \\
\text { Hepatitis C }\end{array}$ \\
\hline Cathepsin B & $\begin{array}{c}\text { Anthrax }^{11} \\
\text { Diphtheria }^{18}\end{array}$ & $\begin{array}{c}\text { HIV-1 }{ }^{19} \\
\text { Ebola }^{15} \\
\text { Influenza A }\end{array}$ \\
\hline Caspase-3 & $\begin{array}{c}\text { Anthrax }{ }^{11} \\
\text { Diphtheria } \\
\text { P. aeruginosa exotoxin } A^{21} \\
\text { C. difficile toxin } B^{21} \\
\text { Ricin }^{22}\end{array}$ & $\begin{array}{l}\text { HIV-1 }^{23} \\
\text { Hepatitis } \mathrm{C}^{24} \\
\text { Dengue }^{25}\end{array}$ \\
\hline
\end{tabular}

Table 1: Different pathogens exploit similar host proteins to introduce their pathogenicity

The benefits of host oriented therapies have been proven safe, as their use is well developed in fields other than infectious diseases. One of the prime examples of host oriented drugs are statins, drugs known for treating cholestorol. Statins direcly bind and alter the conformation of HMG-CoA reductase enzyme ${ }^{26}$. The alteration of HMG-CoA reductase enzyme will eventually inhbit the conversion process of HMG-CoA into mevalonic acid, a cholesterol precursor ${ }^{26}$. As a result, sterol regulatory element binding proteins (SREBPs) are induced and increase the experession of LDL receptor which help to reduce LDL circulation ${ }^{26}$. Based on this example, there is a strong hypothesis that host oriented drugs have potential for being succesful treatments in the field of infectious diseases. 


\section{Research Tools}

There are two main tools that are being utilized for research: drug libraries and multiple bacterial toxins. Our drug library was purchased from John Hopkins University, and is known as the John Hopkins Clinical Compound Library (JHCCL). The main purpose of utlizing this library was because it it is one of the most extensive drug libraries, that includes 1,581 small molecule drugs that have either been previously approved by the FDA, most of which are off-patent ${ }^{27}$. The safety and pharmacokinetic profiles of these drugs, as they were used in patients, is widely available, which creates opportunities for quick and low-cost drug development ${ }^{27}$. Multiple bacterial toxins such as anthrax, diphtheria, cholera, and $P$. aeruginosa exotoxin A were used, because the mechanisms underlying their pathogenicity are well understood.

\section{Research Approach and Strategy}

The research aim is to identify potential host oriented drugs, host protein targets, and broad spectrum applications of the drugs in infectious disease. Figure 4 outlined two research designs and strategies for discovering potential host oriented inhibitors. 


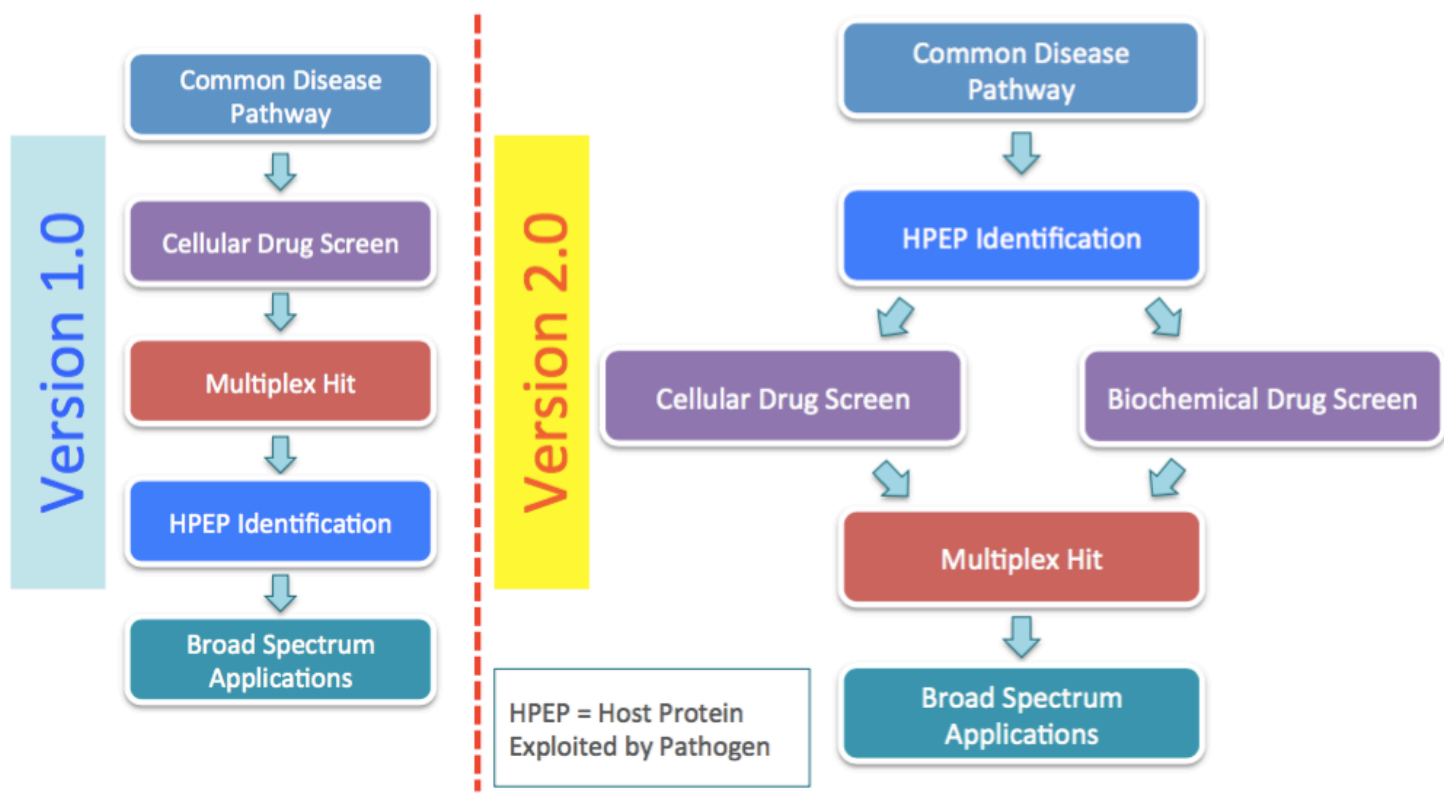

Figure 4: Research Design and Strategy to Identify Potential Host Oriented Drugs

Both studies require an exentesive and deep understanding of common disease pathways, therefore multiple bacterial toxins are incorporated, as the pathway and the targets of each respective toxins are well understood and characterized. In Version 1, the drug library were screened utilizing anthrax and diphtheria toxin. The "multiplex hit" is defined as a drug that protects the cell from toxicity. Once the hit has been identified, multiple studies were designed to identify the specific host protein that is being targeted by the drug. The data that was derived from the experiments was then used to validate the broad specturm application of the drug using different types of toxins. A more in depth explanation of the Version 1 study design can be found in Chapter 2 of this dissertation. 
Version 2 was designed by considering the challenges of identifying specific host targets in Version 1.0. The study began by identifying overlapping host proteins in multiple disease pathways. Once the host protein was identified, both cellular and bio-chemical (multiplex) drug screens were performed to identify "hits". The broad spectrum application was then validated by testing the "hits" against multiple toxins that potentially utilize this host protein to introduce their pathogenicity. A deeper explanation of Version 2 study design can be found in Chapter 3 of this dissertation. 


\section{William Leonardi Contributions}

William Leonardi performed the following experiments (presented on the Figures):

- Figure 1a and 1b

- Figure 2a, 2b, and 2c

- $\quad$ Figure $3 a, 3 b, 3 d$, and $3 e$

- Figure 4a, 4b, 4c, and 4d

- Supplemental Figure: S2, S3, and S4 


\section{Chapter 2 - Identification of agents effective against multiple toxins and viruses by host-oriented cell targeting}

\section{Abstract}

A longstanding and still-increasing threat to the effective treatment of infectious diseases is resistance to antimicrobial countermeasures. Potentially, the targeting of host proteins and pathways essential for the detrimental effects of pathogens offers an approach that may discover broad-spectrum anti-pathogen countermeasures and circumvent the effects of pathogen mutations leading to resistance. Here we report implementation of a strategy for discovering broadspectrum host-oriented therapies against multiple pathogenic agents by multiplex screening of drugs for protection against the detrimental effects of multiple pathogens, identification of host cell pathways inhibited by the drug, and screening for effects of the agent on other pathogens exploiting the same pathway. We show that a clinically used antimalarial drug, Amodiaquine, discovered by this strategy, protects host cells against infection by multiple toxins and viruses by inhibiting host cathepsin B. Our results reveal the practicality of discovering broadly acting anti-pathogen countermeasures that target host proteins exploited by pathogens. 


\section{Introduction}

Whereas medical treatments generally target specific cellular functions of patients to cure or mitigate the effects of diseases, the strategy underlying treatment of infectious disease treatment is to target the infecting pathogen ${ }^{28}$. Inevitably, and not surprisingly, the targeting of pathogens has led to the emergence and spread among pathogens of mutational resistance to countermeasures. Such resistance, together with a desire to expand the utility of countermeasures by increasing their range of therapeutic efficacy, has in recent years sparked interest in agents aimed at host functions that pathogens exploit to enter or be released from host cells ${ }^{28}$. Not infrequently, multiple pathogens or toxins that affect hosts by different mechanisms use the same host pathways ${ }^{29}$, raising the prospect that multiplex strategies that concurrently or sequentially screen for host functions exploited by multiple pathogenic agents may lead to the discovery of broadly active and host-oriented infectious disease countermeasures.

Here we report the discovery, using a cell-based multiplex approach to screen a library of FDA-approved drugs for the ability to interfere with disparately acting pathogens. We report here, that a compound used clinically as an antimalarial agent, inhibits both the detrimental effects of multiple bacterial toxins and the entry of Ebola and other viruses into host cells. We further show that the broad anti-pathogenic actions of Amodiaquine result from its ability to interfere with the functioning of the host protein, cathepsin B. 


\section{Results}

Screening of FDA approved drugs for inhibitors of toxin - induced cell death

In a systematic effort to identify candidates for repurposing drugs as broadspectrum, host-oriented, anti-toxin countermeasures, we screened members of the Johns Hopkins Clinical Compound Library (JHCCL) ${ }^{30}$ of 1,581 agents previously approved as drugs by the U.S. Food and Drug Administration for the ability to reduce lethality of RAW264.7 and C32 cells treated either with Bacillus anthracis lethal toxin or diphtheria toxin (Fig. 1a). These toxins were chosen because the mechanisms underlying their pathogenicity are well understood and are disparate to each other.

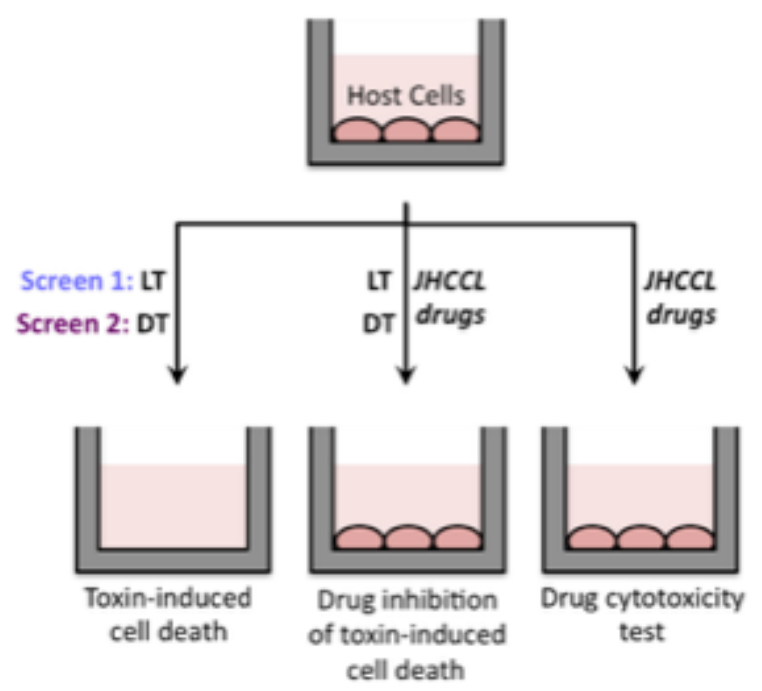

Figure 1a: Schematic diagram of cellular screens to identify drugs that reduce cellular lethality induced by anthrax lethal toxin, LF and PA (LT) and diphtheria toxin (DT). 
Between 50 and 70 percent of cells used for these assays normally undergo cell death, as determined by MTT assay, within 6 and 24 hours of exposure to anthrax lethal toxin and diphtheria toxin respectively, under the experimental conditions employed. A "hit" in our screen was defined as an event where cells exposed to a compound at a concentration of $16 \mu \mathrm{M}$ increased cell survival by at least 16 standard deviations $(\sim 1 \%$ hit rate) above the survival of control cells treated with either toxin, but is not cytotoxic to cells in the absence of toxins. Events defined as "multiplex hits" interfered with cell killing by both of the toxins (Fig. 1b). Five multiplex hits were identified and were tested further.

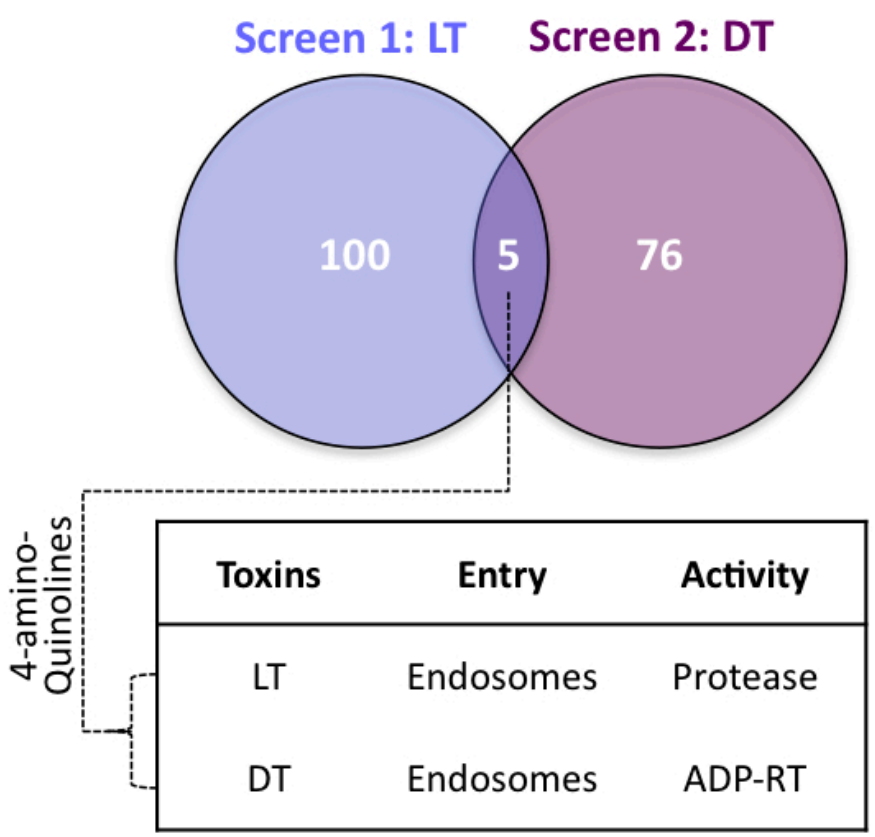

Figure 1b: The distribution of inhibitors obtained in those screens, with a table showing the routes taken by toxins to enter into cellular cytoplasm (Endocytosis), as well as the enzymatic activities of toxins (Protease or ADP-rybosyltransferase (ADP-RT) 


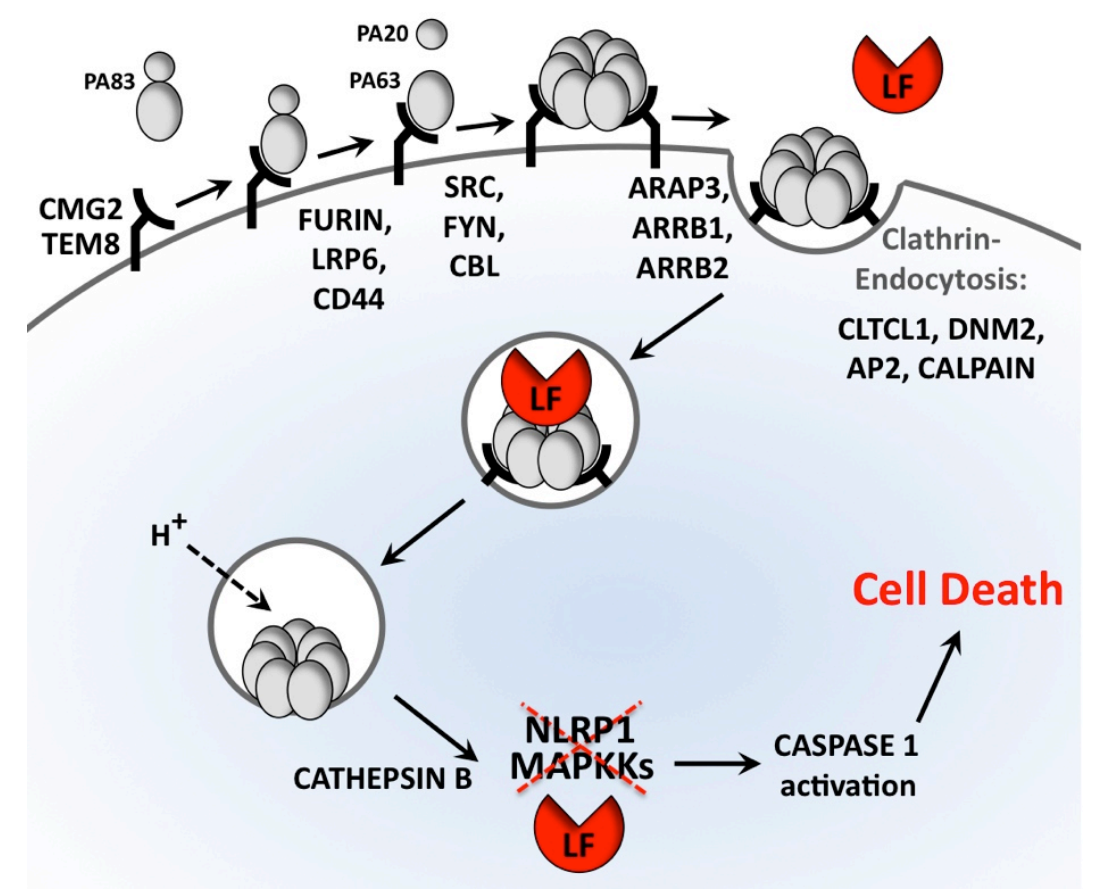

Figure 1c: Schematic depiction of the host pathway that mediates the delivery of anthrax toxin into cytoplasm. Lethal factor (LF) and edema factor (EF) interact with a third $B$. anthracis-generated protein, protective antigen (PA). Three host cell proteins CMG2, TEM8, and ITGB1 can serve as receptors for the bipartite PA/LF and PA/EF toxins. Fifteen additional host proteins are known to assist PA binding and/or internalization.

Anthrax toxin and diphtheria toxin enter the cytoplasm from acidified endosomes 31. Whereas diphtheria toxin is an ADP ribosyltransferase, anthrax toxin is a protease that cleaves host MAPKK (Fig. 1c). To identify agents that inactivate host proteins exploited by toxins, we focused on hits that inhibit the mechanistically differently acting anthrax and diphtheria toxins. In order to elucidate host-targets inhibited by these drugs we used only anthrax toxin, as the host cellular pathway that delivers the anthrax toxin into the cytoplasm is one of the best understood pathways ( ${ }^{32}$ and Fig. 1c). Anthrax lethal toxin is an exotoxin protein complex consisting of protective antigen (PA) and lethal factor (LF), which 
act collectively to damage the host cell ${ }^{11}$. PA is an $83 \mathrm{kDa}$ cellular receptorbinding protein (PA83), and the combination of PA with LF is cytotoxic ${ }^{11}$. LF is a $91 \mathrm{kDa}$ zinc metalloprotease that cleaves the $\mathrm{N}$-terminal substrate docking site of the mitogen-activated protein kinase kinases (MAP2K), preventing the passage of signals in the ERK1/2, p38, and c-Jun N-terminal kinase pathways ${ }^{33}$. Intoxication of a cell begins when PA83 binds to host cellular receptors, capillary morphogenesis protein 2 (CMG2), tumor endothelial marker 8 (TEM8), or integrin beta 1 (ITGB1) ${ }^{29,34,35}$. Once bound, host furin cleaves a $20 \mathrm{kDa}$ fragment from the N-terminus of PA83, thus activating the $63 \mathrm{kDa}$ protein, PA63 ${ }^{36}$. Following activation, PA63 forms a heptamer and binds $\mathrm{LF}^{37}$. The toxin undergoes clathrinmediated endocytosis and a decrease in endosomal $\mathrm{pH}$ induces the formation of an endosomal membrane PA channel, by which LF translocates into the cytosol ${ }^{38}$ before PA pores are transported to lysosomes for rapid degradation ${ }^{34,39,40}$. PA has been shown to induce the process of autophagy, whereby autophagosomes encapsulate endosomes and facilitate the delivery of LF into the cytoplasm ${ }^{41}$. A lysosomal protein, cathepsin B, is necessary for the autophagic flux, whereby LF is delivered from the intralumenal vesicles of the autophagosome-encapsulated multivesicular late endosomes into the cytoplasm through a back fusion process $40,42,43$

We observed that out of five compounds that inhibited anthrax and diphtheria toxins, two compounds were structurally related 4-amino-quinolines, Chloroquine and Amodiaquine. Two anti-malarial drugs, Chloroquine (CQ) and Amodiaquine (AQ), were observed to completely protect host cells against anthrax toxin killing 
in 6-hours toxin killing assay (Fig. 2a). However, our assay showed that unlike AQ, CQ only has a moderate ability to protect cells against LF-PA mediated 24hours killing (Fig. 2b). Interestingly, none of the other quinoline-containing antimalarial compounds, Cinchonine, Primaquine, and Quinidine, from JHCCL were active (Supplementary Fig. 1a-c).
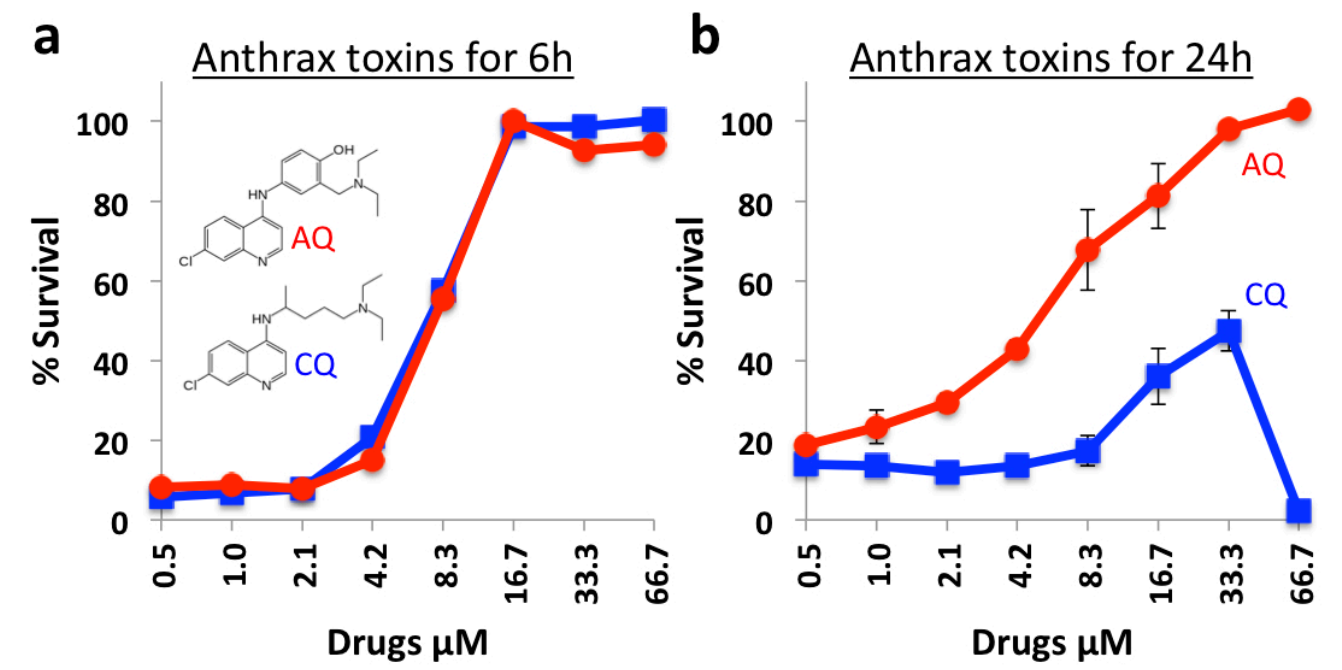

Figure 2a and 2b: Amodiaquine and JHCCL available structural analogs were tested for their ability to inhibit LF-PA-mediated cytotoxicity. RAW264.7 cells were seeded at $1 \times 10^{4}$ cells/well on 96-well plates and the following day were incubated with indicated doses of Amodiaquine or Chloroquine for $1 \mathrm{~h}$, followed by either $6 \mathrm{~h}$ (a) or $24 \mathrm{~h}$ (b) intoxication with $500 \mathrm{ng} / \mathrm{mL}$ PA $+500 \mathrm{ng} / \mathrm{mL}$ LF. Cell viability was determined by MTT assay (Materials and Methods) and is shown as the percentage of survivors relative to cells not treated with drugs.

Amodiaquine and its metabolite are potent inhibitors of LF-PA induced death in vitro and in vivo

After oral administration, AQ is rapidly absorbed and undergoes fast and extensive metabolisation by hepatocytes' cytochrome p450 enzyme to the AQ metabolite, Desethyl-Amodiaquine (DEAQ), the main active metabolite of $A{ }^{42}$. 
We tested the ability of DEAQ to reduce anthrax toxin mediated cellular killing, and observed that just like $A Q, D E A Q$ was able to reduce toxin-mediated cytotoxicity with an EC50 of $5 \mu \mathrm{M}$ (Fig. 2c). Since AQ and its metabolite, DEAQ, protected host cells against anthrax toxin killing, we evaluated the efficacy of $A Q$ as a therapeutic agent during anthrax toxin intoxication in Sprague-Dawley rats. Animals were injected intravenously with a lethal dose of anthrax toxin (LD100) and were intravenously co-injected with $A Q$ at $1.5,3.0$, or $6.0 \mathrm{mg} / \mathrm{kg}$. The $A Q$ doses were selected based on the FDA approved AQ dose of $10 \mathrm{mg} / \mathrm{kg}{ }^{44}$. Animals that received a lethal dose of anthrax toxin without $A Q$ all died within 90 minutes post intoxication (Fig. 2d). While the administration of $A Q$ at $1.5 \mathrm{mg} / \mathrm{kg}$ saved $40 \%$ of the rats, all of the animals in that group displayed classical signs of having undergone a toxin challenge, such as ataxia, lethargy, hyperpnea, and tachypnea. Rats that were challenged with anthrax toxin and treated with $A Q$ at 3.0 and $6.0 \mathrm{mg} / \mathrm{kg}$ all survived without displaying toxin-associated symptoms (Fig. 2d). 


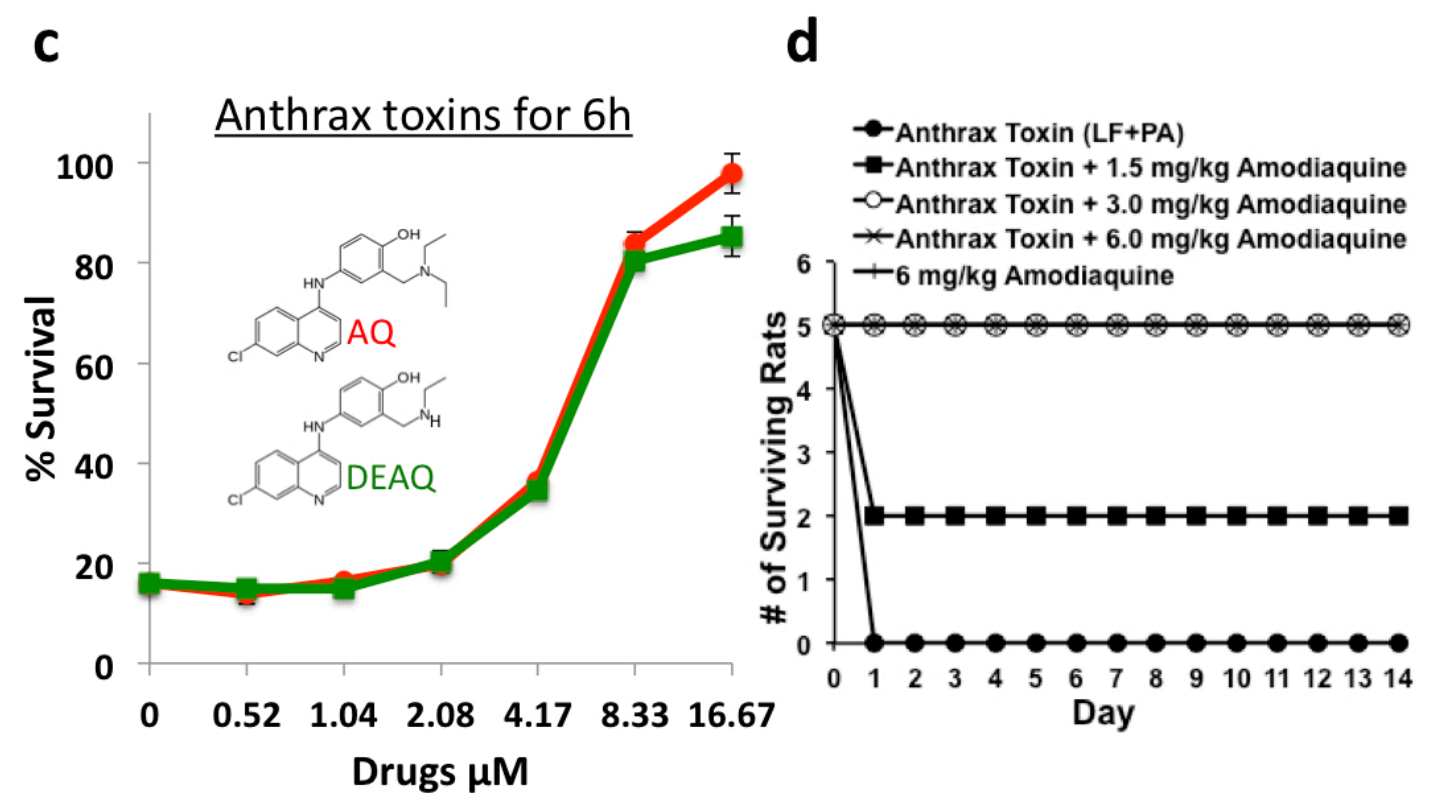

Figure 2c and 2d: AQ and DEAQ were tested for their ability to inhibit LFPA-mediated toxicity in (c) RAW264.7 cells and in (d) Sprague-Dawley rats. RAW264.7 cells were seeded at $1 \times 10^{4}$ cells/well on 96 -well plates and the following day were incubated with indicated doses of $A Q$ or DEAQ for $1 \mathrm{~h}$, followed by $6 \mathrm{~h}$ intoxication with $500 \mathrm{ng} / \mathrm{mL}$ PA $+500 \mathrm{ng} / \mathrm{mL}$ LF. Survival curves of groups of male Sprague-Dawley rats challenged intravenously with $12 \mu \mathrm{g}$ LF and $40 \mu \mathrm{g}$ PA along with varying amounts of $A Q(1.5,3.0$, and $6.0 \mathrm{mg} / \mathrm{kg}$ ). Control groups of rats either received toxin only or $6.0 \mathrm{mg} / \mathrm{kg}$ of $A Q$ only.

\section{Amodiaquine Inhibits Cytosolic Entry of LF}

In order to identify the step at which AQ inhibits LF-PA-mediated lethality, we assessed the processes that mediate the cellular entry of this toxin and toxininduced pyroptosis in the presence and in the absence of this drug. Caspase-1 activation, which occurs late in LF-PA intoxication, was monitored using a fluorescent probe, FLICA. This probe specifically binds to active caspase-1. While we observed high levels of caspase-1 activity upon LF-PA treatment in the absence of $A Q$, active caspase-1 was not detected in AQ-treated cells that were 
challenged with anthrax toxin (Fig. 3a). This result shows that $A Q$ inhibits cytotoxicity upstream of caspase-1 activation.

a

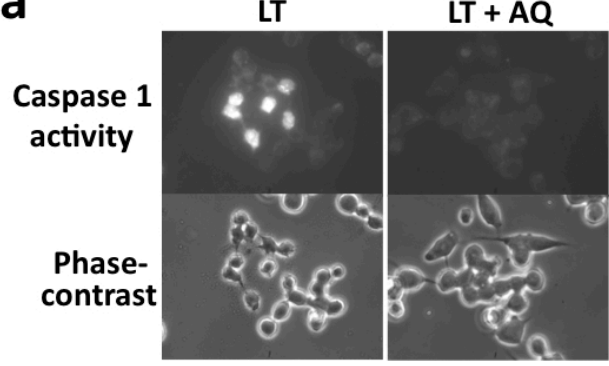

b

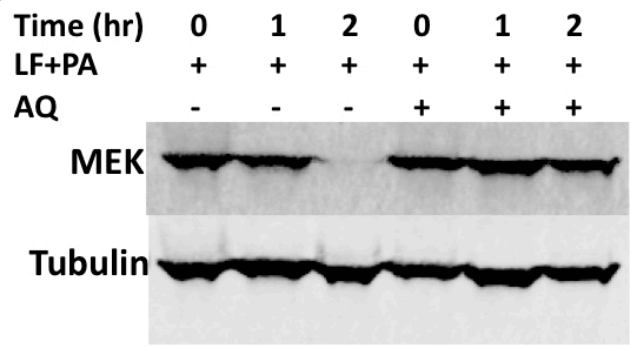

Figure 3a and 3b: (a) $A Q$ inhibits LT-mediated caspase-1 activation. RAW264.7 cells were seeded and allowed to adhere overnight, and then incubated with $16 \mu \mathrm{M} \mathrm{AQ}$ or DMSO for $1 \mathrm{~h}$ before addition of $500 \mathrm{ng} / \mathrm{mL}$ PA $+\mathrm{LF}$ for $2 \mathrm{~h}$. FLICA was added for a further $1 \mathrm{~h}$ and then cells analyzed by fluorescence microscopy. (b) AQ inhibits LT-mediated cleavage of MEK-2. RAW264.7 cells were incubated with AQ or DMSO for $1 \mathrm{~h}$ before addition of vehicle control or $1 \mu \mathrm{g} / \mathrm{mL}$ PA + LF for up to $2 \mathrm{~h}$. Cells were lysed and analyzed via immunoblotting with a MEK-2-specific antibody. Tubulin was used as a loading control.

Activation of caspase-1 by LF is a late step in pyroptosis, and depends on LF catalytic activity ${ }^{45}$. To determine whether $A Q$ blocks proteolysis of cellular MAPKKs by LF, we assessed the cleavage of MEK2 by immunobloting. While MEK2 was cleaved in LF-PA treated RAW264.7 cells, treatment with AQ completely prevented this effect (Fig. $3 b$ ). These results show that $A Q$ inhibits either cytotoxicity upstream of MAPKK cleavage or blocks LF directly.

In order to test whether $A Q$ inhibits the enzymatic activity of LF, we used a Fluorescence Resonance Energy Transfer (FRET) based assay, in which an MEK2 peptide containing a cleavage site for LF with a fluorogenic DABCYL 
group at the N-terminus and FITC quenching group at the C-terminus was used as LF substrate for in vitro assays. After cleavage by LF, the fluorescence emitted by the DABCYL increased (Fig. 3c). We tested the ability of $A Q$ to inhibit the proteolytic activity of LF at $100 \mu \mathrm{M}$ using FRET. In the presence of a known small molecule inhibitor of LF, surfen hydrate ${ }^{46}$, no emission at $523 \mathrm{~nm}$ was seen (Fig. 3c). In the absence of any chemical inhibitor, LF cleaved MAPKK peptide, and the fluorescence emission was observed (Fig. 3c). A similar emission at $523 \mathrm{~nm}$ was observed when LF was able to cleave MAPKK peptide in the presence of $A Q$, which shows that $A Q$ does not block the proteolytic activity of LF at $100 \mu \mathrm{M}$.

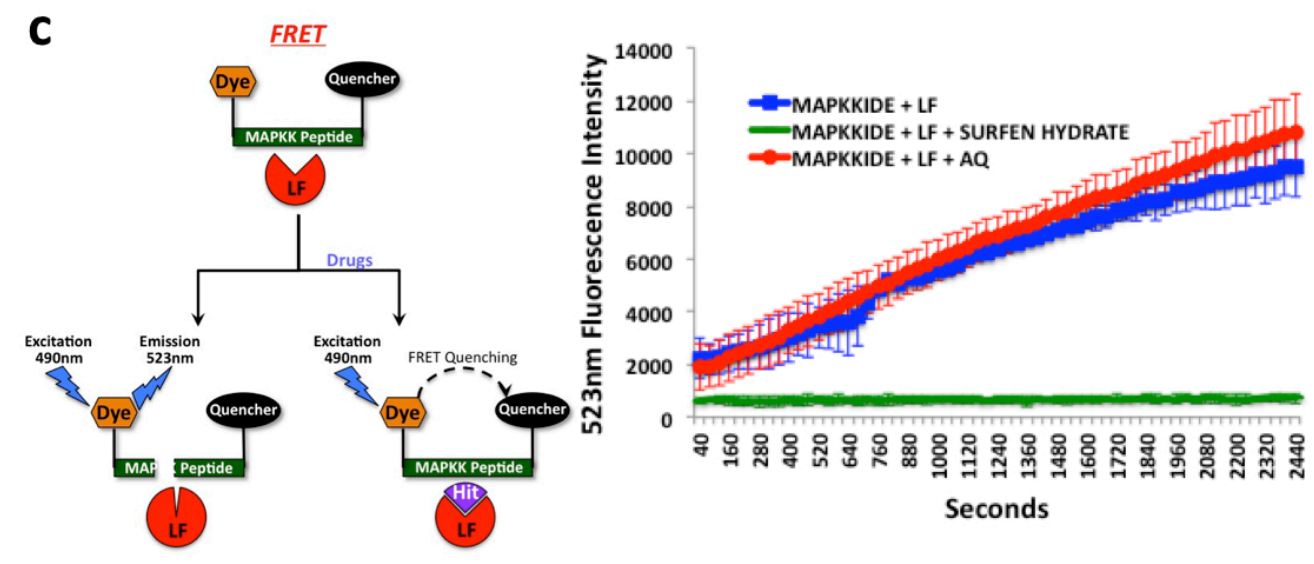

Figure 3c: FRET data showing fluorescence emission from three reactions, where $5.8 \mu \mathrm{g} / \mathrm{ml}$ LF cleaves fluorescently labeled MAPKK peptide without drugs, in the presence of a known LF inhibitor, $100 \mu \mathrm{M}$ surfen hydrate, or in the presence of $100 \mu \mathrm{MAQ}$.

AQ-treated cells were found to be less sensitive to treatment with PA + FP59 (Fig. 3d and e). FP59 is a hybrid toxin, which contains the PA binding site of LF as well as a toxin domain derived from $P$. aeruginosa exotoxin $A{ }^{47}$, that has 
been widely used as an LF surrogate, and kills cells by a different mechanism ${ }^{29}$. This result, along with the caspase-1 and MEK2 data, strongly suggest that $A Q$ interferes with PA mediated toxin entry.
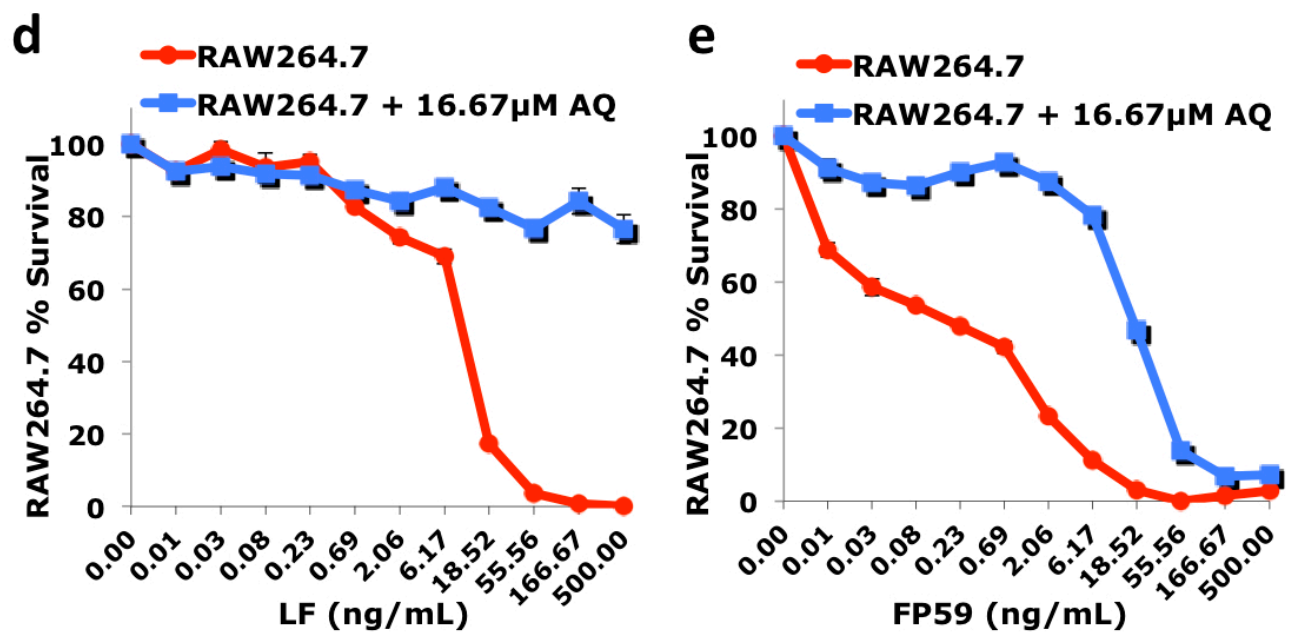

Figure 3d and 3e: (d and e) AQ protects cells from PA + FP59. RAW264.7 cells were preincubated with a titration of $A Q$ for $1 \mathrm{~h}$, followed by a $6 \mathrm{~h}$ intoxication with $500 \mathrm{ng} / \mathrm{mL}$ PA + LF (d) or FP59 (e). Cell viability was measured via MTT.

\section{Amodiaquine binds to and inhibits host cathepsin B}

In order for LF to reach the cytosol, PA83 must bind to host cell receptors, be cleaved by furin into PA63, heptamerize into a pre-pore form, bind LF, and proceed to low-pH endosomes where PA-heptamers undergo an acid-dependent conformational change from pre-pore to pore ${ }^{48}$. Host-cell binding of PA and its proteolytic cleavage were monitored by immunoblot in the presence and in the absence of $A Q$. We observed that $A Q$ did not block binding of PA83 to cells or block proteolytic processing of PA to generate PA63 (Fig. 4a). The inability of AQ to block the activity of host furin cleavage of PA83 is consistent with our 
observation that $A Q$ equally reduces sensitivity of host cells to both PA83+LF and PA63+LF treatments (Supplementary Fig. 2). These results indicate that AQ blocks intoxication at a step downstream of PA binding and assembly on the host-cell surface.
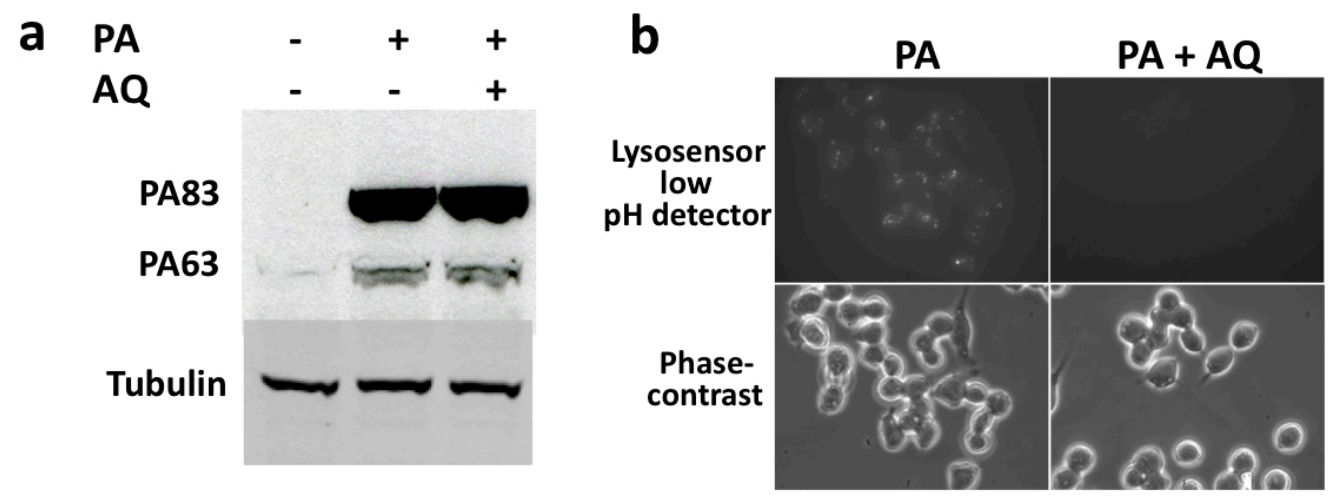

Figure 4a and 4b: a) AQ does not inhibit PA binding to RAW264.7 cells. Cells were incubated with $A Q$ for $1 \mathrm{~h}$ at $4^{\circ} \mathrm{C}$ before addition of $1 \mu \mathrm{g} / \mathrm{mL}$ PA for an additional $1 \mathrm{~h}$. Cells were lysed and analyzed by immunoblotting with a PA-specific antibody. (b) AQ neutralizes acidic vesicles. RAW264.7 cells were pre-treated with $A Q$ or vehicle control for $1 \mathrm{~h}$ and then treated with $500 \mathrm{ng} / \mathrm{ml}$ of PA for an additional hour at $37{ }^{\circ} \mathrm{C}$ before addition of Lysosensor Green DND-189 for a further $10 \mathrm{~min}$. Cells were then visualized by fluorescence microscopy.

$\mathrm{CQ}$ was previously shown to prevent endosomal acidification ${ }^{49}$. Since $A Q$ is structurally similar to $C Q$, we tested whether $A Q$ neutralizes anthrax toxin induced endosomal acidification. We used Lysosensor Green DND-189 to probe acidic organelles in the cells. Lysosensor is a green fluorescent dye used for tracking acidic organelles in the cell. Neutralization of these compartments can be visualized as a loss in punctate-fluorescent structures. In the absence of $A Q$, PA-treated cells displayed Lysosensor fluorescence, and AQ markedly 
decreased cell-associated Lysosensor fluorescence (Fig. 4b). These results predict that $\mathrm{AQ}$ may block the ability of $\mathrm{PA}$ to either access acidified endosomes or to form PA pores. It is known that the pore formation of PA, which results from exposure to acidic $\mathrm{pH}$ within endosomes, is resistant to dissociation by SDS and runs as an oligomer on SDS-PAGE ${ }^{48}$. Surprisingly, treatment of cells with $A Q$ resulted in higher, rather than lower, abundance of SDS-resistant PA-oligomers compared to cells treated with PA only (Fig. 4c).
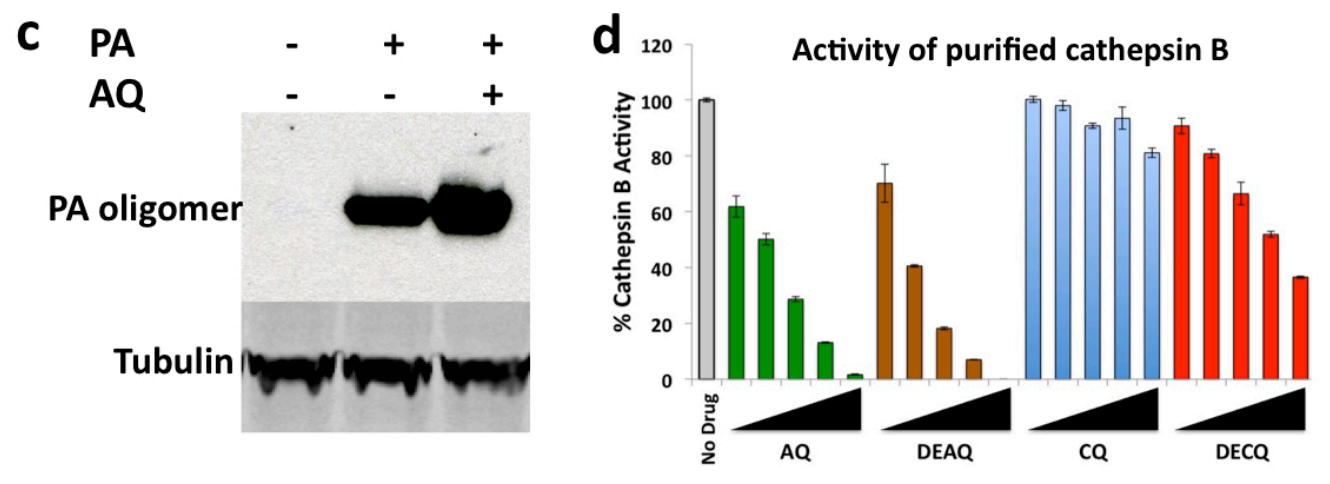

Figure 4c and 4d: (c) AQ results in increased abundance of PA pores. Cells were pre-treated with $A Q$ for $1 \mathrm{~h}$ at $37^{\circ} \mathrm{C}$ and then were exposed to $1 \mu \mathrm{g} / \mathrm{mL}$ of PA at $37^{\circ} \mathrm{C}$ for $1 \mathrm{~h}$. Cells were lysed and analyzed by immunoblotting with a PA-specific antibody. (d). FRET assay showing the activity of purified human cathepsin $B$ without drugs, or with addition of $A Q, D E A Q, C Q$, or DECQ at $4,8,16,33$, or $66 \mu \mathrm{M}$.

A similar observation was reported by Ha et al ${ }^{40}$, who showed that an inhibition of host lysosomal cathepsin B by an unrelated small molecule CA-074, resulted in (i) elevated accumulation of PA pores in late endosomes, (ii) the inability of LF to be released from the late endosomes into the cytoplasm, and (iii) results in reduction of cellular sensitivity to LF-PA. Upon formation of the SDS-resistant PA63 pore in acidic endosomes, PA pores are then transported to lysosomes for 
rapid degradation ${ }^{50}$. Ha et al showed that cathepsin $B$ mediates the fusion of lysosomes with endosomes, and that this fusion is necessary for the release of LF from the endosomes into the cytoplasm ${ }^{40}$. In order to gain further insight into the mechanism of AQ-mediated protection of cells against anthrax toxin killing, we tested whether $A Q$ inhibits cathepsin $B$ protease activity of purified human cathepsin B using a FRET assay. We observed that both $A Q$ and DEAQ directly inhibit cathepsin B activity in a dose dependent manner without drug preincubation, at drug concentrations used in cellular experiments (Fig. 4d). We tested whether AQ inhibits cathepsin B in RAW264.7 cells. We observed that cells pre-treated with $A Q$ or with DEAQ for 1 hour lost cathepsin $B$ enzymatic activity in a dose dependent manner (Supplementary Fig. 3a). In addition, we tested the ability to $A Q$ to inhibit cathepsin $B$ activity in a protein lysate from cells that were not exposed to drugs prior to the lysis and observed that $A Q$ and DEAQ inhibited cathepsin B activity (Supplementary Fig. 3b). We determined that the addition of drugs to cathepsin $\mathrm{B}$ reactions did not change the $\mathrm{pH}(\mathrm{pH} 5.8)$ of the reaction buffer. In all of the cathepsin $B$ experiments we observed that $C Q$ and its metabolite, Desethyl-Chloroquine (DECQ), were weaker inhibitors of cathepsin B activity (Figs. 4d and S3), which corresponds to the phenotypic data seen in Fig. 2. 


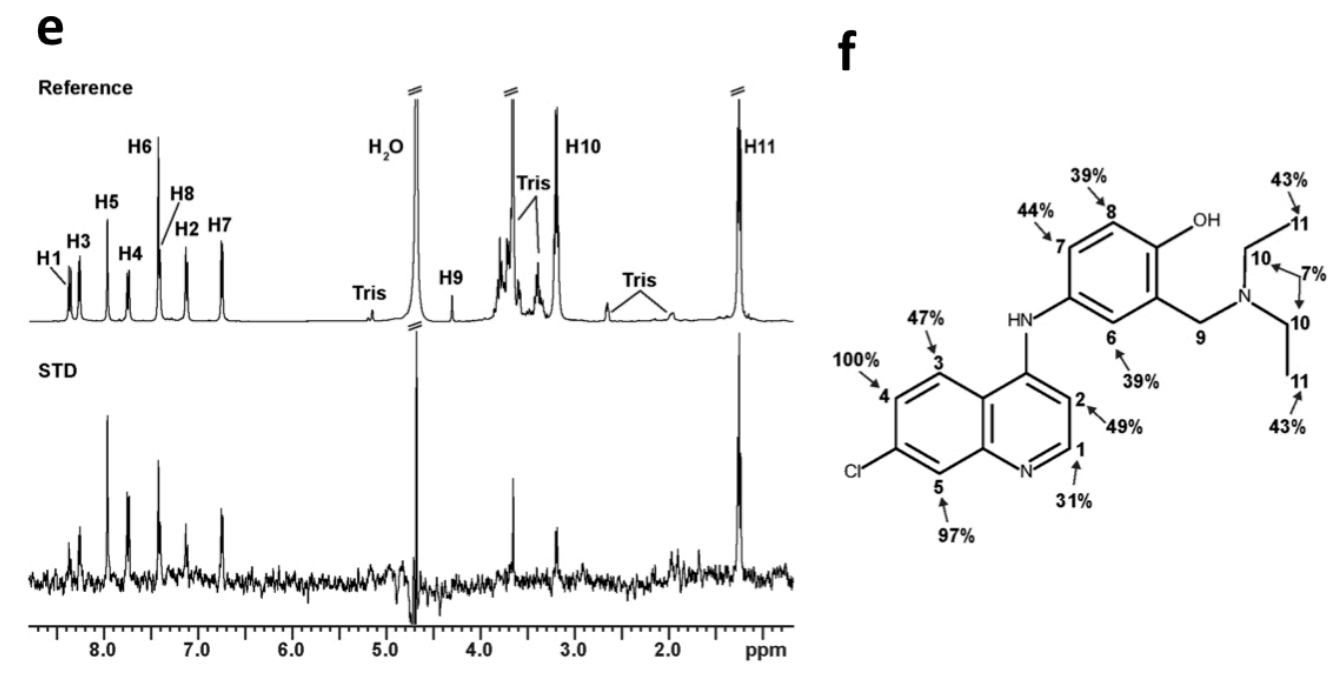

Figure 4e and 4f: (e) ${ }^{1} \mathrm{H}-\mathrm{NMR}$ spectra of $A Q$ in the presence of cathepsin $\mathrm{B}$. The reference spectrum of $A Q$ with its atoms labeled (top), and the STD spectrum (bottom) are shown. The data were collected using a protein:ligand ratio of 1:100 with on- and off-resonance saturation at 0.04 ppm and $30 \mathrm{ppm}$, respectively. (f) Chemical structure of $A Q$ showing the atom-specific magnitude of the STD effects. The STD effect was calculated according to the formula $A_{S T D}=\left(I_{0}-I_{s a t}\right) / I_{0}$. All STD effects are expressed as a percentage relative to the $\mathrm{H} 4$ atom $(100 \%)$.

The interaction between $A Q$ and cathepsin $B$ was probed using saturation transfer difference NMR spectroscopy (STD). This technique is a powerful labelfree ligand-observed tool to study molecular interactions in solution ${ }^{51,52}$. STD relies on the transfer of selective saturation (excitation) of the protein's atoms to atoms located in the bound ligand. Two $1 \mathrm{D}{ }^{1} \mathrm{H}-\mathrm{NMR}$ spectra are acquired-one in which the protein's signals are selectively saturated ("on" resonance, $I_{\text {sat }}$ ), and another in which no signals are saturated ("off" resonance, $\mathrm{I}_{0}$ ). Ligand binding is evident by the difference spectrum $\left(I_{0}-I_{\text {sat }}\right)$, as only when binding occurs are the signals of the ligand affected. Figure $4 \mathrm{e}$ shows the ${ }^{1} \mathrm{H}-\mathrm{NMR}$ spectrum of $2 \mathrm{mM}$ 
$A Q$ in the presence of $20 \mu \mathrm{M}$ cathepsin $\mathrm{B}$ (ligand:protein molar ratio of 100:1), and its corresponding STD difference spectrum. The presence of $A Q$ signals in the difference spectrum clearly indicates that it is binding to the enzyme. An inspection of the atom-specific effects provides insight into the mode of binding. Atoms in the quinoline backbone display the largest reduction in their intensities, suggesting that they are in close proximity to cathepsin B (Fig. 4f, atoms $\mathrm{H} 4$ and H5 exhibit STD effects of 100 and $97 \%$, respectively). In contrast, the H9 and $\mathrm{H} 10$ methylene protons are modestly affected suggesting that in the complex they are located distal to hydrogen atoms in the protein. Interestingly, several atoms in the phenol ring display substantial STD effects suggesting that they are near the protein. This is consistent with the lower biological activities of $A Q$ analogs that remove the phenol ring (Fig. 2 and Supplementary Fig. 1). The importance of the AQ quinoline ring revealed by STD is also compatible with the crystal structure of cathepsin B bound to nitroxoline, as this small molecule contains a quinoline moiety that interacts extensively with the enzyme ${ }^{53}$.

\section{Amodiaquine inhibits pathogenicity of Ebola virus}

Upon observing that $A Q$ protects cells from anthrax and diphtheria toxins, we hypothesized that $A Q$ and DEAQ might also be able to inhibit the entry of Ebola virus. Ebola virus, among other viruses, requires low endosomal $\mathrm{pH}^{54}$ as well as host cathepsin B function ${ }^{55}$ for membrane fusion and infection of host cells. In fact, $A Q$ and $C Q$ have recently been reported to inhibit Ebola virus pathogenicity in cells ${ }^{54,55}$. We re-tested $A Q$ and CQ's ability to inhibit Ebola virus abundance in infected HeLa cells by visualizing infected cells using immune-staining, and in 
addition we tested the ability of their metabolites, DEAQ and DECQ, to inhibit Eboa virus propagation in cultured cells in vitro. To test AQ-mediated inhibition of viral propagation, we compared infection by Ebola virus (Kikwit) at $\mathrm{MOI}$ of 0.5 with and without drugs for 48 hours. To detect infected cells, immuno-staining was completed with anti-Ebola-glycoprotein antibodies. AQ and DEAQ effectively inhibited propagation of Ebola virus in HeLa cells with EC50's in the low $\mu \mathrm{M}$ range (Table 1): the EC50's of AQ and DEAQ were 3.8 and $3.6 \mu \mathrm{M}$ respectively. The EC50's of CQ and DECQ in HeLa were 4.8 and $7.3 \mu \mathrm{M}$ respectively. This data shows that DEAQ is more efficacious in inhibiting Ebola propagation compared to DECQ. Similar results were obtained by testing $A Q, C Q, D E A Q$, and DECQ for their ability to inhibit Ebola virus in primary human cell line, HFF-1 (Supplementary Table 1). This result confirms that anti-viral effect of $A Q$ is not related to its effects on the host cell cycle or cellular proliferation.

\begin{tabular}{cccccc} 
Pathogen & $\begin{array}{c}\text { Drug, } \\
\text { hours }\end{array}$ & EC50 $\mu \mathrm{M}$ & SD $\mu \mathrm{M}$ & CC50 $\mu \mathrm{M}$ & SI50 \\
\hline EBOV & AQ, 48h & 3.8 & 0.38 & 50 & 13.2 \\
EBOV & DEAQ, 48h & 3.6 & 0.35 & 50 & 13.9 \\
EBOV & CQ, 48h & 4.8 & 0.57 & 100 & 20.7 \\
EBOV & DECQ, 48h & 7.3 & 0.55 & 100 & 13.8
\end{tabular}

Table 1: The effect of $A Q, C Q$, and its metabolites, DEAQ and DECQ, on the pathogenicity of EBOV in HeLa cells. The ability of drugs to reduce the abundance of Ebola virus (EBOV) in host cells was measured in cells by fluorescent microscopy. 
The life cycle of Ebola virus in cultured host cells is $20-24$ hours. To more clearly evaluate effects of $A Q$ and DEAQ on a single viral life cycle, we compared the inhibitory effects of these drugs after 24 and 48 hours of Ebola virus infection in cells. We observed that $A Q$ and $D E A Q$ are at least two times more potent after $24 \mathrm{~h}$ of infection (EC50's $2 \mu \mathrm{M}$ ), compared to $48 \mathrm{~h}$, during which time the secondary round of infection occurs and possibly slightly decreases the antiviral efficacies of AQ and DEAQ (EC50's 4 $\mu \mathrm{M})$ (Table 2).

\begin{tabular}{cccccc} 
Pathogen & $\begin{array}{c}\text { Drug, } \\
\text { hours }\end{array}$ & EC50 $\mu \mathrm{M}$ & SD $\mu \mathrm{M}$ & CC50 $\mu \mathrm{M}$ & SI50 \\
\hline EBOV & $\mathrm{AQ}, 24 \mathrm{~h}$ & 2.38 & 0.47 & $>50$ & $>21$ \\
EBOV & $\mathrm{AQ}, 48 \mathrm{~h}$ & 4.46 & 0.44 & $>50$ & $>11.2$ \\
EBOV & DEAQ, 24h & 2.15 & 0.48 & $>50$ & $>23.3$ \\
EBOV & DEAQ, 48h & 4.12 & 0.36 & $>50$ & $>12.1$
\end{tabular}

Table 2: The effect of time of $A Q$ and its metabolite treatments on the pathogenicity of EBOV. The $\mathbf{5 0 \%}$ effective $\left(\mathrm{EC}_{50}\right.$, virus-inhibitory) concentrations and $50 \%$ cytotoxic $\left(\mathrm{CC}_{50}\right.$, cell-inhibitory) concentrations were determined. $\mathrm{CC}_{50}$ divided by $\mathrm{EC}_{50}$ indicate the selectivity index (SI) value.

Amodiaquine inhibits pathogenicity of other Category $A, B$, and $C$ pathogenic agents that enter into host cytoplasm from acidified endosomes

In addition to anthrax toxin ${ }^{41}$, diphtheria toxin ${ }^{56}$, and Ebola virus ${ }^{55,57}$, other pathogenic agents SARS coronavirus ${ }^{57}$, Venezuelan equine encephalitis virus $\left(\right.$ VEEV) ${ }^{58}$, Rabies virus ${ }^{59}$, Junin virus ${ }^{60}$, Chikungunya virus ${ }^{61}$, and Clostridium difficile toxin $\mathrm{B}^{62}$ enter the cytoplasm from endosomes and all require the 
acidification of endosomes. We demonstrated that all of those pathogenic agents are inhibited by $A Q$ in their respective in vitro cellular assays (Table 3 and Supplementary Fig. 4a). We also tested the ability of DEAQ to inhibit pathogenicity of Junin and Chikungunya viruses, and observed that DEAQ inhibits those two viruses with EC50's similar to those of AQ (Supplementary Table 2).

Other pathogenic agents, including cholera toxin ${ }^{63}$, Pseudomonas aeruginosa exotoxin $A^{64}$, Poliovirus $3^{44}$, and Herpes simplex virus $1^{65}$ are transported in a retrograde fashion to the endoplasmic reticulum $(E R)$ and retrotranslocated into the cytoplasm by the host ER-associated degradation pathway ${ }^{63,64}$. We observed that cytotoxicity mediated by those pathogens was not blocked by $A Q$ (Table 3 and Supplementary Fig. $4 \mathrm{~b}$ and $\mathrm{c}$ ). In addition, the inability of $\mathrm{AQ}$ to inhibit cholera and Pseudomonas toxins, which are both ADPrybosyltransferases, suggests that AQ's adverse effect on diphtheria toxin (Fig. 1), which is also ADP-rybosyltransferase, occurs by inhibition of host cathepsin B only.

Another group of pathogens enter the cytoplasm by ways that do not rely on the acidification of endosomes, and include Human Cytomegalovirus ${ }^{66}$ and Respiratory syncytial virus ${ }^{67}$. We determined that $A Q$ did not reduce the pathogenicity of those viruses (Table 3). This data supports the conclusion that $A Q$ inhibits the entry of toxins into the cytoplasm from acidified endosomes. 


\section{Discussion}

The discovery and development of novel drugs against biological threat agents such as Bacillus anthracis and Ebola virus, is an important concern worldwide. We have shown that $A Q$ is a broad-spectrum drug that can be applied rapidly to cure biological emergencies caused by the several identified pathogens (Fig. 5). For example, the current Ebola crisis has already killed more than 10,000 people in 2014 and 2015. Repurposing of a compound with well-established safety and pharmacokinetic profiles - as well as proven high-volume GMP manufacturing — may be the only way that a therapy can be tested and deployed in time to protect the $21+$ million people in the three hardest-hit West African countries.

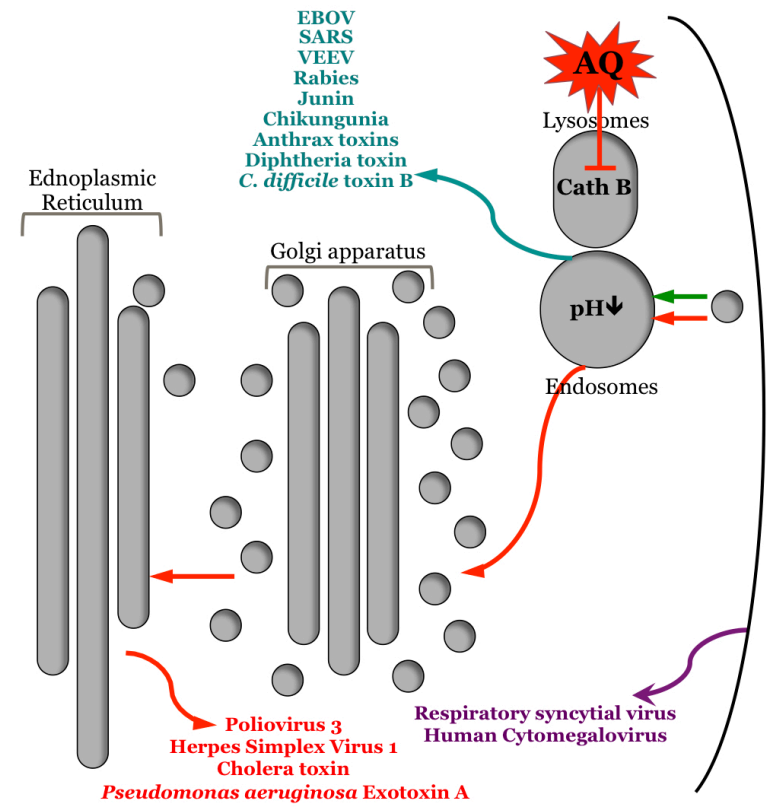

Figure 5: $A Q$ reduces the activities of pathogens that enter into host cytoplasm from acidified endosomes by exploiting cellular cathepsin $B$. AQ does not inhibit the entry of pathogens that enter through a retrograde fashion to the endoplasmic reticulum (ER) and retrotranslocated into the cytoplasm by the host ER-associated degradation pathway or by $\mathrm{pH}$ independent entry into cytoplasm. 
To help address this Ebola crisis, as we were preparing this manuscript, we communicated our discoveries to Médecins Sans Frontières (MSF, Doctors Without Borders), and encouraged them to explore whether the administration of $A Q$ in West African countries hit by Ebola epidemic is associated with a reduced mortality due to Ebola infections. MSF conducted a study and observed that the administration of $A Q$ provided a substantial protection against Ebola mortality and reduced the mortality risk by $31 \%$, and in this study MSF acknowledged the authors of this study (https://www.youtube.com/watch?v=rTyoc4s1Mco).

As seen in current Ebola epidemic, the human host can be co-exposed to numerous deadly pathogens and thus the infected individual will need to take numerous countermeasures (each with their own side-effects) to protect against multiple infectious organisms. Therefore, therapies capable of inhibiting multiple pathogens are needed. Broad-spectrum anti-pathogen drugs, capable of simultaneously inhibiting numerous unrelated pathogens, could be developed by targeting host proteins commonly exploited by those pathogens. In this work we show that $A Q$ inhibits the host target rather than the pathogen, which makes $A Q$ host-oriented broad-spectrum antimicrobial that is less likely to be circumvented by pathogen mutations that lead to microbial resistance to the countermeasure.

AQ was discovered by Parke-Davis in the 1940s and was approved by the FDA as an anti-malarial in the late 1940s and early 1950s under the trade name Camoquine. AQ is currently on the WHO's Model List of Essential Medicines. Today $A Q$ is recommended as a frontline anti-malarial therapy in combination 
with artemisinin. $A Q$ belongs to the "quinoline antimalarials" (Reviewed in $\left.{ }^{68}\right) . A Q$ inhibits Plasmodium falciparum phosphoethanolamine methyltransferase, an enzyme found in malarial parasites but not in humans ${ }^{69}$. Here we report that $A Q$ also binds and blocks the function of host cathepsin B protein and thus entry of key pathogens into the cytoplasm.

Since $A Q$ has been used for the past 60 years, its safety and pharmacokinetic profiles are well known. For example, it has been determined that after oral administration in healthy subjects, $A Q$ is quickly absorbed and biotransformed into its main active form, DEAQ, which in turn is slowly eliminated with a terminal half-life of 9-18 days. The availability of PK values for $A Q$ allows us to compare it to our in vitro data. The EC50 values for all of the tested pathogens inhibited by $A Q$ or by $D E A Q$ were at low $\mu \mathrm{M}$ range. Importantly, the known Cmax values (maximal amounts of drug in the blood after oral administration) of DEAQ in humans are in low $\mu \mathrm{M}$ range ${ }^{69-71}$, and are comparable to the DEAQ EC50 values found in vitro for tested pathogens. This means that it is possible to achieve antipathogen effective $A Q$ doses in blood by orally administered $A Q$. 


\section{Materials and Methods}

Chemicals and Reagents:

All toxins were purchased from List Biological Laboratories. FP59 was a kind gift from S. Leppla (National Institute of Allergy and Infectious Diseases /National Institutes of Health, Bethesda, MD). An FDA-approved drug library comprising of 1,581 drugs was purchased from Johns Hopkins, titled, Johns Hopkins Clinical Compound Library (JHCCL) version 1.0. The drugs arrived as $10 \mathrm{mM}$ stock solutions in sealed microtiter plates and were made using DMSO or water as solvents. Drugs were arrayed in 96-well plates and screened at a stock concentration of $3.3 \mathrm{mM}$. Amodiaquine, Chloroquine, Cinchonine, Primaquine, and Quinidine were purchased from Sigma-Aldrich (St. Louis, MO, USA). All drugs were prepared at $10 \mathrm{mM}$ using DMSO as a solvent. Desethyl-amodiaquine and desethyl-chloroquine were purchased from Toronto Research Chemicals Inc. Anti-N-terminal MEK-2, anti-tubulin, and anti-PA antibodies were purchased from Santa Cruz Biotechnology. Purified human cathepsin B protein used for NMR experiments was purchased from ACROBiosystems.

\section{Cellular Drug Screens:}

RAW264.7-pGIPZ(-) ${ }^{29}$ mouse macrophage cells were maintained in DMEM (Sigma-Aldrich) supplemented with 10\% FBS (Bioexpress) and $100 \mu \mathrm{g} / \mathrm{mL}$ penicillin and $100 \mu \mathrm{g} / \mathrm{mL}$ streptomycin. RAW264.7-pGIPZ(-) cells (10,000 per well) were seeded in 96-well plates $(100 \mu l /$ well) 24 hours before the assay. During the drug library screen assay, $0.75 \mu$ of $3.3 \mathrm{mM}$ drugs were added to $150 \mu \mathrm{l}$ 
of cell-containing media to achieve $16 \mu \mathrm{M}$ of each compound per well. Cells were treated with compounds for 1 hour at $37{ }^{\circ} \mathrm{C} 5 \% \mathrm{CO}_{2}$, and then challenged with anthrax toxins, such that the final toxins concentrations were $0.5 \mu \mathrm{g} / \mathrm{ml}$. Cells were treated with toxin and drugs for 6 hours. As rodent cells are resistant to diphtheria toxin, C32 human melanoma cell line was used for diphtheria toxin screening, where cells were treated with $2 \mu \mathrm{g} / \mathrm{ml}$ for 24 hours. Determination of cell viability by 3-(4,5-dimethylthiazol-2-yl)-2,5-diphenyltetrazolium bromide (MTT) assay was performed as described ${ }^{72}$. Cell viability is shown as the percentage of surviving cells obtained relative to cells treated with DMSO $(100 \%)$.

FRET MAPKKide LF activity:

For drug testing in 96-well plates, the reaction volume was $250 \mu \mathrm{l}$ per well, containing $20 \mathrm{mM}$ HEPES pH 7.2, $5 \mu \mathrm{M}$ MAPKKide conjugated with DABCYL and FITC (List Biological Laboratories, Inc), and $100 \mu \mathrm{M}$ of JHCCL compound. The reaction was initiated by adding LF to a final concentration of $5.8 \mu \mathrm{g} / \mathrm{ml}$. Kinetic measurements were obtained at $37 \mathrm{C}$ every $40 \mathrm{sec}$ for 40 min using a fluorescent plate reader. Excitation and emission wavelengths were $490 \mathrm{~nm}$ and $523 \mathrm{~nm}$, respectively, with a cutoff wavelength of $495 \mathrm{~nm}$.

\section{Toxins Treatments:}

Cells were seeded in a 96-well plate at a density of 10,000 cells/well $1 \mathrm{~d}$ before toxin treatment. Various concentrations of LF or FP59 combined with a fixed 
concentration of PA $(500 \mathrm{ng} / \mathrm{mL})$ were added to the wells, and cells were incubated for $6 \mathrm{~h}$ at $37^{\circ} \mathrm{C}$. Cell viability was measured by MTT assay. In other toxin treatment experiments, cells were pre-treated with various concentrations of drugs, and then treated with constant concentrations of $8.3 \mu \mathrm{g} / \mathrm{ml}$ of $C$. difficile toxin $\mathrm{B}, 500 \mathrm{ng} / \mathrm{ml}$ of $P$. aeruginosa Exotoxin $\mathrm{A}$, or $500 \mathrm{ng} / \mathrm{ml}$ of Cholera toxin for 6 hours. RAW264.7 survival was measured by MTT assay. Each data point shown for MTT assays indicates the mean \pm SD value obtained in triplicate assays done in a representative experiment. At least three such experiments were routinely carried out.

\section{MEK Cleavage Assay:}

RAW264.7 cells were pre-treated with $66.67 \mu \mathrm{M}$ of $\mathrm{AQ}$ for 1 hour. Following the pre-treatment, the cells exposed to $1 \mu \mathrm{g} / \mathrm{mL}$ of PA and LF at $37^{\circ} \mathrm{C}$ for up to two hours in the presence of $16.67 \mu \mathrm{M}$ of $\mathrm{AQ}$. The cells were then washed with cold PBS for $5 x$ and lysed with RIPA buffer containing a protease inhibitor mixture (Roche). Cell lysates were quantified using the BCA protein quantification kit (Pierce) and loaded onto 4-12\% denaturing gels (Criterion XT Precast Gel, BioRad). After electrophoresis for several hours, the gel was transferred overnight to nitrocellulose membranes; membranes were probed with anti-MEK-2 or anti tubulin antibodies. Quantitative Western blot analyses of the bands were accomplished using the VersaDoc 1000 instrument (Bio-Rad) or Odyssey infrared imaging system (LI-COR Biosciences). 
Biochemical Assay of PA Binding and Internalization:

Cells were pre-treated with $A Q$ as described above for $1 \mathrm{~h}$, either at $4^{\circ} \mathrm{C}$ for $\mathrm{PA}$ binding or at $37^{\circ} \mathrm{C}$ for PA internalization assays cells were exposed to $1 \mu \mathrm{g} / \mathrm{mL}$ of PA at $4^{\circ} \mathrm{C}$ for $1 \mathrm{~h}$ for binding assay or at $37^{\circ} \mathrm{C}$ for $1 \mathrm{~h}$ for internalization assay. Cells were then washed with PBS solution three times and lysed in RIPA buffer containing a protease inhibitor mixture (Roche). Western blot analysis was performed using anti-PA antibody anti-tubulin monoclonal antibody (SigmaAldrich). Chemiluminescence of bands and their relative intensities were revealed using a VersaDoc 1000 instrument (Bio-Rad).

\section{Caspase-1 Activity Assay:}

Cells were treated with $A Q$ for $1 \mathrm{~h}$ before addition of $500 \mathrm{ng} / \mathrm{ml}$ LF-PA for an additional 2h. FAM FLICA ${ }^{\mathrm{TM}}$ Caspase 1 Assay Kit was obtained from ImmunoChemistry Technologies LLC. FLICA reagent was added for $1 \mathrm{~h}$. FLICA fluorescence was visualized as follows: cells were washed three times in PBS, fixed in $4 \%(\mathrm{wt} / \mathrm{vol})$ paraformaldehyde, and examined under a fluorescence microscope (DM5500 B; Leica).

Staining Cells with Lysosensor Green DND-189:

Cells were treated with $A Q$ for $1 \mathrm{~h}$ before an addition of $500 \mathrm{ng} / \mathrm{ml} \mathrm{PA}$ for an additional hour and then stained with Lysosensor Green DND-189 for $10 \mathrm{~min}$ at $37^{\circ} \mathrm{C}$. Cells were then washed and fluorescence was visualized as follows: cells 
were fixed in $4 \%(\mathrm{wt} / \mathrm{vol})$ paraformaldehyde, and examined under a fluorescence microscope (DM5500 B; Leica).

\section{Cathepsin B Activity Assay:}

Cathepsin B activity in total cell lysates was determined using an InnoZyme TM cathepsin B activity assay kit (EMD Milipore) and performed according to the manufacturer's instruction. Cathepsin B activity in cellular lysates was tested in the following way: RAW264.7 cells untreated with drugs were lysed, and equal amount of cathepsin B containing protein lysate was added to the substrate solution (EMD Milipore) with and without $A Q, C Q, D E A Q$, or DECQ at concentrations of $4,8,16,33$, or $66 \mu \mathrm{M}$. Cellular cathepsin B activity with and without drugs was tested by pre-treating cells with drugs for 1 hour, followed by lysing cells and testing cathepsin B activity with a fluorescently labeled substrate. The activity of $0.5 \mathrm{ng} / \mu \mathrm{l}$ of purified human cathepsin B was mixed with and without drugs without pre-incubation and detected with a fluorescently labeled substrate. Fluorescence intensity indicating cathepsin B activity was measured at an excitation wavelength of $370 \mathrm{~nm}$ and emission wavelength of $450 \mathrm{~nm}$ (Molecular Devices, Spectra Max 384 PLUS).

\section{Rat intoxication challenge:}

The rat studies were performed at Explora Biolabs, San Diego, CA following Institutional Animal Care and Use Committee (IACUC) approved protocols. Five Male Sprague-Dawley rats (226 to 250 g; Charles River) per group were used. 
The toxin mixture was prepared for each group by mixing $12 \mu \mathrm{g}$ of LF with $40 \mu \mathrm{g}$ of PA or with $1.5,3.0$, or $6.0 \mathrm{mg} / \mathrm{kg}$ of Amodiaquine in a $500-\mu l$ volume per rat. Rats were monitored for signs of clinical illness or death for 14 days after the challenge.

\section{NMR spectroscopy:}

All STD experiments were performed at $25^{\circ} \mathrm{C}$ using a Bruker Avance $500-\mathrm{MHz}$ spectrometer equipped with a cryogenic probe. The pulse scheme employed excitation sculpting with gradients, and a $50 \mathrm{~ms}$ spin lock filter $\left(T_{1 \rho}\right)$ to suppress signals originating from the water and protein signals, respectively ${ }^{51}$. An irradiation power of $26 \mathrm{~Hz}$ was applied on-resonance at $0.04 \mathrm{ppm}$, and offresonance at $30 \mathrm{ppm}$, for a total saturation time of $4 \mathrm{~s}$. Spectra were collected in an interleaved manner to account for any temporal fluctuations. Separate control experiments were performed using samples of cathepsin B or Amodiaquine to confirm the selectivity of saturation. STD spectra were acquired with 4096 scans and 32k data points using a spectral width of $7002.8 \mathrm{~Hz}$ centered at $2352 \mathrm{~Hz}$. All experiments were performed in deuterated tris buffer: $50 \mathrm{mM} \mathrm{D}_{11}$-Tris, $150 \mathrm{mM}$ $\mathrm{NaCl}$, pH 7.5 supplemented with $8 \% \mathrm{D}_{2} \mathrm{O}$. The sample used for STD measurements contained $20 \mathrm{mM}$ and $2 \mathrm{mM}$ cathepsin B and Amodiaquine, respectively. The STD NMR data were processed and analyzed using Topspin 3.1 software (Bruker, Billerica Ma). STD effects were calculated according to the formula: $A_{S T D}=\left(I_{0}-I_{\text {sat }}\right) / I_{0}$, where $I_{\text {sat }}$ and $I_{0}$ are the intensity of the Amodiaquine signal recorded with and without saturation of the protein, respectively. 
Viral tests:

The procedures of all viral experiments are described in supplemental materials and methods. Specifically, infection of HeLa cells with Ebola was done using Ebola virus (Kikwit) $\mathrm{MOI}=0.5$ (calculated for $4,000 \mathrm{cells} / \mathrm{well}$, assuming one complete round of replication of HeLa cells at $15 \pm 2$ hrs after cell seeding). Cells were incubated with the virus for 24 or $48 \mathrm{~h}$. Infection was terminated by fixing samples in formalin solution, and immuno-staining was used to visualize infected cells. Cells were treated with anti-GP specific monoclonal antibody (6D8) (1 to 1000 dilution) followed by anti-mouse IgG conjugated with Dylight488 (Thermo) (1 to 1000 dilution) in blocking buffer containing 3\% BSA in PBS. Nuclei were stained with Draq5 (Biostatus) diluted in PBS buffer. Images were acquired on the Opera imaging instrument (Perkin Elmer) using 10x Air objective and four images/well were acquired and analyzed using PE Acapella algorithms. 


\section{Supplemental}

\section{Supplemental Figures}

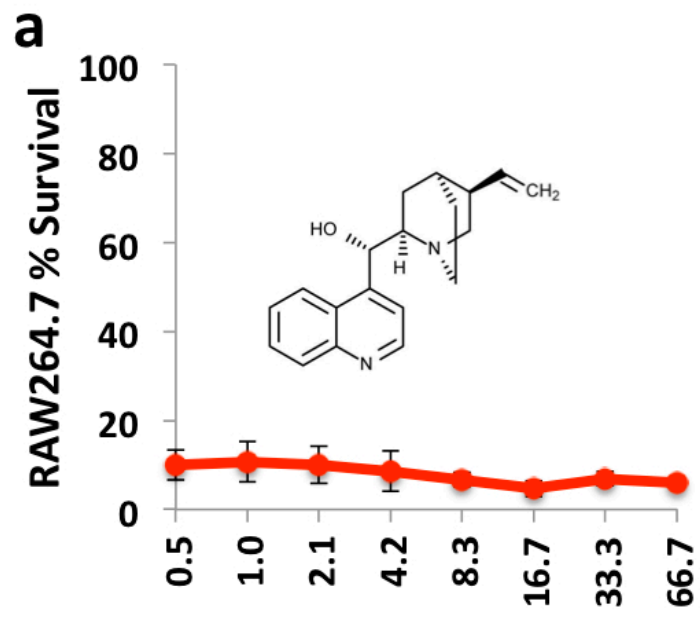

Cinchonine $\mu \mathrm{M}$

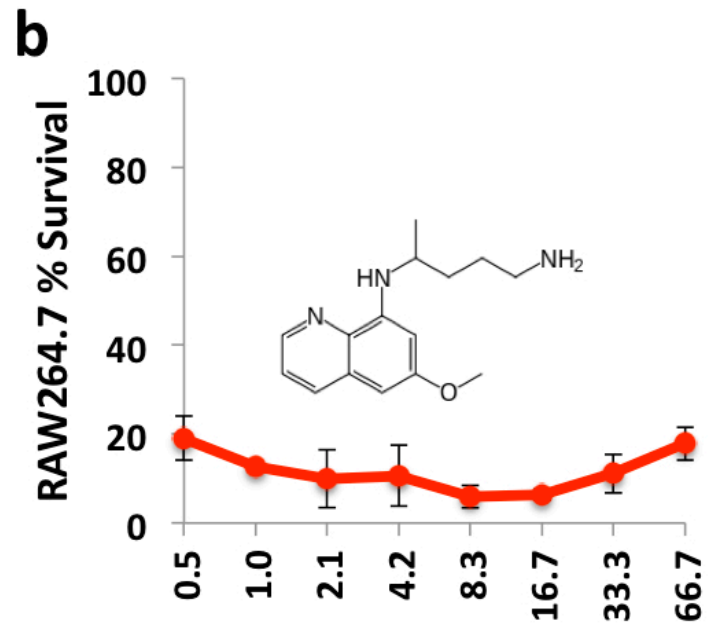

Primaquine $\mu \mathrm{M}$

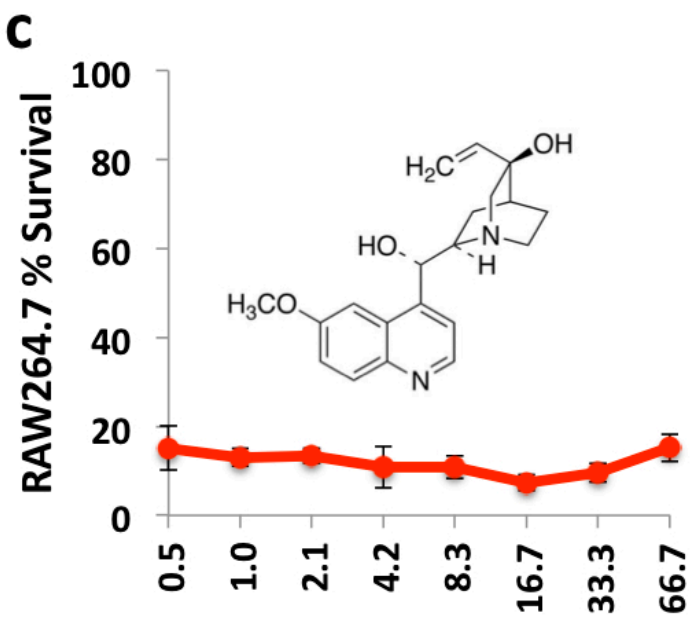

Quinidine $\mu \mathrm{M}$

Figure 1: The effect of quinolone anti-malarials on sensitivities of cells treated with anthrax toxins. RAW264.7 cells were pretreated with indicated drugs at shown concentrations for 1 hour, and then treated with anthrax toxins for 6 hours. RAW264.7 survival was measured by MTT assay. 


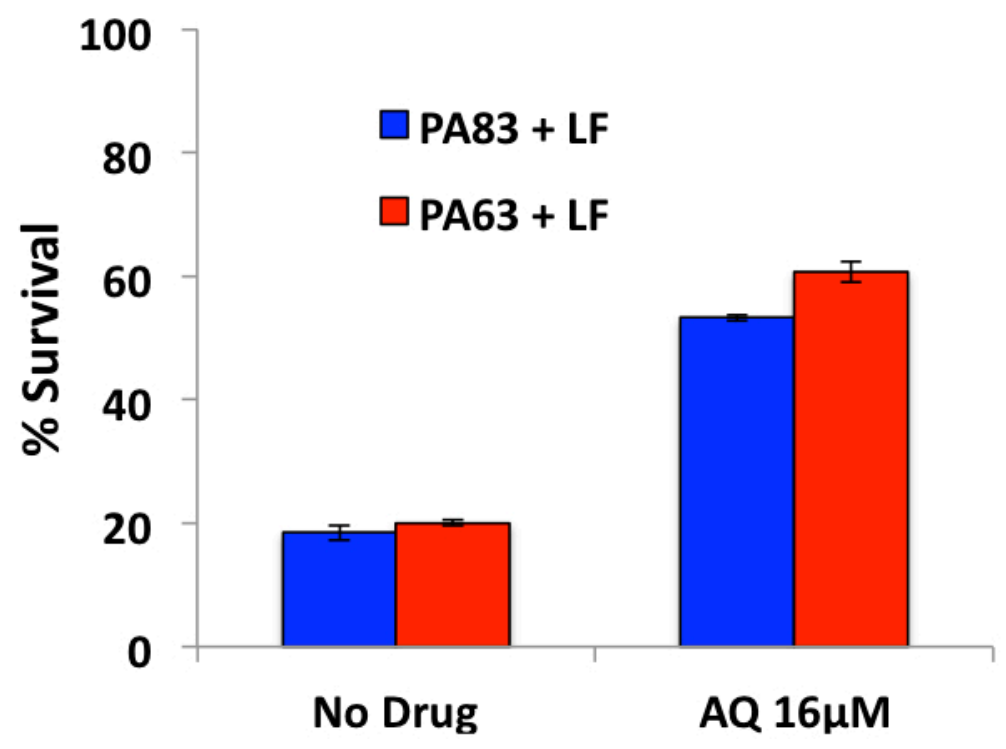

Figure 2: Amodiaquine reduces cellular sensitivity to LF+PA83 and LF+PA63. RAW264.7 cells were pretreated either with DMSO or with $A Q$ for 1 hour, and then treated with $500 \mathrm{ng} / \mathrm{ml}$ of $L F$ in the presence of $1.5 \mu \mathrm{g} / \mathrm{ml}$ of either of PA83 or PA63 for 6 hours 

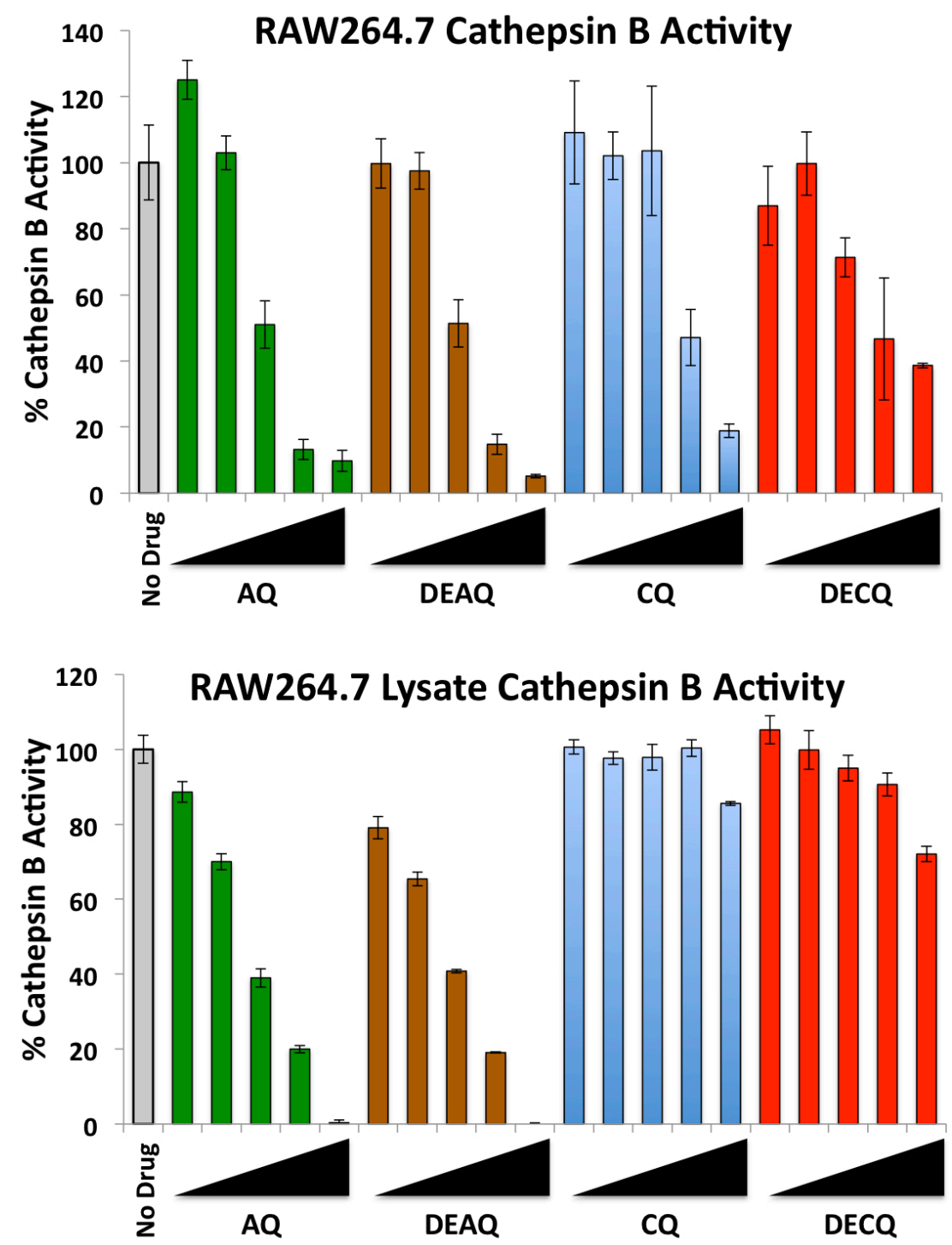

Figure 3: The effect of Amodiaquine, Chloroquine, and their metabolites on the activity of host cathepsin B. FRET assay showing the activity of cathepsin B without drugs, or with addition of $A Q, D E A Q, C Q$, or DECQ at $4,8,16,33$, or $66 \mu \mathrm{M}$. RAW264.7 cells were treated with drugs for 1 hour prior to lysis and determination of cathepsin B activity (a), or untreated RAW264 cells were lysed, the lysate was treated with drugs, and then the activity of cathepsin B was assessed (b). 

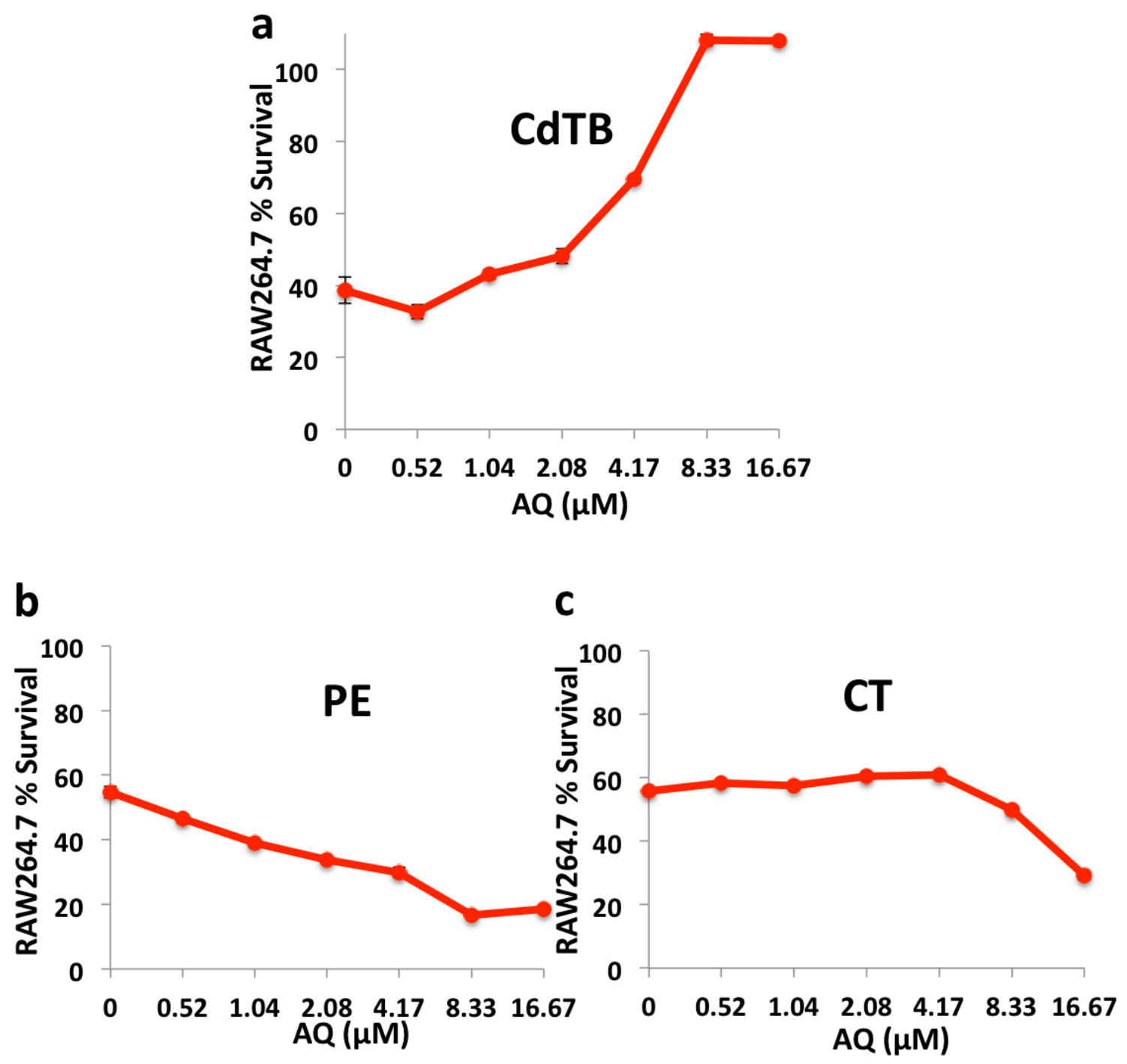

Figure 4: The effect of Amodiaquine on sensitivities of cells treated with bacterial toxins. RAW264.7 cells were pretreated with indicated AQ concentrations for 1 hour, and then treated with (a) $8.3 \mu \mathrm{g} / \mathrm{ml}$ of Clostridium difficile toxin B (CdTB), (b) $500 \mathrm{ng} / \mathrm{ml}$ of Pseudomonas aeruginosa Exotoxin A (PE), or (c) $500 \mathrm{ng} / \mathrm{ml}$ of Cholera toxin (CT) for 6 hours. RAW264.7

\section{Supplementary Tables}

Table 3: Amodiaquine, Chloroquine and theirmetabolites inhibit Ebola virus in HFF-1 cells. The effect of $A Q, C Q$, and its metabolites, DEAQ and DECQ, on the pathogenicity of EBOV in HFF-1 cells. The ability of drugs to reduce the abundance of Ebola virus (EBOV) in host cells was measured in cells 
by fluorescent microscopy. The $50 \%$ effective $\left(E C_{50}\right.$, virus-inhibitory) concentrations and $50 \%$ cytotoxic $\left(\mathrm{CC}_{50}\right.$, cell-inhibitory) concentrations were determined. $\mathrm{CC}_{50}$ divided by $\mathrm{EC}_{50}$ indicate the selectivity index (SI) value.

\begin{tabular}{cccccc} 
Pathogen & $\begin{array}{c}\text { Drug, } \\
\text { hours }\end{array}$ & EC50 $\mu \mathrm{M}$ & SD $\mu \mathrm{M}$ & CC50 $\mu \mathrm{M}$ & SI50 \\
\hline EBOV & AQ, 48h & 2.6 & 0.19 & 30 & 11.4 \\
EBOV & DEAQ, 48h & 2.1 & 0.48 & 30 & 14.4 \\
EBOV & CQ, 48h & 2.5 & 0.88 & 70 & 28.0 \\
EBOV & DECQ, 48h & 3.2 & 0.62 & 70 & 22.1
\end{tabular}

Table 4: Amodiaquine and its metabolite inhibits Chikungunya (CHIV) and Junin (JUNV) viruses in host cells. The effect of $A Q$ and DEAQ on the pathogenicity of EBOV in HFF-1cells. The ability of drugs to reduce the abundance of viruses in host cells was measured in cells by fluorescent microscopy. The $\mathbf{5 0 \%}$ effective ( $\mathrm{EC}_{50}$, virus-inhibitory) concentrations and $50 \%$ cytotoxic $\left(\mathrm{CC}_{50}\right.$, cell-inhibitory) concentrations were determined. $\mathrm{CC}_{50}$ divided by $\mathrm{EC}_{50}$ indicate the selectivity index (SI) value.

\begin{tabular}{cccccc} 
Pathogen & Drug & EC50 $\mu \mathrm{M}$ & SD $\mu \mathrm{M}$ & CC50 $\mu \mathrm{M}$ & SI50 \\
\hline CHIV & AQ & 18.4 & 0.56 & $>50$ & $>2$ \\
CHIV & DEAQ & 17.3 & 0.64 & $>50$ & $>2.9$ \\
JUNV & AQ & 16.9 & 1.92 & 50 & 3.0 \\
JUNV & DEAQ & 13.8 & 2.02 & 40 & 2.9
\end{tabular}

Supplemental Materials and Methods:

Screening Assays for Ebola virus (EBOV, Strain Kikwit).

High Content Imaging virus infection assay

Cell Culture and infection 
HeLa cells (ATCC) were cultured for 3 days in T175 or T225 (Corning) flasks in culture media containing Minimum Essential Medium (MEM, Corning Cellgro) supplemented with 10\% Fetal Bovine Serum (Hyclone), 1\% L-Glutammine (Hyclone), $10 \mathrm{mM}$ Hepes 7.0-7.6 (Sigma), 1\% non-essential amino acids (Sigma). Cells were lifted using Trypsin-EDTA (Sigma, T3974) and 2,000 cells/well were plated in $35 \mu \mathrm{l}$ of culture media into imaging 384 well assay plates (Aurora 384, IQ-EB, 384 IQ-EB/NB, 200mclear, \#1052-11130) and incubated for about 20h before compound treatment.

\section{Compound treatment}

Treatment of the cells with test and control compounds was done $2 \mathrm{~h}$ prior infection. EC50 determination for test compound done with 2 fold step at least for 10 doses starting from highest concentration of 100uM (with stock concentration of $10 \mathrm{mM}$ ) using HP D-300 digital dispenser. Each dose dispensed directly from the concentrated stock with highest volume of $500 \mathrm{~nL}$. Concentration of DMSO in all wells was normalized to $1 \%$. Cells were pre-treated with serially diluted compounds for 2 hours before infection. Each dose were repeated 4 times on one plate $(n=4)$.

\section{Infection}

Infection was done using Ebola virus (Kikwit) $\mathrm{MOI}=0.5$ (calculated for 4,000 cells/well, assuming one complete round of replication of HeLa cells at $15 \pm 2 \mathrm{hrs}$ after cell seeding) and 10ul of virus dilution was dispensed in each well except 
column 2, representing "no infection control". Cells were incubated with the virus for 24 or $48 \mathrm{~h}$. Infection was terminated by fixing samples in formalin solution.

\section{Immuno-staining assay}

Immune-staining was used to visualize infected cells. Cells were treated with anti-GP specific monoclonal antibody (6D8) (1 to 1000 dilution) followed by antimouse IgG conjugated with Dylight488 (Thermo) (1 to 1000 dilution) in blocking buffer containing 3\% BSA in PBS. Nuclei were stained with Draq5 (Biostatus) diluted in PBS buffer.

\section{Image and Data analysis.}

Images were acquired on the Opera imaging instrument (Perkin Elmer) using 10x Air objective and four images/well were acquired. Signal from anti-virus staining was detected at $488 \mathrm{~nm}$ emission wavelength and Nuclei at $640 \mathrm{~nm}$.

Image analysis was performed using PE Acapella algorithms. Several well-based output parameters were measured including: Number of Objects (Nuclei) and Positive Virus Number of Objects (Ave of Intensity for virus specific signal). The $\%$ of Infected cells were calculated by Acapella directly as

$$
\% \text { Infected cells }=\frac{\text { Positive Virus Number of Objects }(s)}{\text { Number of objects }(s)} * 100
$$


$\%$ infection rate was analyzed for each plate using Median of \% Positive virus cells (for all Neutral control wells that are infected and treated with DMSO only; S-sample

\section{Data analysis}

\section{Data normalization}

\% Inhibition. Data normalization was done using GeneData Explorer software. Data was normalized on the plate based level converting the \%Virus positive cells associated with each wells into $\%$ Activity $=\%$ of inhibition of infection (or $\%$ Inhibition or \% INH). Control wells were indicated as follows:

NC =Neutral control; Infection + DMSO (or minimal activity of inhibitor)

$\mathrm{BC}=$ Blank control; No infection (or maximum inhibition of viral infection possible). Median of the values is used for all controls.

$$
\% \text { Inhibition }=\frac{\text { Median } \% \text { Virus positive }(N C)-\% \text { Virus positive }(S)}{\text { Median } \% \text { Virus positive }(N C)-\text { Median } \% \text { Virus positive }(B C)} * 100 \%
$$

$\%$ Viability. Number of objects represented the amount of cells in each treated well and was also used as indication of the cyto-toxic or cyto-static effect. The numbers of objects were converted by GeneData Condeseo to \% Viability for with a compound dose response. 


$$
\% \text { Viability }=\frac{\text { Nuclei Nuber Sample }}{\text { MedianNulei number }(N C)} * 100 \%
$$

Dose response curve fitting analysis

Analysis of dose response curve for $\%$ Inhibition and $\%$ Viability was used to determine $\mathrm{EC}_{50}$ and $\mathrm{CC}_{50}$, and was applying GeneData Condoseo software with Levenberg-Marquardt algorithm (LMA) for curve fitting strategy. The Curve-fitting applied validity criteria, such aschi ${ }^{2}, \mathrm{SE} \log \mathrm{EC}_{50}$, minimal number of valid data points, to indicate if curve fitting converging was successful and indicated in table with results. $R^{2}$ value quantifies goodness of fit. Fitting strategy was considered acceptable if it gave conversion with $R^{2}>0.8$.

\section{Screening Assays for Venezuelan equine encephalitis virus (VEEV, Strain} $\underline{\mathrm{TC}-83) .}$

Primary cytopathic effect (CPE) reduction assay. Four-concentration CPE inhibition assays are performed. Confluent or near-confluent cell culture monolayers in 96-well disposable microplates are prepared. Cells are maintained in MEM or DMEM supplemented with FBS as required for each cell line. For antiviral assays the same medium is used but with FBS reduced to $2 \%$ or less and supplemented with $50 \mu \mathrm{g} / \mathrm{ml}$ gentamicin. The test compound is prepared at four $\log _{10}$ final concentrations, usually $0.1,1.0,10$, and $100 \mu \mathrm{g} / \mathrm{ml}$ or $\mu \mathrm{M}$. The virus control and cell control wells are on every microplate. In parallel, a known 
active drug is tested as a positive control drug using the same method as is applied for test compounds. The positive control is tested with each test run. The assay is set up by first removing growth media from the 96-well plates of cells. Then the test compound is applied in $0.1 \mathrm{ml}$ volume to wells at $2 \mathrm{X}$ concentration. Virus, normally at $<10050 \%$ cell culture infectious doses (CCID50) in $0.1 \mathrm{ml}$ volume, is placed in those wells designated for virus infection. Medium devoid of virus is placed in toxicity control wells and cell control wells. Virus control wells are treated similarly with virus. Plates are incubated at $37^{\circ} \mathrm{C}$ with $5 \% \mathrm{CO}_{2}$ until maximum CPE is observed in virus control wells. The plates are then stained with $0.011 \%$ neutral red for approximately two hours at $37^{\circ} \mathrm{C}$ in a $5 \% \mathrm{CO}_{2}$ incubator. The neutral red medium is removed by complete aspiration, and the cells may be rinsed $1 \mathrm{X}$ with phosphate buffered solution (PBS) to remove residual dye. The PBS is completely removed and the incorporated neutral red is eluted with $50 \%$ Sorensen's citrate buffer $/ 50 \%$ ethanol $(\mathrm{pH} \mathrm{4.2)}$ for at least 30 minutes. Neutral red dye penetrates into living cells, thus, the more intense the red color, the larger the number of viable cells present in the wells. The dye content in each well is quantified using a 96-well spectrophotometer at $540 \mathrm{~nm}$ wavelength. The dye content in each set of wells is converted to a percentage of dye present in untreated control wells using a Microsoft Excel computer-based spreadsheet. The $50 \%$ effective (EC $\mathrm{EC}_{50}$, virus-inhibitory) concentrations and $50 \%$ cytotoxic $\left(\mathrm{CC}_{50}\right.$, cell-inhibitory) concentrations are then calculated by linear regression analysis. The quotient of $\mathrm{CC}_{50}$ divided by $\mathrm{EC}_{50}$ gives the selectivity index (SI) value. 


\section{Screening Assays for Herpes Simplex Virus 1 (HSV-1, Strain E-377) and Human Cytomegalovirus (CMV, Strain AD169).}

Human foreskin fibroblast (HFF) cells were prepared from human foreskin tissue. The tissue was incubated at $4^{\circ} \mathrm{C}$ for $4 \mathrm{~h}$ in Clinical Medium and then placed in phosphate buffered saline (PBS) to remove the red blood cells, and resuspended in trypsin/EDTA solution. The tissue suspension was incubated at $37^{\circ} \mathrm{C}$ and gently agitated to disperse the cells, which were collected by centrifugation. Cells were resuspended in $4 \mathrm{ml}$ Clinical Medium and placed in a flask and incubated at $37^{\circ} \mathrm{C}$ in a humidified $\mathrm{CO}_{2}$ incubator for $24 \mathrm{~h}$. The media was then replaced with fresh Clinical Medium and the cell growth was monitored daily until a confluent monolayer has formed. The HFF cells were then expanded through serial passages in standard growth medium of MEM with Earl's salts supplemented with $10 \%$ FBS and antibiotics. The cells were passaged routinely and used for assays at or below passage 10 .

Primary Cytopathic Effect (CPE) Reduction Assay. Low passage (3-10) HFF cells were trypsinized, counted, and seeded into 96 well tissue culture plates in $0.1 \mathrm{ml}$ of MEM supplemented with $10 \% \mathrm{FBS}$. The cells were then incubated for $24 \mathrm{~h}$ at $37^{\circ} \mathrm{C}$. The media was then removed and $100 \mu \mathrm{l}$ of MEM containing $2 \%$ FBS was added to all but the first row. In the first row, $125 \mu$ of media containing the experimental drug was added in triplicate wells. Media alone was added to both cell and virus control wells. The drug in the first row of wells was then diluted serially $1: 5$ throughout the remaining. The plates were then incubated for 60 min and $100 \mu \mathrm{l}$ of a virus suspension was added to each well, excluding cell 
control wells which received $100 \mu \mathrm{l}$ of MEM. The plates were then incubated at $37^{\circ} \mathrm{C}$ in a $\mathrm{CO}_{2}$ incubator for three days for HSV-1, or $14 \mathrm{~d}$ for CMV. After the incubation period, media was aspirated and the cells stained with crystal violet in formalin for $4 \mathrm{~h}$. The stain was then removed and the plates were rinsed until all excess stain was removed. The plates were allowed to dry for $24 \mathrm{~h}$ and the amount of CPE in each row determined using a BioTek Multiplate Autoreader. $\mathrm{EC}_{50}$ and $\mathrm{CC}_{50}$ values were determined by comparing drug treated and untreated cells using a computer program.

\section{Screening Assays for Rabies (Strain Flury).}

Confluent BHK-21 cells were prepared in T-150 flask. Cells were Trypsinized cells and made as cell suspensions. $50 \mu \mathrm{l}$ of $5 \times 10^{5}$ cells $/ \mathrm{ml}$ cell suspension (25,000 cells/well) were added into each well of the 96 well plates, except row $\mathrm{H}$. 2X concentration of antivirals were made (Isoprinosine and test drug(s)). 6 concentration points are done. $100 \mu \mathrm{l}$ per well that will be tested for effective concentration (drug wells) and cytotoxic concentration (tox wells) were added. The rabies virus was diluted $1: 1000.50 \mu$ was added per well in the drug wells and virus control wells. This gave a final dilution of 1:4000. The final volume was

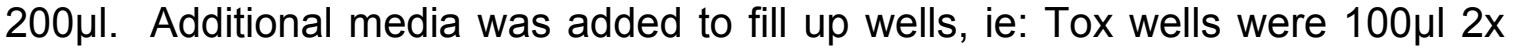
drug, $50 \mu \mathrm{l}$ cells $(5 \mathrm{e} 5 \mathrm{cells} / \mathrm{ml})$, and $50 \mu \mathrm{l}$ media. Plates were covered and incubated $\left(37^{\circ} \mathrm{C} ; 5 \% \mathrm{CO}_{2}\right)$ for 5 days. After 5 days the Promega CellTiter-Glo Luminescent Cell Viability Assay was run using the Fluoroskan FL to scan for luminescence. 


\section{Screening Assays for Poliovirus 3}

Principal Viruses and Cells:

Poliovirus: WM3, Cells: LLC-MK2 clone 7.1

CellTiter 96 (Cytopathic effect/Toxicity). The primary screen is a cytopathic effect (CPE) reduction assay. Briefly, 96-well cultures of cells are infected with virus in the presence of test compounds and incubated for 4-7 days (depending on the specific virus/cells). Each virus is pre-titered such that control wells exhibit approximately $95 \%$ loss of cell viability due to virus replication. Therefore, antiviral effect, or cytoprotection, is observed when compounds prevent virus replication. Each assay plate contains cell control wells (cells only), virus control wells (cells plus virus), compound toxicity control wells (cells plus compound only), compound colorimetric control wells (compound only, no cells or virus), as well as experimental wells (compound plus cells plus virus). Cytoprotection and compound cytotoxicity are assessed by MTS (CellTiter®96 Reagent, Promega, Madison WI) dye reduction. The \% reduction in viral CPE (antiviral activity) and $\%$ cell viability (cytotoxicity) are determined and reported.

\section{Screening Assays for Respiratory syncytial virus and SARS CoV}

Principal Viruses and Cells:

Respiratory syncytial virus (RSV): Strain A-2 in Hep2 cells

SARS CoV: Strain Urbani in Vero76 cells 
CellTiter-Glo (Cytopathic effect/Toxicity). The antiviral cytoprotection assays examine the effects of compounds at designated dose-response concentrations in specific cell types to test the efficacy of the compounds in preventing the virusinduced cytopathic effect. Ribavirin is included as a positive control drug for influenza and RSV, while calpain IV inhibitor is used for SARS antiviral assays. Subconfluent cultures of cells are plated into 96-well plates for the analysis of cell viability (cytotoxicity) and antiviral activity (CPE). For the standard assay, drugs are added to the cells 24 hours later. The CPE wells also received 100 tissue culture infectious doses $\left(100 \mathrm{TCID}_{50} \mathrm{~S}\right)$ of titered virus. 72 hours later the cell viability will be determined. Measurement of viral-induced CPE is based on quantitation of ATP, an indicator of metabolically active cells. The CPE assay employs a commercially available CellTiter-Glo* Luminescent Cell Viability Kit (Promega, Madison, $\mathrm{WI}$ ), and is a reliable method for determining cytotoxicity and cell proliferation in culture. The procedure involves adding the single reagent (CellTiter-Glo Reagent) directly to previously cultured, subconfluent cells in media. This induces cell lysis and the production of a bioluminescent signal (half-life greater than 5 hours, depending on the cell type) that is proportional to the amount of ATP present (which is a biomarker for viability). 


\section{Transition}

In Chapter 2, we utilized multiplex cellular drug screening to rapidly identify Amodiaquine as an anti-toxin and anti-viral treatment. In addition, we successfully identified cathepsin B as the protein target of Amodiaquine. The study also validates the broad-spectrum applications of Amodiaquie as a hostoriented therapy. Although we were successfully showed the multiplex, we found a limitation in our approach: multiplex cellular drug screening requires additional target identification steps to discover the host protein target of a drug in the cell. In an effort to improve and streamline our technique, we merged drug screening and protein target identification into one process. Chapter 3 outlines our new approach of multiplex drug screening. We performed parallel biochemical and cell-survival screens to identify the new therapy and also its protein target. 


\section{William Leonardi Contributions}

William Leonardi performed the following experiments (presented on Figures):

- Figure 2c, 2d

- Figure $3 b, 3 c$, and $3 d$

- Figure $4 \mathrm{~d}, 4 \mathrm{e}, 4 \mathrm{f}, 4 \mathrm{~g}$, and $4 \mathrm{~h}$

- Figure $5 a, 5 b, 5 c, 5 d, 5 e$, and $5 f$

- Figure 6c 


\section{Chapter 3 - Bithionol blocks pathogenicity of bacterial toxins, ricin, and Zika virus}

\section{Abstract}

Diverse pathogenic agents often utilize overlapping host networks, and hub proteins within these networks represent attractive targets for broad-spectrum drugs. Using bacterial toxins, we describe a new approach for discovering broadspectrum therapies capable of inhibiting host proteins that mediate multiple pathogenic pathways. This approach can be widely used, as it combines geneticbased target identification with cell survival-based and protein function-based multiplex drug screens, and concurrently discovers therapeutic compounds and their protein targets. Using B-lymphoblastoid cells derived from HapMap Project cohort of persons of African, European, and Asian ancestry we identified host caspases as hub proteins mediating lethality of multiple pathogenic agents. We discovered that an approved drug, Bithionol, inhibits host caspases and also reduces the detrimental effects of anthrax lethal toxin, diphtheria toxin, cholera toxin, Pseudomonas aeruginosa exotoxin A, Botulinum neurotoxin, ricin, and Zika virus. Our study reveals the practicality of identifying host proteins mediating multiple disease pathways and discovering broad-spectrum therapies that target these hub proteins. 


\section{Introduction}

In recent years, a better understanding of protein interaction networks has led to the identification of highly connected hub proteins and pathways that are commonly used by a number of different pathogens and in a range of diseases ${ }^{73}$. These hubs represent promising targets for drug development.

Most disease networks have the "small-world" property, where proteins are only a few interactions away from any other proteins ${ }^{74}$. Therefore, inhibiting a given node can potentially affect the state of most nodes in its vicinity as well as the activity of the network itself. In this way, therapeutic inhibition of nodes and hubs within one disease network can affect other disease modules or pathways. Here we develop an approach to systematically identify broad-spectrum drugs that target proteins exploited by multiple human disease pathways (Fig. 1a). Frequently, multiple infectious pathogens or toxins that negatively affect hosts by different mechanisms exploit the same host pathways ${ }^{75}$. This notion raises the prospect that multiplex approaches may lead to the discovery of broadly active and host-oriented infectious diseases countermeasures that target host functions exploited by multiple pathogenic agents. We use genetics and a new drug screening methodology to identify and characterize the previously approved drug Bithionol as an inhibitor of host caspases, which reduces pathogenicity of a wide range of pathogenic agents, including ricin, anthrax lethal toxin, Botulinum neurotoxin A, diphtheria toxin, Pseudomonas aeruginosa exotoxin A, cholera toxin, and Zika virus. 
a

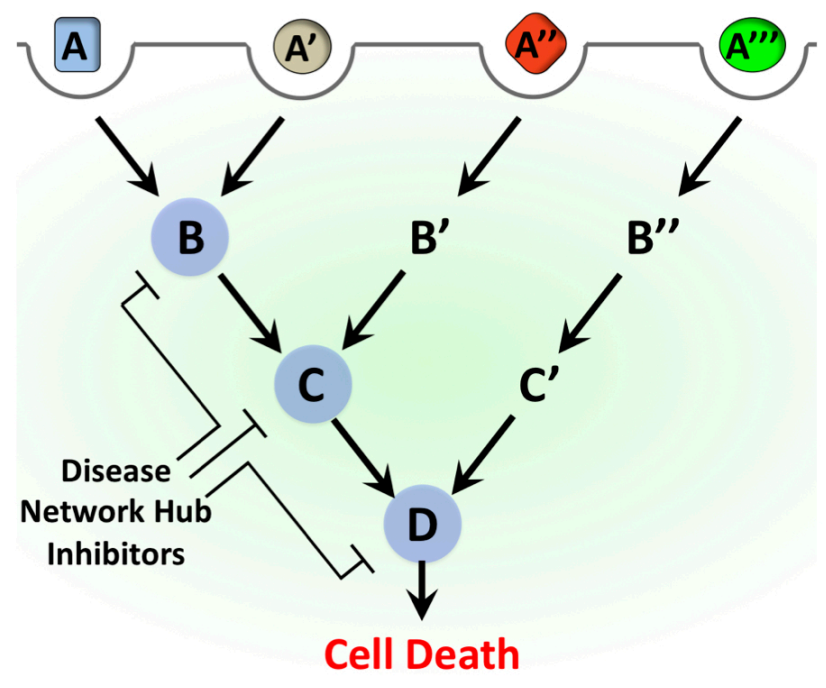

Figure 1a: Depiction of the concept where multiple pathogenic pathways overlap, and hub proteins (purple circles) mediate multiple disease pathways. This model proposes a drug screen design to look for compounds that simultaneously inhibit the function of the hub protein and reduce cellular lethality caused by multiple pathogenic pathways. 


\section{Results}

\section{Identification of host hub proteins exploited by multiple pathogenic toxins}

Cytotoxic bacterial and plant toxins have evolved to exploit host proteins and cellular pathways that mediate the entry of those toxins into host cells and to induce cell-death. Although toxins exploit unique host pathways, these pathways are interconnected. While anthrax, diphtheria, and Botulinum toxins reach the cytoplasm from acidified endosomes, cholera, Pseudomonas aeruginosa and ricin toxins are transported into the cytoplasm through the host ER-associated degradation pathway ${ }^{63}$. These pathways interconnect at host "hub" proteins. Using one of those toxins, Pseudomonas aeruginosa exotoxin A (PE), we set out to identify such hub proteins by i) determining whether known genetic mutations in host proteins exploited by PE affect the sensitivity of host cells to this toxin, and ii) investigating whether these host proteins are also exploited by additional pathogenic agents. The protein hubs will be used as targets in drug screens, in order to discover broad-spectrum host-oriented anti-pathogenic agents drugs (Fig. 1b). 
b

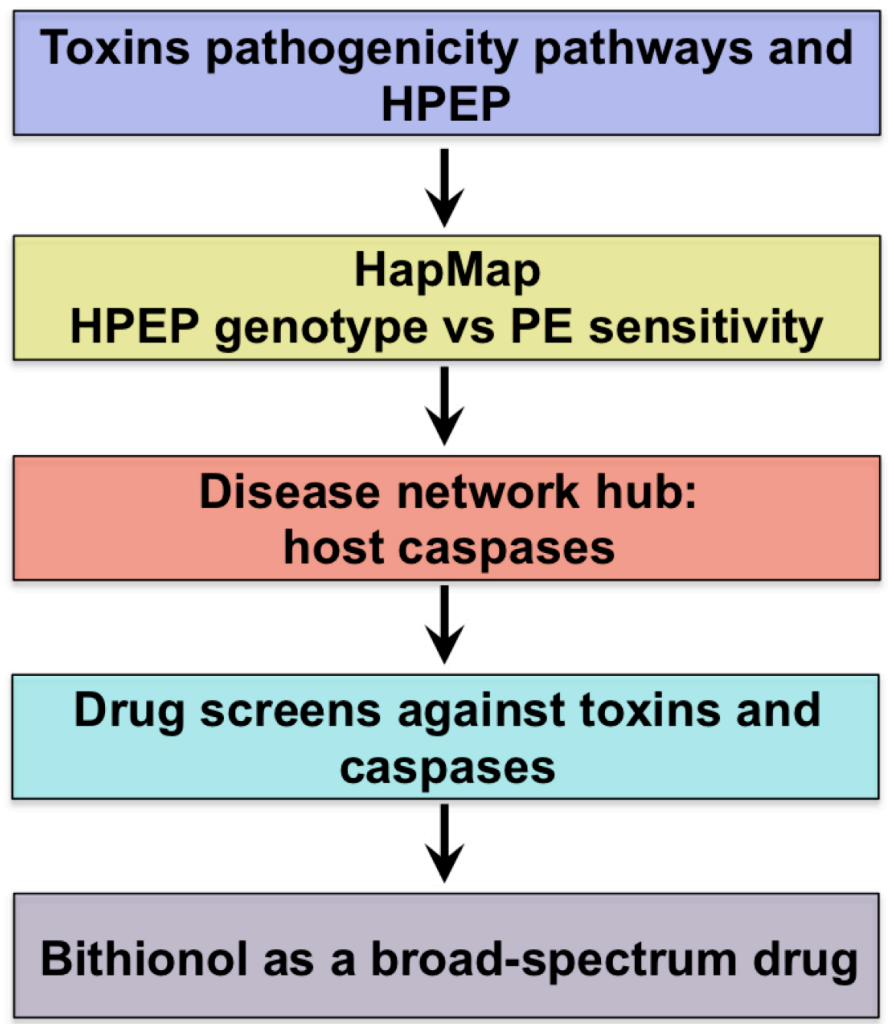

Figure 1b: A depiction of the design of the current study. The known host pathways and host proteins exploited by pathogens (HPEP) are considered. HapMap cell lines are used to study the association between cellular sensitivity to Pseudomonas aeruginosa exotoxin $A$ (PE) and genetic mutations in genes coding for proteins exploited by PE. Mutations in host caspases associate with altered sensitivity to PE, and these proteins are defines as disease network hubs, which will be used as targets for the following drug screens. This approach yields broad-spectrum host-oriented drug, Bithionol. 
The effect of caspase mutations on the sensitivity of human B-cells to $P$.aeruginosa exotoxin $A$

It has previously been shown that PE exploits several host proteins for its binding to and entry into host cells ${ }^{76}$ and initiates programmed cell death by inducing activities of host caspase-3, -6 , and $-7^{21}$. We investigated whether known mutations in host proteins exploited by PE associate with altered cytotoxicity of the toxin in cells from tissues that are naturally attacked by this toxin. The availability of human B-cells, which are physiological targets of $\mathrm{PE}{ }^{77}$ through the HapMap Project ${ }^{78}$ has provided us with an opportunity to test whether mutations in host proteins that constitute PE pathogenicity pathway affect the cellular sensitivity to this toxin. Our initial tests with cells from a few individuals revealed that their sensitivity to PE varies greatly. Remarkably, our further investigation of PE sensitivity of B-lymphoblastoid cells derived from 234 individuals in geographically and ethnically diverse human populations [87 Yoruba in Ibadan, Nigeria (YRI), 60 Utah residents with ancestry from northern and western Europe (CEU), 43 Japanese in Tokyo, Japan (JPT), and 44 Han Chinese in Beijing, China (CHB)] showed a prominent 200-fold difference in lethality to the toxin (Figs. 2a and b). The range in PE sensitivity, as measured by the dose required to kill $20 \%$ of the cells $[\log (1 / \mathrm{LD} 20)]$, was similar in all four human cell populations (Fig. 2c). Analysis of toxin sensitivity in parent/children trios indicated that relative sensitivity to $P E$ is a heritable trait $(P$-value $<0.0001)$ (Fig. $2 \mathrm{~d})$.

The widespread and unimodal distribution observed for log(1/LD20) (Fig. 2b) is likely a result of a polygenic inheritance model, consistent with evidence that 
multiple host proteins mediate PE lethality ${ }^{21,76}$. To learn whether genetic variations in the genes encoding for these proteins account for any of the variation in sensitivity of B-cells to PE seen in Fig. 2a, we tested the association of numerous previously reported mutations with PE sensitivity. Caspase-7 and -3 mutations that were previously reported to associate with cancer and rheumatoid arthritis ${ }^{79-83}$ demonstrated a significant association with PE sensitivity in the individual HapMap populations (CASP7, rs3814231, CEU, $P=0.01$; CASP7, rs2227309, CEU, $P=0.02$; CASP3, rs4647601, rs4647693, and rs1049216, East Asian populations $\mathrm{CHB}$ and JPT combined, $P=0.04$ for each SNP) (Figs. 2e and S1). These results show that the activity of caspases affects host cell sensitivity to toxins, and that these proteins are potential therapeutic intervention points and targets for the following drug screens. In addition to PE, ricin and toxins of anthrax, diphtheria, Botulinum, and cholera induce programmed cellular death by activating host caspases ${ }^{21,22,45,84-88}$ (Fig. 3a). Therefore, a drug screen against hub caspases is of great interest, as these proteins are exploited by multiple pathogenic pathways, and therefore caspase inhibitors can act as broad-spectrum drugs. 


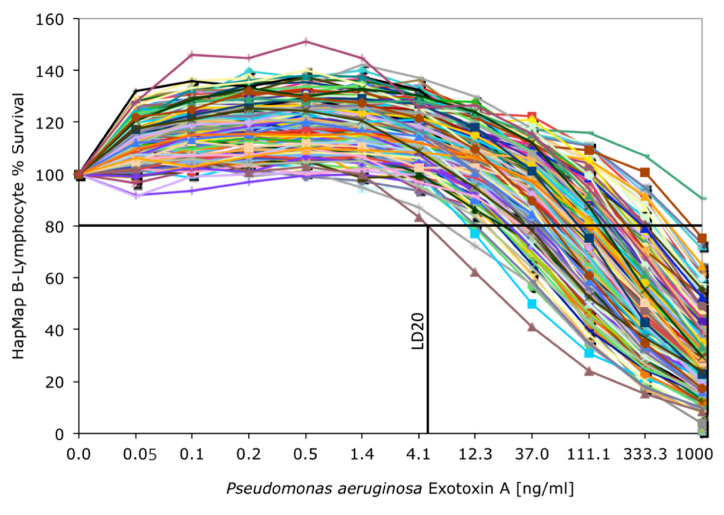

C
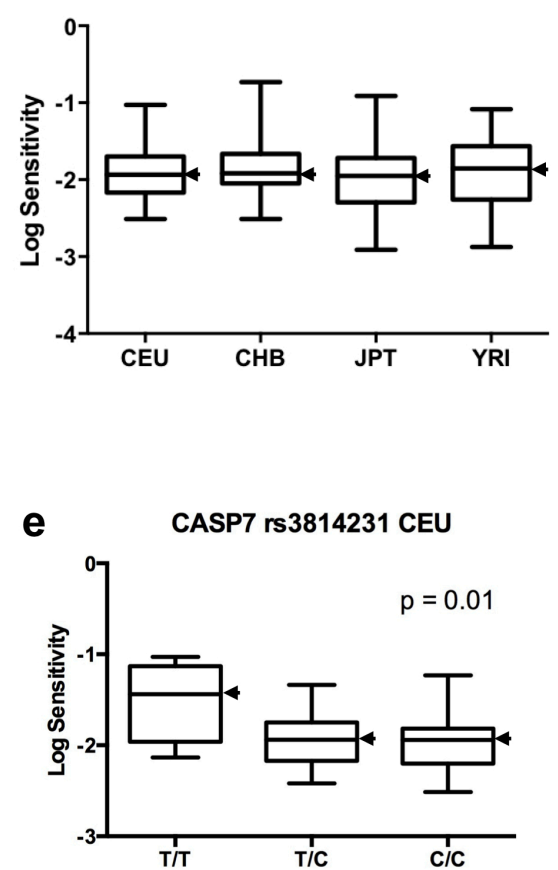

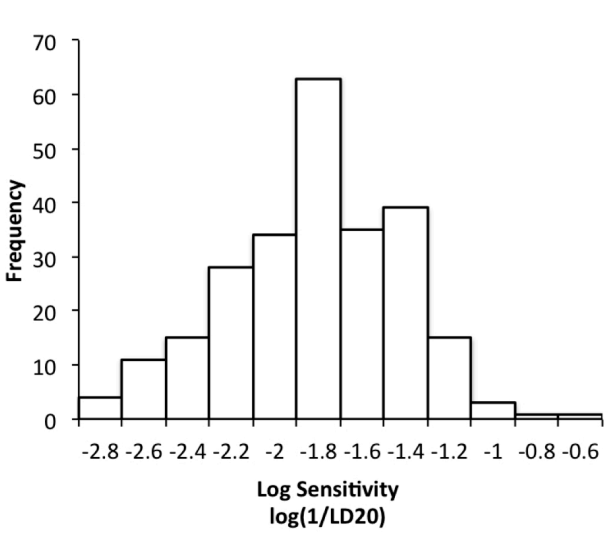

d

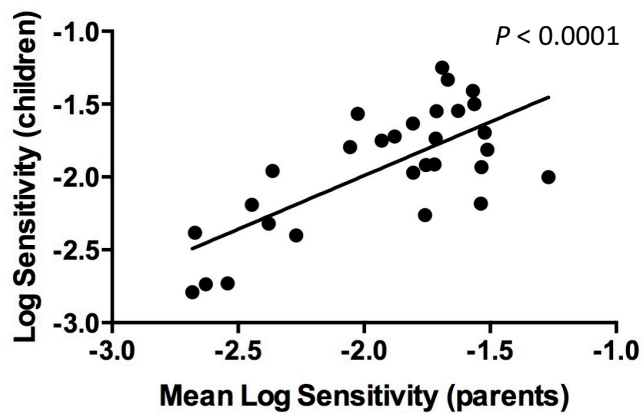

Figure 2: The effect of Bithionol on $P$. aeruginosa exotoxin $A$ in human $B-$ lymphoblastoid cells. (a and b) Human lymphoblastoid cells sensitivity to $P$. aeruginosa exotoxin A (PE)-mediated toxicity. (a) 234 B-lymphocytes were treated with PE at concentrations shown. Cell viability was determined by Alamar Blue assay (Materials and Methods) and is shown as the percentage of survivors relative to cells treated with PE alone. The LD20 calculation for the most sensitive cell line is shown as an example. (b) LD20 values $(\mathrm{ng} / \mathrm{ml}$ of PE) were calculated and expressed on an inverse log10 scale. For calculations, PE sensitivity is defined numerically as 1/LD20. (c) Populationspecific distribution of toxins sensitivities. CEU, YRI, JPT, and CHB denote European, Yoruba, Japanese, and Chinese Han, respectively. One CHB 
outlier is excluded. For each population, the black bar represents the median log sensitivity; the box extends from the lower to the upper quartile and the whiskers extend to the most extreme data point. (d) Heritability of log sensitivity in Yoruba trios. Plot of the log toxin sensitivity of the children against the mean log toxin sensitivity of the parents. The heritability is estimated as the slope (0.74) of the regression of the children phenotype on the midparent phenotype. (e) In CEU caspase-7 SNP rs3814231 associates with log PE sensitivity.

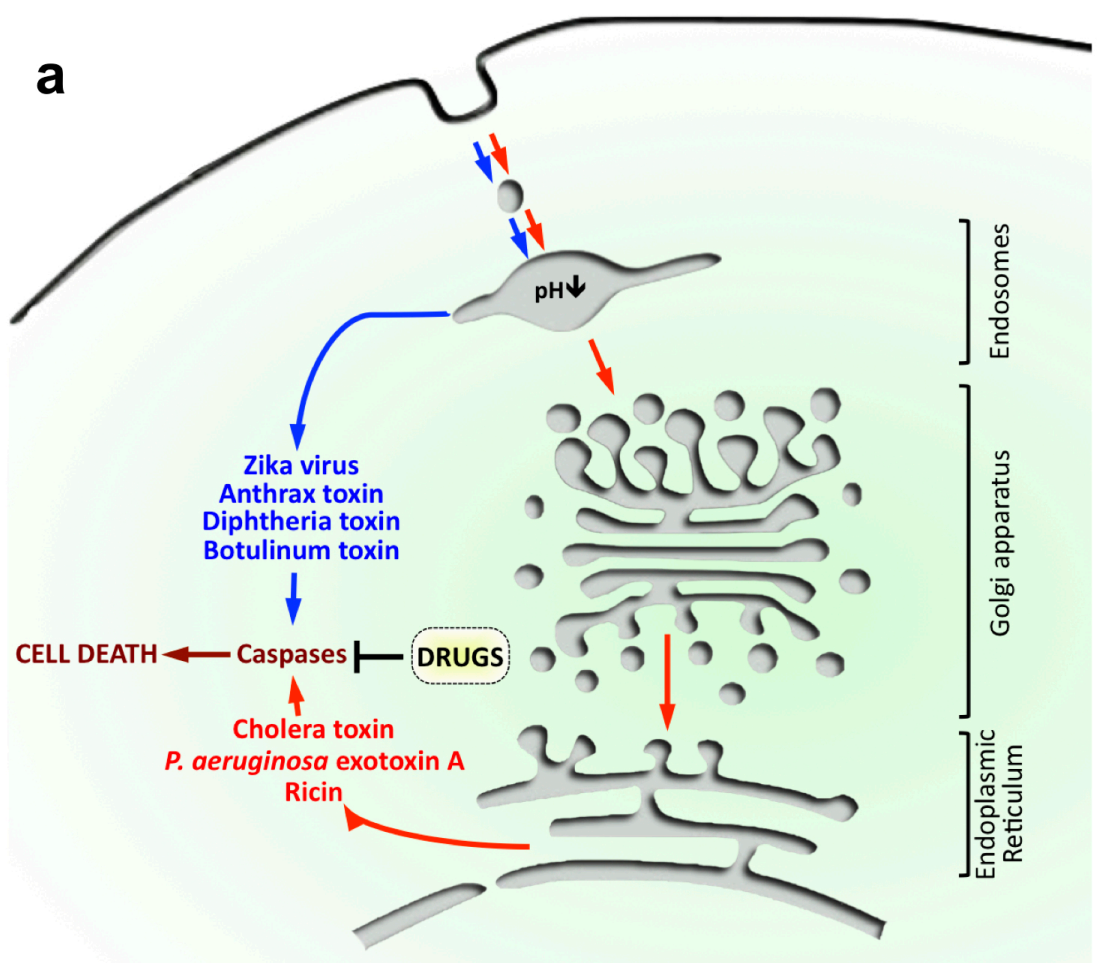

Figure 3a: The use of Clinical Compound Library (CCL) to screen for inhibitors of hubs of human disease networks. (a) Depiction of toxins as well as their pathways that induce caspase-mediated cell death. These toxins enter into host cytoplasm either from acidified endosomes or endoplasmic reticulum. Broad-spectrum anti-toxin drugs are screened to identify inhibitors of host caspases. 


\section{A multiplexed cellular screen for CCL drugs that inhibit cytotoxic activities of bacterial toxins exploiting unique but interconnected host pathways}

In an effort to identify existing drugs that might be repurposed as novel hostoriented broad-spectrum therapies, we screened a Clinical Compound Library $(C C L)^{30}$ through multiplex-based drug screening (Fig. 3b). We searched for compounds capable of both i) reducing cytotoxicities of diphtheria toxin, cholera toxin, and PE, and ii) inhibiting proteolytic activities of host caspases-3, -6 , and -7 exploited by these toxins in biochemical assays (Figs. 3b-d). In principle, a combination of biochemical and cellular drug screens could provide drug hits that reduce toxins' cytotoxicities by inhibiting host caspases, and thus, this approach could simultaneously provide drug candidates and their protein targets.

We screened members of the CCL for the ability to reduce cell death of host RAW264.7 and C32 cells treated with PE, cholera toxin, or diphtheria toxin (Fig. 3c). At the indicated doses, between 30 and 50 percent of RAW264.7 cells undergo cell death within 12 hours for Pseudomonas and cholera toxins. For C32 cells, similar cell death was observed at 24 hours exposure to diphtheria toxin under the experimental conditions employed. A "hit" in our screen was defined as an event where cells exposed to a drug increased cell survival by at least 20 standard deviations $(\sim 1 \%$ hit rate) above the survival of control cells treated with either toxin, and is not cytotoxic to cells in the absence of toxins. Events defined as "multiplex hits" interfered with cell killing by at least two toxins. The two multiplex hits that were identified as capable of reducing the cytotoxicities of all three toxins were Bithionol and Pyrogallol (Fig. 3b). 

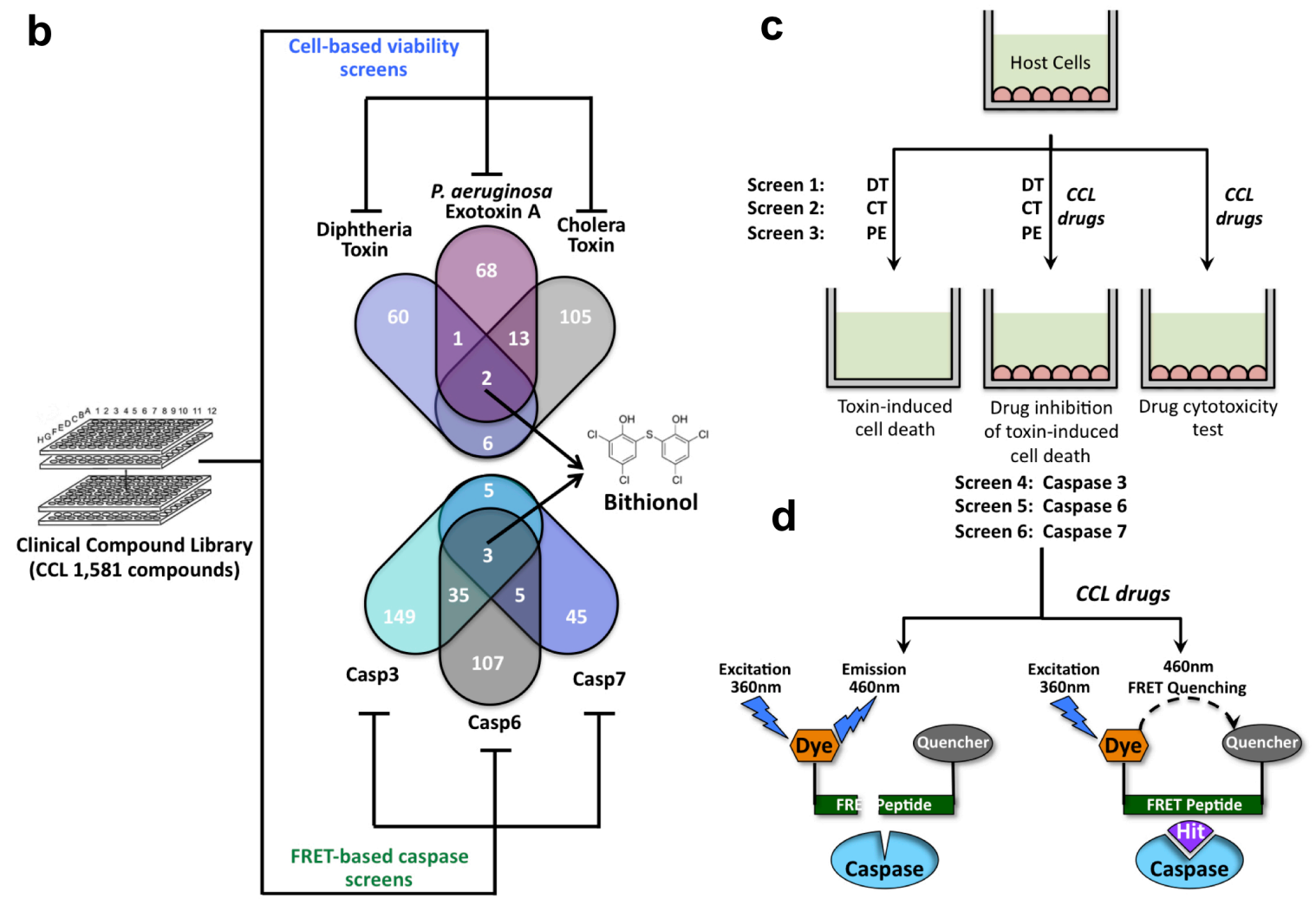

Figure 3b,c, d: Overall approach scheme: $C C L$ is screened by a multiplex approach that incorporates biochemical FRET and cell survival assays looking for drugs capable of simultaneously inhibiting host caspases-3/6/7 and reducing cytotoxicities of three bacterial toxins. The output of this approach is the discovery of broad-spectrum and host-oriented drug, Bithionol. c) Schematic diagram of cellular screens to identify drugs that reduce cellular lethality induced by diphtheria toxin, Pseudomonas aeruginosa exotoxin $A$, and cholera toxin. Numbers are the distribution of inhibitors obtained in all screens. d) Schematic diagram of parallel FRET screen to identify drugs that inhibit proteolytic reaction of caspases-3, -6 , and -7 . 


\section{A multiplex protein function-based screen for CCL drugs that inhibit proteolytic activities of host caspase-3, -6 , and -7}

In parallel experiments, we screened the $\mathrm{CCL}$ for drugs that could inhibit the function of hub caspases-3, -6 , and -7 (Fig. 3d) that mediate cytotoxicity caused by bacterial toxins used in our multiplex cellular drug screens (Fig. 3b). Caspase activities were induced in RAW264.7 cells by PE treatment. To screen and identify drugs that inhibit proteolytic activities of caspases we utilized a fluorescencebased FRET assay. Optimized substrate peptides for caspase-3, -6, and $-3 / 7$ proteolytic activities were used with a fluorogenic 7-amino-4-methylcoumarin group at the $\mathrm{N}$-terminus and acetyl quenching group at the C-terminus. As a FRET substrate that is uniquely cleaved by caspase- 7 hasn't been identified, and since caspases-3 and -7 are close orthologues, we searched for caspase-7 inhibitors that could block proteolysis of a caspase-3/7 - specific substrate and not caspase-3 - specific substrate. After cleavage by caspase the fluorescence of AMC at $460 \mathrm{~nm}$ increases, while inhibitors of caspases prevent it. Compounds that showed greater than $80 \%(\sim 1 \%$ hit rate) inhibition were defined as hits and selected for re-validation and further studies. Events defined as "multiplex hits" interfered with proteolytic activities of at least two caspases. Bithionol was one of the three multiplex hits identified as capable of prominently reducing the proteolysis of all three caspase substrates (Figs. 3b and 4a-c). Since Bithionol was identified by both cellular and biochemical multiplex screens (Fig. 3b), we further investigated the efficacy of Bithionol and the breadth of its potential as a host-oriented anti-pathogenic agent. 

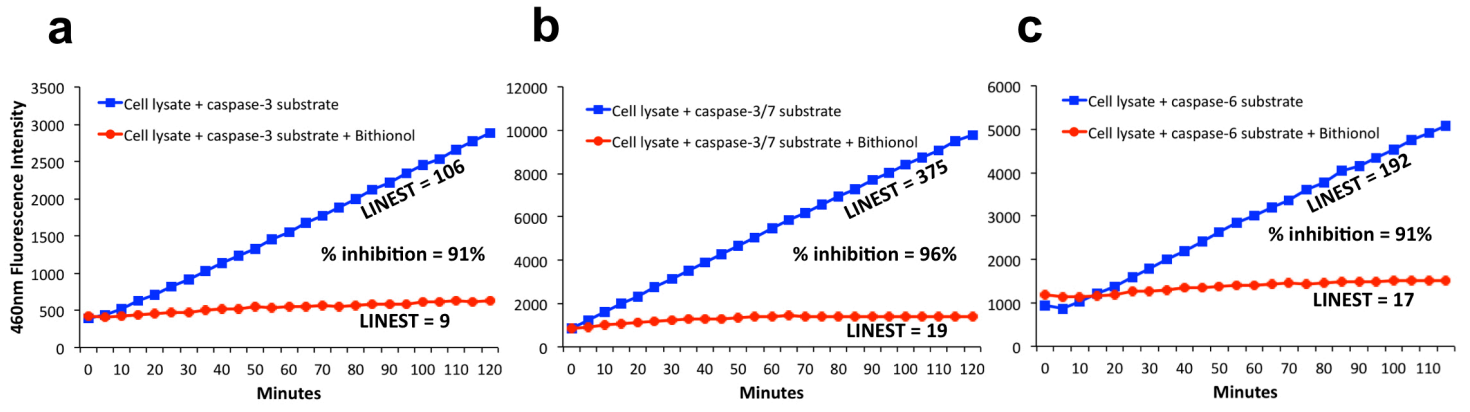

Figure 4 a, b, c: Bithionol inhibits caspases. FRET data showing fluorescence emission from two reactions, where caspase-containing cellular lysate cleaves fluorescently labeled substrate peptide without drugs, or in the presence of $33 \mu \mathrm{M}$ Bithionol. FRET substrates were specific for cleavage by caspase-3 (a), caspase-3/7 (b), and caspase-6 (c).

Bithionol reduces the pathogenicity of a range of toxins by inhibiting host caspases

To investigate the potency of Bithionol, we first performed drug titration curves in host RAW264.7 and C32 cells. We demonstrated that Bithionol was able to reduce diphtheria, cholera, and Pseudomonas toxins-mediated cytotoxicities with an EC50 of $10 \mu \mathrm{M}$ (Figs. 4d-f). We tested the effect of different concentrations of Bithionol for the ability to inhibit the proteolytic cleavage of substrates specific for cellular caspases-3, 6, and 3/7. We observed a linear dose-dependent caspaseinhibitory efficacy of Bithionol, with IC50 of 21,13 , and $11 \mu \mathrm{M}$ for caspases-3, -6 , and $-3 / 7$, respectively (Fig. $4 \mathrm{~g}$ ). These results are consistent with anti-toxins EC50's of Bithionol in cellular tests (Fig. 4d-f).

We also tested whether Bithionol reduces cellular sensitivity to PE in randomly selected PE-sensitive HapMap cells. We observed that the drug protected three 
cell lines treated with amounts of PE sufficient to kill $80 \%$ of cells (Fig. $4 \mathrm{~h}$ ). These results confirm the anti-toxin potential of Bithionol in host cells.

Humans have 10 well-characterized caspases that collectively form a pathway, often referred to as "the caspase cascade", where caspases- $3,-6$, and -7 are the executioners of cell death and are activated by other caspases ${ }^{89}$. We tested the ability of Bithionol to inhibit activities of ten purified recombinant human caspase proteins, and we demonstrated that in addition to caspases-3, -6 , and -7 , Bithionol inhibited activities of caspases-1 and -9 , while having no inhibitory effects on other caspases (Fig. 4i). Together, these results demonstrate that Bithionol is a direct inhibitor of a select subset of caspases, and that it reduces cellular sensitivity to toxins by targeting at least host caspases.
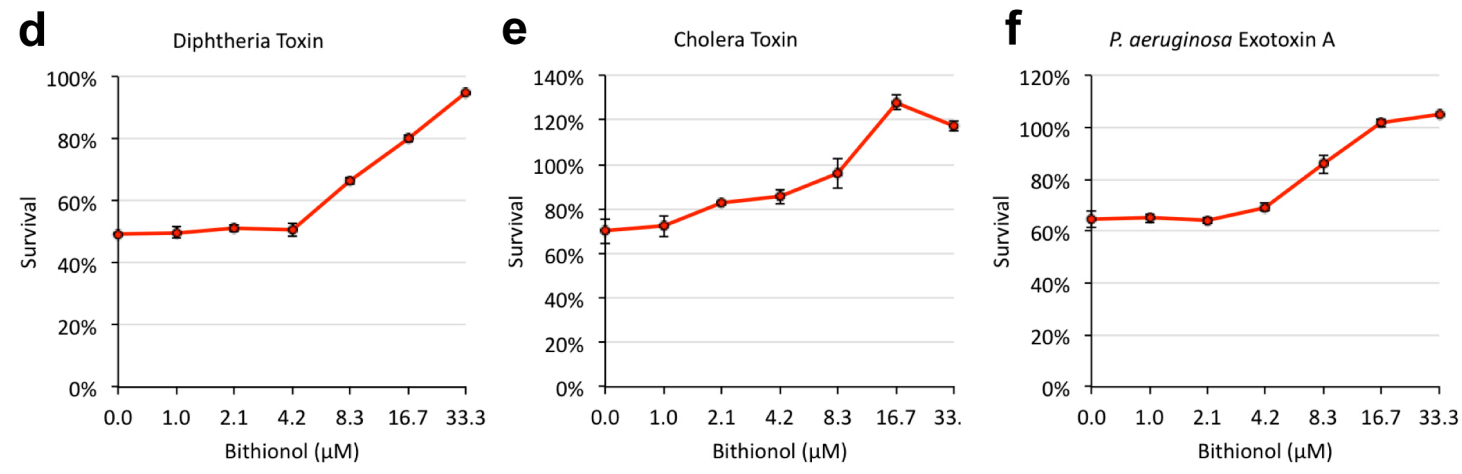

Figure $4 \mathrm{~d}$, e, f: Bithionol was tested for its ability to inhibit cytotoxicities mediated by toxins of cholera, diphtheria, and Pseudomonas. RAW264.7 cells were incubated with indicated doses of Bithionol for 1 hour, followed by 12 hours intoxication with Pseudomonas and cholera toxins. Diphtheria toxin was added to C32 cells for $\mathbf{2 4}$ hours. Cell viability was determined by MTT assay and is shown as the percentage of survivors relative to cells not treated with drugs. 
g

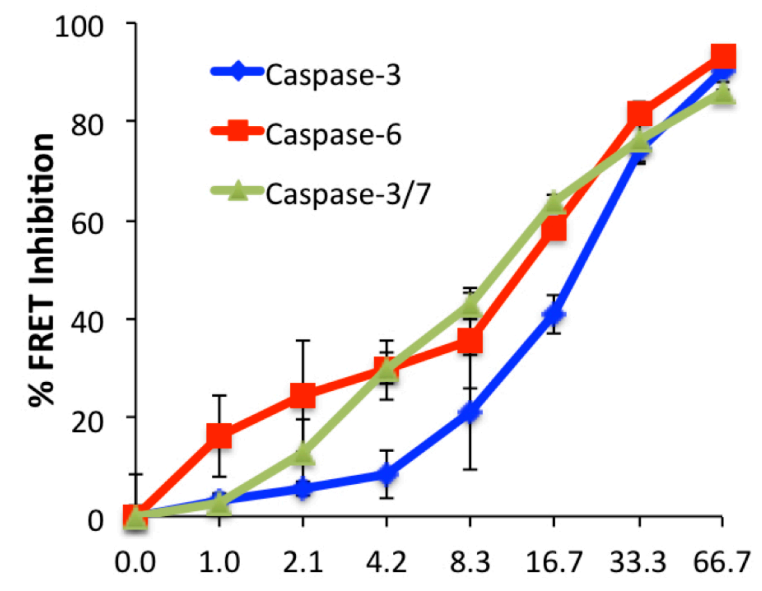

Figure 4g: Different concentrations of Bithionol are tested for their ability to inhibit caspase activity in cellular lysate of cells. Cells were pre-treated with Pseudomonas aeruginosa exotoxin A to induce caspases. FRET was done using substrates cleaved by caspases-3, -6 , and $-3 / 7$.

h Bithionol $(\mu \mathrm{M})$

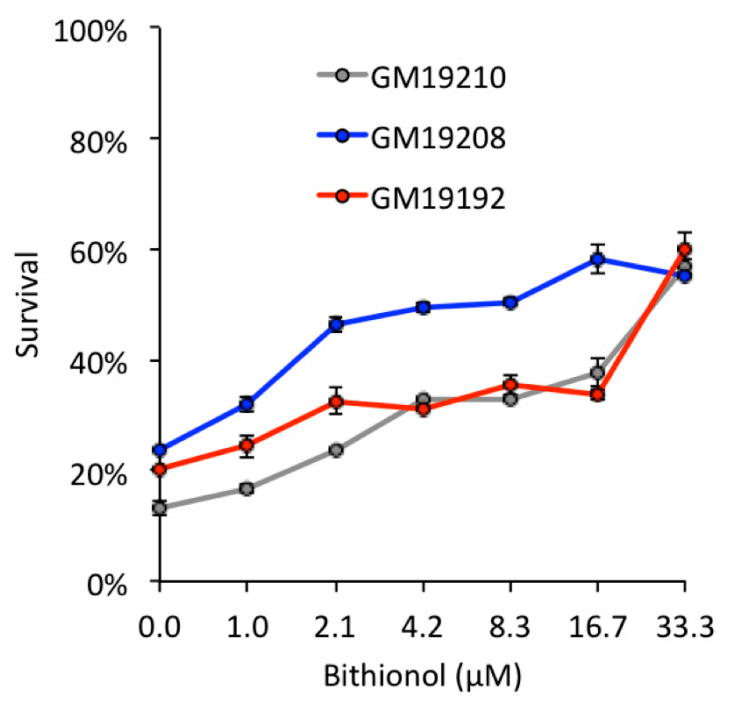

Figure 4h: Bithionol inhibits cytotoxicity mediated by $P$. aeruginosa exotoxin A in sensitive human B-lymphocytes. B-cells were seeded at $1 \times 10^{4}$ cells/well on 96-well plates and were incubated with indicated doses of Bithionol for 1 hour, and then challenged with the toxin for 6 hours. Cell viability was determined by Alamar Blue assay and is shown as the percentage of survivors relative to cells not treated with drugs. 


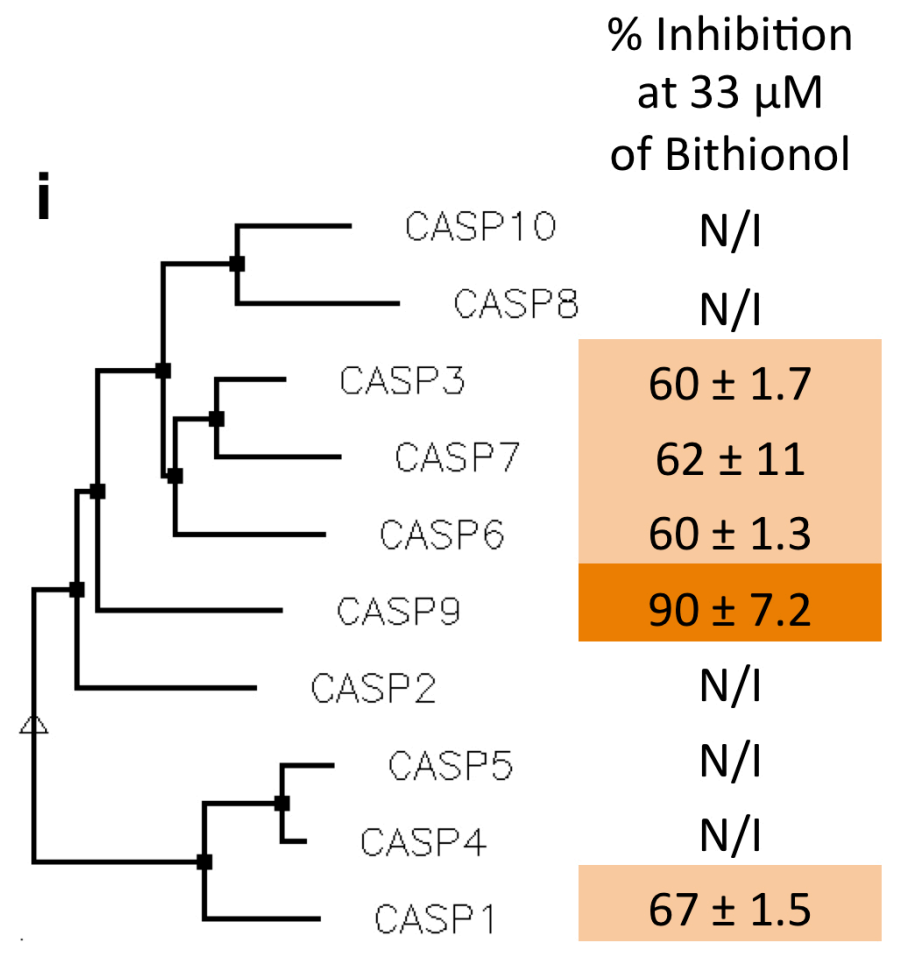

Figure 4i: Bithionol inhibits caspases-1, -3, -6, -7, and -9. Bithionol was tested at $33 \mu \mathrm{M}$ for its ability to inhibit FRET reactions of purified human caspases-1 through 10. Percent inhibition values are shown, and compared to activity of caspases untreated with Bithionol. Phenogram of ten human caspases, assembled by Multalin using Dayhoff alignment parameters, is used to demonstrate relative homology of caspases.

\section{Bithionol inhibits cytotoxic activity of anthrax toxins}

Anthrax toxins, the major virulence factors of the Bacillus anthracis bacterium, include an exotoxin protein complex consisting of a protective antigen (PA) and lethal factor (LF) that act collectively to damage host cells. PA binds to cellular receptors, while LF acts as a protease cleaving cytoplasmic MAPKKs ${ }^{90}$. Three additional host proteases mediate entry and lethality of anthrax toxin: furin, cathepsin-B, and caspase- $1^{40,45,90}$. 
To test the ability of Bithionol to neutralize cytotoxic activity of anthrax toxin, we examined its effect on cell viability in LF-PA - treated RAW264.7 cells. While $80 \%$ of cells used for these assays normally undergo cell death within 6 hours of exposure to anthrax toxin, Bithionol provided substantial protection against LF-PA - mediated cell killing at $33 \mu \mathrm{M}$ (Fig. 5a).

Caspase-1 activation, which occurs in LF-PA intoxication, was monitored using a FRET assay. While we observed an induction of caspase-1 activity upon LF-PA treatment in the absence of Bithionol, caspase-1 induction was not detected in Bithionol-treated cells challenged with anthrax toxin (Fig. 5b). This result confirms that Bithionol inhibits anthrax toxin cytotoxicity by at least inhibiting caspase-1 activity.

We investigated whether additional anthrax toxin pathway proteases are inhibited by Bithionol in live cells. By utilizing MAPKK immunobloting (Fig. 5c), a hybrid toxin FP59 ${ }^{47}$ that enters host cells by utilizing PA, but kills cells by LFindependent mechanism (Figs. 5d and e), and cathepsin-B FRET assay (Fig. 5f), we demonstrated that Bithionol does not inhibit proteolytic activities of cellular LF, furin, and cathepsin-B. 


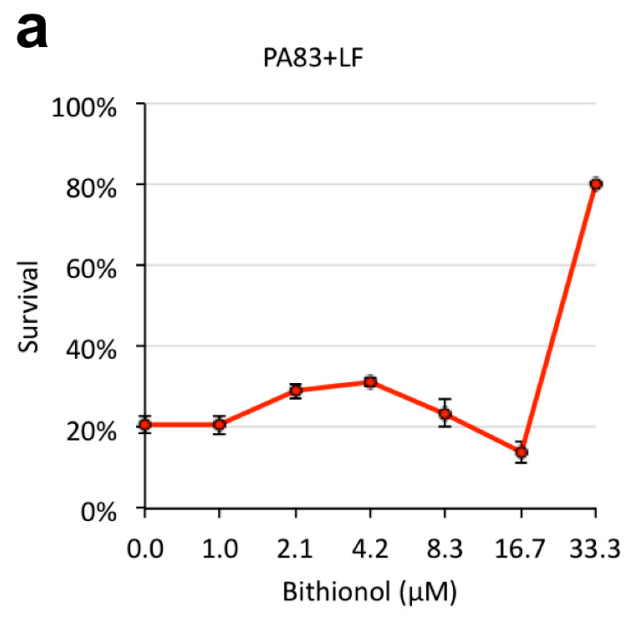

Figure 5a: Bithionol was tested for its ability to inhibit anthrax toxinmediated cytotoxicity. RAW264.7 cells were incubated with indicated doses of Bithionol for 1 hour, followed by 6 hours intoxication with anthrax toxin PA-LF. Cell viability was determined by MTT assay and is shown as the percentage of survivors relative to cells not treated with drugs.

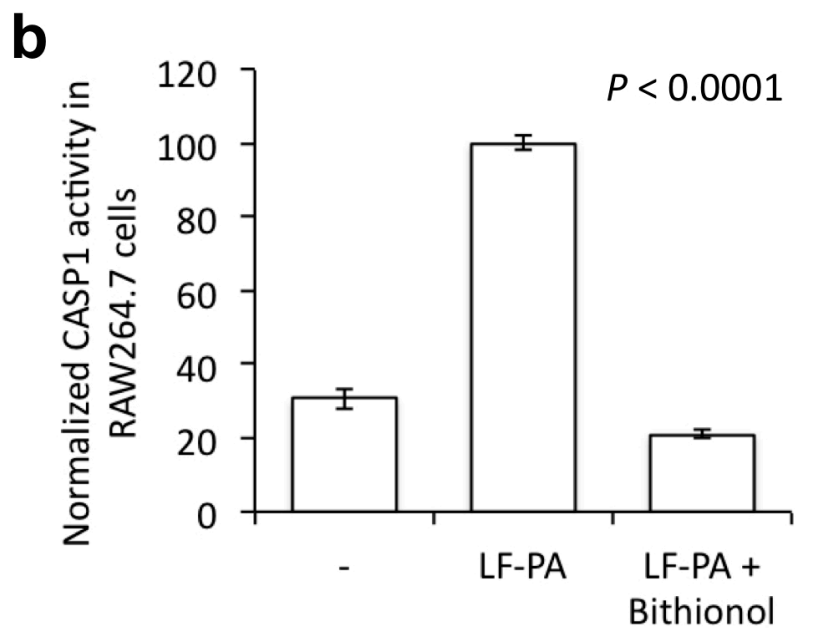

Figure 5b: Bithionol inhibits LF-PA - induced activity of cellular caspase-1. RAW264.7 cells were treated with LF-PA for 1 hour, and then treated either with $33 \mu \mathrm{M}$ Bithionol or DMSO for 1 hour prior to lysis and determination of caspase-1 activity. The activity of caspase- 1 was measured by FRET assay. 


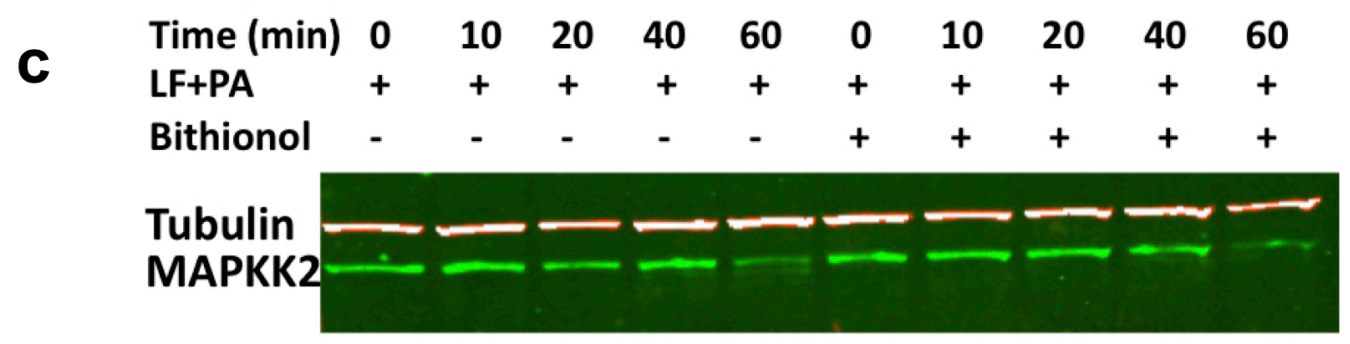

Figure 5c: MAPKK2 immunobloting showing that Bithionol does not block proteolysis of cellular MAPKKs by anthrax LF toxin. While MAPKK2 was cleaved in LF-PA treated RAW264.7 cells, treatment with Bithionol did not affect this process. RAW264.7 cells were incubated with Bithionol or DMSO for 1 hour before addition of vehicle control or $1 \mu \mathrm{g} / \mathrm{ml} \mathrm{PA}+$ LF for up to 60 minutes. Cells were lysed and analyzed via immunoblotting with a MAPKK2-specific antibody. Tubulin was used as a loading control.

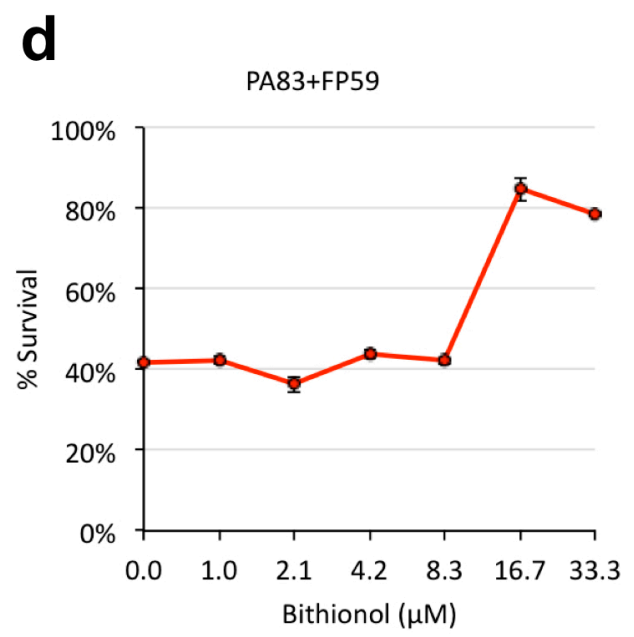

e

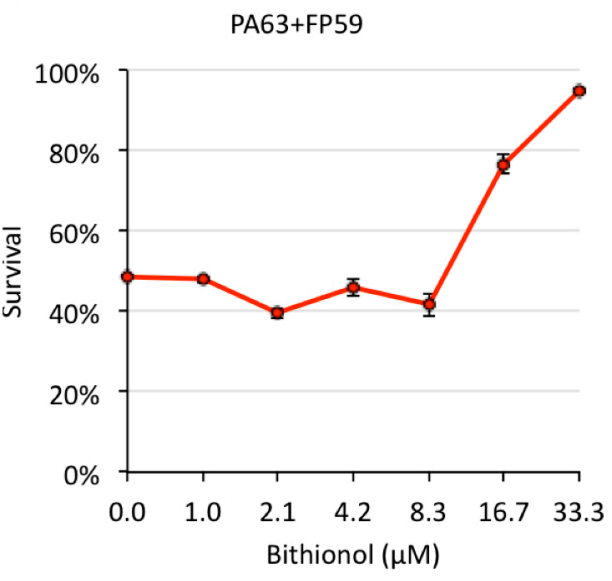

Figure 5d and 5e: Bithionol reduces cell death induced by the hybrid toxin FP59, which has been widely used as an anthrax LF surrogate and contains the PA binding site of LF, as well as a toxin domain derived from PE. Bithionol-treated cells were found to be less sensitive to treatment with PA + FP59. PA was either in the native $83 \mathrm{kDa}$ form (d), or used as $63 \mathrm{kDa}$ lacking $20 \mathrm{kDa}$ Furin cleavage domain (e). RAW264.7 cells were preincubated with a titration of Bithionol for 1 hour, followed by a 6 hours intoxication with $0.5 \mu \mathrm{g} / \mathrm{ml} 83 \mathrm{kDa}$ PA + FP59 or Furin processed $63 \mathrm{kDa}$ PA + FP59. Cell viability was measured via MTT. 


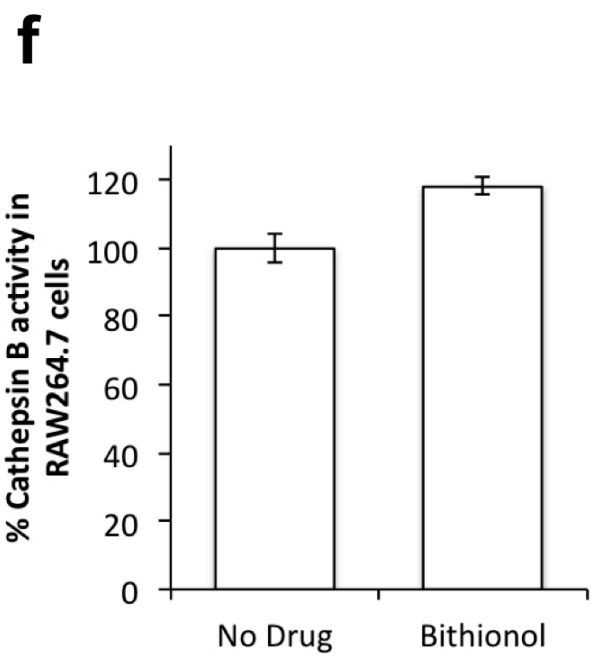

Figure 5f: Bithionol doesn't inhibit cathepsin B protease activity in RAW264.7 cells. RAW264.7 cells were treated with $33 \mu \mathrm{M}$ Bithionol of DMSO for 1 hour prior to lysis, and determination of cathepsin B activity was assessed by FRET assay. 


\section{Bithionol inhibits ricin and Botulinum Neurotoxin $A$ - induced death in vitro and in vivo}

Ricin is another toxin known to induce host caspases-3, -6 , and -7 is ricin ${ }^{22,88}$. It reaches the mammalian cytoplasm through the retrograde transport route from the plasma membrane to ER via endosomes and the Golgi apparatus (Fig. 3a). Once in the cytoplasm, ricin inhibits cellular protein synthesis by cleaving a glycosidic bond within the large rRNA of the 60S subunit of eukaryotic ribosomes 63. We tested the ability of Bithionol to reduce ricin - mediated cellular killing and observed that the drug was able to reduce toxin-mediated cytotoxicity with an EC50 of $10 \mu \mathrm{M}$ (Fig. 6a).

Botulinum neurotoxin serotype $\mathrm{A}(\mathrm{BoNT} / \mathrm{A})$ is a protease that translocates into the host cytoplasm from acidic endosomes, where it cleaves the synaptosomeassociated protein, SNAP-25, and inhibits neurotransmitter release among neurons, leading to muscular paralysis ${ }^{91}$. BoNT/A has been reported to cause cellular caspases-3 and -7 - dependent apoptosis ${ }^{84}$.

After oral administration, Bithionol crosses the intestinal epithelium and is absorbed into the bloodstream in humans and many animals ${ }^{92}$. We evaluated the efficacy of Bithionol as a therapeutic agent during BoNT/A intoxication in Swiss Webster mice. Animals were given a lethal oral dose of BoNT/A complex in the presence and absence of Bithionol. Ninety percent of animals that received a lethal dose of BoNT/A without Bithionol died within 3 days of intoxication (Fig. 6b). All mice that were challenged with BoNT/A and treated with Bithionol at 6.0 
$\mathrm{mg} / \mathrm{kg}$, survived without displaying toxin-associated symptoms, such as wasp waist and paralysis (Fig. 6b).

Since BoNT/A acts as a protease, we investigated whether Bithionol directly inhibits the proteolytic activity of BoNT/A by utilizing a FRET assay. An optimized SNAP-25 peptide with a fluorogenic FITC group at the N-terminus and DABCYL quenching group at the $\mathrm{C}$-terminus was used as the substrate ${ }^{93}$. After cleavage by BoNT/A the fluorescence of FITC at $523 \mathrm{~nm}$ increases. We determined that Bithionol did not affect the proteolysis rate of the fluorescent substrate (Fig. 6c). This result shows that Bithionol protects mice by inhibiting host targets, rather than by inhibiting the toxin itself.

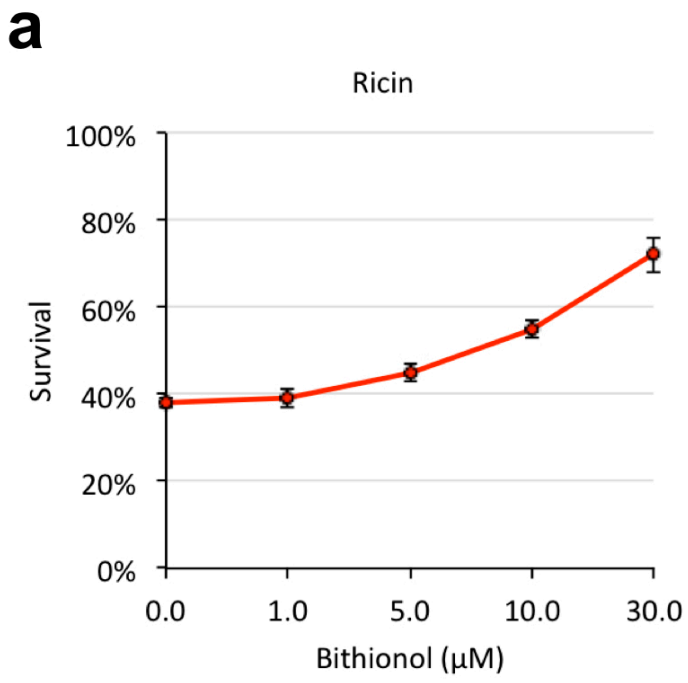

Figure 6a: Bithionol reduces ricin mediated cellular killing. Human K562 cells were incubated with indicated doses of Bithionol for 2 hours, and then challenged with ricin for 24 hours. Cell viability was determined by FSC/SSC flow cytometry. 


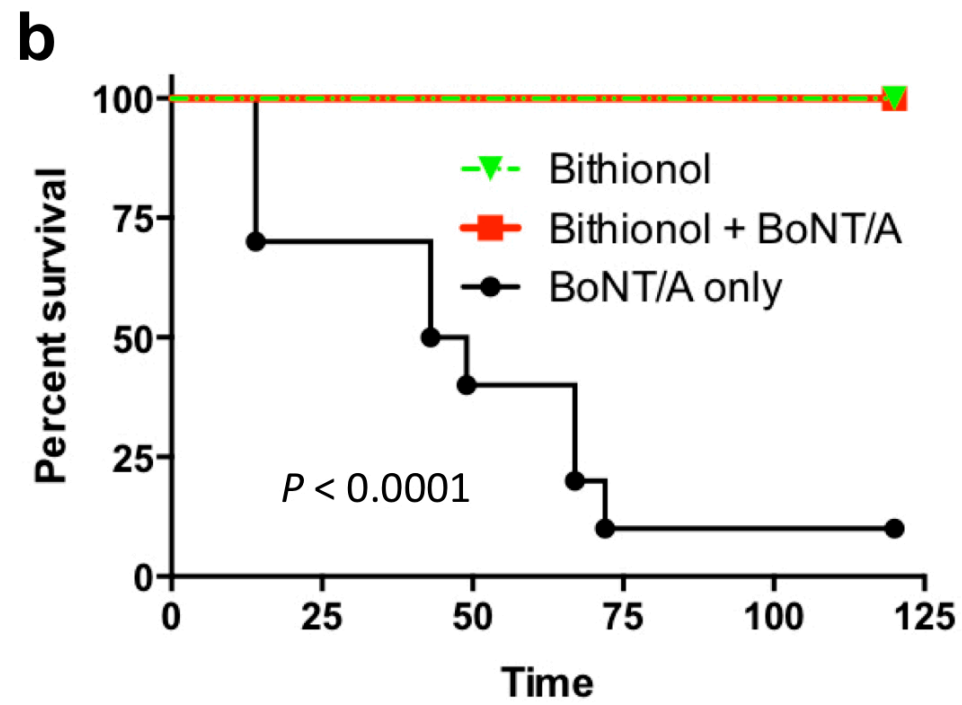

Figure 6b: Ten Swiss Webster CFW mice were treated with $6 \mathrm{mg} / \mathrm{kg}$ Bithionol in the presence or absence of botulinum neurotoxin serotype $A$ complex (BoNT/A) by oral gavage. Animals were observed over 7 days. The Bithionol and BoNT/A survival curves are statistically different based on the Log-rank (Mantel-Cox) test, $P<0.0001$. 


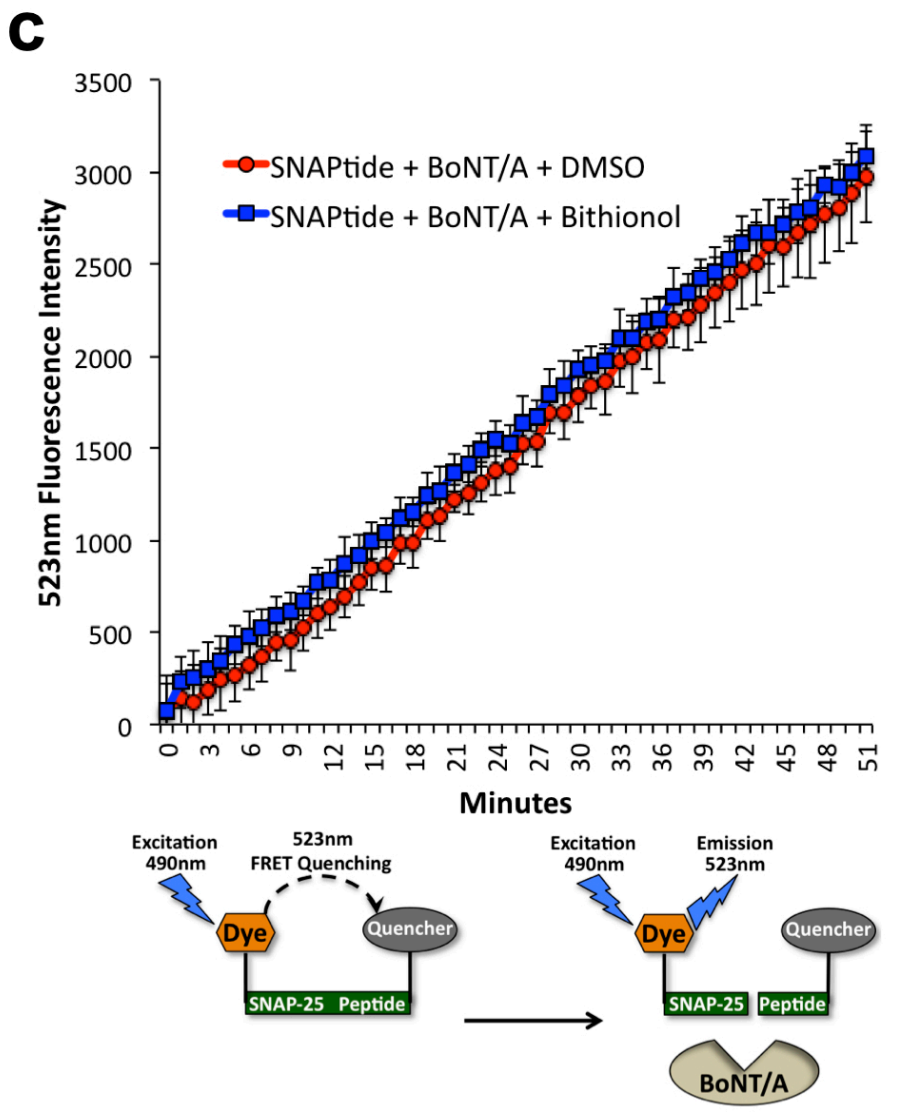

Figure 6c: Bithionol does not inhibit proteolytic activity of BoNT/A. FRET data showing fluorescence emission from two reactions, where $5 \mathrm{nM}$ BoNT/A light chain cleaves fluorescently labeled SNAP-25 substrate peptide without drugs or in the presence of $33 \mu \mathrm{M}$ Bithionol. 


\section{Bithionol acts as a Zika virus Inhibitor}

In addition to pathogenic toxins, viruses are also known to propagate by activating host caspases and inducing programmed cell death ${ }^{94}$. Similarly to toxins, Zika virus (ZIKV) has been reported to lead to cell-death by inducing host caspase-3 and neuronal apoptosis during its propagation ${ }^{95,96}$. Moreover, caspases have previously been reported to cleave various viral proteins, affect viral protein localization, promote viral genome replication and viral assembly, and have been reported to be necessary for viral replication and propagation ${ }^{97,98}$.

Upon observing that Bithionol protects cells from caspase-inducing toxins, we hypothesized that Bithionol might also be able to inhibit the pathogenicity of the Zika virus. The strains utilized in this study were chosen to gauge the ability of Bithionol to inhibit Zika virus strains found within both ZIKV lineages. Both strains utilized in this study had low passage histories and had intact glycosylation sites. Furthermore, both strains were geographically and genetically divergent. Puerto Rico Zika strain, PRVABC59, is closely related to virus strains circulating in the New World including those strains isolated in Brazil and Guatemala. The African ZIKV lineage is ancestral to the Asian lineage; as such DAK AR D 41525 was selected as it is a low passage strain that is mycoplasma free. We tested Bithionol's ability to inhibit Senegal and Puerto Rico isolates of ZIKV in infected Vero E6 cells and human astrocytes. To detect infected cells, immuno-staining was performed using anti-Flavi-virus envelope protein antibodies. Bithionol inhibited the abundance of Puerto Rico ZIKV in Vero E6 cells with EC50 of $6.7 \mu \mathrm{M}$ as well as Senegal ZIKV in Vero E6 and human astrocytes with EC50's of 5.5 and 
$6.3 \mu \mathrm{M}$ respectively (Fig. $6 \mathrm{~d}$ and Table S1). These data indicate that Bithionol is effective in inhibiting ZIKV in host cells.

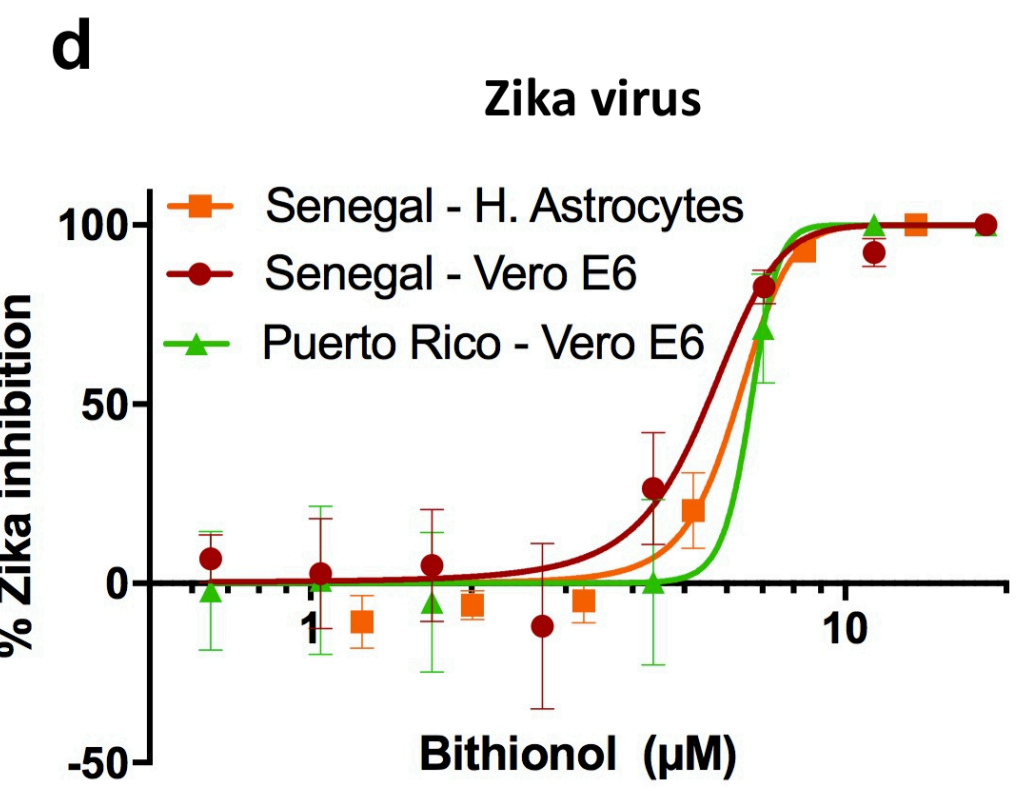

Figure 6d: The ability of Bithionol to inhibit Zika virus (ZIKV) in host Vero E6 cells and astrocytes was measured by fluorescent microscopy. The virusinhibitory EC50 concentrations were determined. 


\section{Discussion}

In order to discover the inhibitors of pathway hubs that mediate the lethality of multiple bacterial toxins, we identified host caspases as hubs and focused the discovery process on therapies that are able to inhibit caspases and reduce toxins' cytotoxicities. Collectively, utilization of both cellular- and biochemicalbased multiplex drug screens provided us with i) a drug hit (Bithionol), ii) a drugtarget (caspases), and iii) an assessment of breadth of spectra of the drug. This disease-network-based approach utilizing two diverse multiplex drug screenings, which we term "Disparate Dual Multiplexing", could significantly shorten the time needed for drug-discovery followed by target-identification steps in a historically lengthy process. In the future, additional types of drug screens could be included in disparate multiplex-based drug screens, such as genetic-based, and immunology-based screens, thus expanding our approach to Disparate Triple, Disparate Quadruple (etc.) Multiplex drug screening.

Bithionol was previously approved to treat helminthes, and although the exact target within these species is not known, it is believed that the drug inhibits oxidative phosphorylation of parasites ${ }^{99}$. Our study has uncovered five additional Bithionol targets: caspases- $1,-3,-6,-7$, and -9 , which by definition makes Bithionol a polypharmacolocial drug. Polypharmacological phenomena include a single drug acting on multiple targets of either a unique or multiple disease pathways. Just like in the current study, many of the polypharmacological approaches aim to discover the unknown off targets for existing drugs, and this

approach is called "drug repurposing" ${ }^{75,100}$. Therefore, this raises the possibility 
that Bithionol targets additional non-caspase host proteins exploited by toxins. To our knowledge, no other drugs used in humans have been reported to inhibit caspases. In the future, Bithionol can be investigated for its efficacy to treat other non-infectious human diseases caused by detrimental activities of caspases, such as neurodegenerative diseases and inflammatory bowel disease.

Bithionol was replaced by the more effective anti-helminthic, Praziquantel ${ }^{99}$. Moreover, Bithionol was used as a bacteriostatic additive in cosmetic products, but was discontinued in 1967 due to photosensitizing effects ${ }^{92}$. Presently, Bithionol is still used to treat helminthic cases in some Asian and European countries and is included as an active ingredient in Fonergine $₫$, used to treat mouth and throat disorders in Argentina ${ }^{101}$. The current drug discovery and development process can take many years for the successful introduction of a new drug into the market. Thus, the current de novo drug discovery and development paradigm is ineffective for dealing with rapidly emerging biological threat agents. Under such circumstances, drug repurposing may offer numerous advantages. Since Bithionol already has a well-established safety and pharmacokinetic profiles in patients and animals, as well as bulk manufacturing methods ${ }^{92}$, the drug could rapidly be made available for a new indication if a biological emergency was to occur. Most notably, it has been shown that after oral administration of $50 \mathrm{mg} / \mathrm{kg}$ of Bithionol in humans, the drug reaches serum concentrations that range from 225 to $480 \mu \mathrm{M}{ }^{92}$, which is on average 30 times higher than the EC50 achieved by our cellular tests (Figs. 4-6). This suggests that it is possible to achieve effective anti-toxin and anti-Zika Bithionol doses in blood 
by oral administration. In addition, Bithionol was i) used to treat cerebral paragonimiasis ${ }^{102}$ and is known to cross the brain-blood barrier ${ }^{103}$; ii) reported to cross the placental barrier ${ }^{104}$; and iii) was used to treat paragonimiasis in a population that included children and pregnant women ${ }^{105}$. All of these observations suggest that Bithionol is likely to achieve anti-Zika efficacy in humans. 


\section{Materials and Methods}

Chemicals and reagents: All bacterial toxins were purchased from List Biological Laboratories (Campbell, CA). FP59 was a gift from Stephen Leppla (NIAID). Ricin was purchased from Vector Laboratories. Clinical Compound Library (CCL) drug library was purchased from Johns Hopkins University Bloomberg School of Public Health. Bithionol was repurchased from Sigma-Aldrich.

Cell culture and cell lines: RAW264.7 mouse macrophage and human C32 melanoma cells (ATCC CRL-1585) were maintained in DMEM (Sigma-Aldrich). Human B-lymphocytes were grown in IMDM (Invitrogen). Human K562 chronic myelogenous leukemia cells (ATCC CCL-243) were grown in RPMI 1640 Medium (Invitrogen). Vero E6 (ATCC CRL-1586) were maintained in MEM (Corning). Primary human Astrocytes (NHA-Astrocytes-AGM, Lonza, \#CC-2565) were cultured in Astrocyte Basal Medium (Clonetics ABM, Lonza) supplemented with AGM SingleQuot Kit Supplement and Growth factors (CC-4123). All media were supplemented with FBS, penicillin, and streptomycin.

Human B-lymphocytes sensitivity to Pseudomonas toxin-mediated lethality: Human B lymphocytes were treated with serial dilutions of $P$. aeruginosa exotoxin A for 48 hours. The viability of $B$ cells was determined by Alamar Blue (AbD Serotec, BioRad) fluorescence, as described by the manufacturer. Each data point shown in Fig. 2a represents the average and SD of results from three wells. 
Cell viability is shown as the percentage of survivors obtained relative to cells in the absence of the toxin (100\% survival). LD20 was calculated for each cell line. Statistical analysis and graphical presentation were performed using GraphPad Prism software. A $P$ value $<0.05$ was considered statistically significant. Homozygous medians were compared by an unpaired $t$ test. CHB and JPT, two East Asian populations, were pooled in order to obtain a more accurate estimate of effect size in the larger combined population. Because linear regression is sensitive to outliers, we removed one outlier in $\mathrm{CHB}$, as the log sensitivity of this cell line couldn't be determined within the toxin range tested.

Cellular drug screens: RAW264.7 cells (10,000 per well) were seeded in 96-well plates 24 hours before the assay. Cells were treated with compounds for 1 hour, and then challenged with either $2 \mu \mathrm{g} / \mathrm{ml}$ PE or $4 \mu \mathrm{g} / \mathrm{ml}$ cholera toxin for 12 hours. As rodent cells are insensitive to diphtheria toxin, C32 cells were treated with 2 $\mu \mathrm{g} / \mathrm{ml}$ of diphtheria toxins for 24 hours. Determination of RAW264.7 and C32 viability was performed by MTT assay. Cell viability is defined as the percentage of surviving cells obtained relative to cells treated with DMSO (100\% survival).

Caspases FRET drug tests: Caspases were induced in RAW264.7 by treating cells with $2 \mu \mathrm{g} / \mathrm{ml}$ of PE for 4 hours. Caspases were extracted and their activity was measured using Caspase Assay Kit (Sigma-Aldrich) with or without drugs. 
The FRET reaction was performed in 96 well plates, and each reaction contained $16 \mu \mathrm{M}$ substrate peptides (Peptides International) conjugated with a 7-amino-4methylcoumarin group at the $\mathrm{N}$-terminus and acetyl group at the $\mathrm{C}$-terminus. The amino acid sequences of substrates were: DNLD for caspase-3, DQTD for caspases-3 and -7 , and VEID for caspase-6. CCL compounds were tested at the final concentration of $33 \mu \mathrm{M}$, as pilot testing indicated that $\mathrm{CCL}$ screen at $16 \mu \mathrm{M}$ would not yield a sufficient number of multiplex hits. Reactions were initiated by adding caspase - containing lysate to a final concentration of $6 \mu \mathrm{g} / \mathrm{ml}$. Kinetic measurements were obtained at $37^{\circ} \mathrm{C}$ every 5 minutes for 2 hours using a fluorescent plate reader. Excitation and emission wavelengths were $360 \mathrm{~nm}$ and $460 \mathrm{~nm}$, respectively, with a cutoff wavelength of $365 \mathrm{~nm}$. Rates of reactions were quantified by the Microsoft Excel LINEST function. A BioVision kit was used to test Bithionol's ability to inhibit FRET reactions of purified recombinant human caspases-1 through 10. One unit of caspase was used in a single FRET reaction.

Toxins treatments and cell viability assays: Cells (10,000 per well) were seeded in 96-well plates 24 hours before the assay. Cells were treated with Bithionol for 1 hour. RAW264.7 cells were challenged with anthrax toxins that include LF or FP59 and PA83 or PA63 (for 6 hours), PE (for 12 hours), or cholera toxin (for 12 hours) at $0.5,2$, and $4 \mu \mathrm{g} / \mathrm{ml}$ respectively. C32 cells were treated with $2 \mu \mathrm{g} / \mathrm{ml}$ of diphtheria toxin for 24 hours. Determination of cells viability was performed by MTT assay. B-lymphocytes cells were seeded in a 96-well plates at 10,000 cells/well 1 hour before toxin treatment, treated with Bithionol for 1 hour, and then 
challenged with $8 \mu \mathrm{g} / \mathrm{ml}$ PE for 6 hours. Determination of lymphocyte viability was determined by Alamar Blue (AbD Serotec, BioRad) fluorescence, as described by the manufacturer. Each data point shown for MTT and Alamar Blue assays indicates the mean $\pm S D$ value obtained in triplicate assays done in a representative experiment. At least three such experiments were carried out.

MAPKK2 cleavage assay: N-terminal MAPKK2, anti-tubulin, and anti-PA antibodies were purchased from Santa Cruz Biotechnology. RAW264.7 cells were pre-treated with $33 \mu \mathrm{M}$ of Bithionol for 1 hour. Following pre-treatment, the cells were exposed to $0.5 \mu \mathrm{g} / \mathrm{ml}$ of $P A$ and $L F$ at $37^{\circ} \mathrm{C}$ for up to three hours in the presence of $33 \mu \mathrm{M}$ of Bithionol. The cells were then washed with cold PBS five times and lysed with RIPA buffer containing a protease inhibitor mixture (Santa Cruz Biotechnology, Inc.). Cell lysates were quantified using the BCA protein quantification kit (Pierce) and loaded onto $4-12 \%$ denaturing gels (Criterion XT Precast Gel, Bio-Rad). After electrophoresis for several hours, the gel was transferred overnight to nitrocellulose membranes; membranes were probed with anti-MAPKK2 or anti tubulin antibodies. Quantitative Western blot analyses of the bands were accomplished using the Odyssey infrared imaging system (LI-COR Biosciences).

Cellular cathepsin B and caspase-1 activity assays: Cathepsin B and caspase-1 activities in total cell lysates were determined using an InnoZyme cathepsin B 
activity assay kit (EMD Milipore) and caspase activity assay kit (BioVision), performed according to the manufacturers' instructions. Cellular cathepsin B or caspase- 1 activities with and without Bithionol were tested by pre-treating cells with $33 \mu \mathrm{M}$ of Bithionol for 1 hour, followed by lysing cells and testing protease activities with fluorescently labeled specific substrates. Caspase- 1 activities were induced by 1 hour pretreatment of cells with $0.5 \mu \mathrm{g} / \mathrm{ml}$ of $L F+P A$, and was compared to cells un-induced by the toxin. Fluorescence intensities indicating cathepsin B or caspase-1 activities were measured (Molecular Devices, Spectra Max 384 PLUS).

Ricin treatment and cell viability assay: K562 cells were seeded at a density of $2 \times 10^{5}$ cells/well in 24 -well plates. Cells were pre-treated with Bithionol for 2 hours and $0.4 \mathrm{ng} / \mathrm{ml}$ ricin was added to the treated wells. Following the 24-hour ricin treatment, the percent of viable cells (within the live gate by $\mathrm{FSC} / \mathrm{SSC}$ ) was measured by flow cytometry using a BD Accuri C6 Flow Cytometer. Experiment was performed in duplicate for each condition.

Mice intoxication studies: 10 Swiss Webster (CFW) mice (6 week old) were treated with $0.125 \mathrm{mg} / \mathrm{mouse}$ Bithionol in the presence or absence of BoNT/A complex ( $3 \mu \mathrm{g} /$ mouse, Metabiologics, Madison $\mathrm{WI}$ ) in phosphate gelatin buffer (0.028 $\mathrm{M}$ sodium phosphate $\mathrm{pH} 7.0,0.2 \%$ gelatin) by oral gavage. Animals were observed over a period of 7 days. Methods were carried out in accordance with 
approved guidelines. All experiments were performed in accordance with relevant guidelines and regulations. All animal experiments have been approved by the Western Regional Research Center IACUC. Euthanasia protocols follow recommendations established by the American Medical Veterinary Association Guideline for Euthanasia to minimize animal pain and suffering.

BoNT/A light chain FRET assay: The reaction volume was $250 \mu$ per well in 96 wells plate, containing 50 mM HEPES pH 7.4 containing $0.05 \%$ TWEEN 20, $5 \mu \mathrm{M}$ SNAPtide (BoNT/A substrate peptide) conjugated with DABCYL and FITC (List Biological Laboratories, Inc), and $33 \mu \mathrm{M}$ of Bithionol. Reactions were initiated by adding BoNT/A light chain to a final concentration of $5 \mathrm{nM}$. Kinetic measurements were obtained at $37^{\circ} \mathrm{C}$ every $1 \mathrm{~min}$ for $50 \mathrm{~min}$ using a fluorescent plate reader. Excitation and emission wavelengths were $490 \mathrm{~nm}$ and $523 \mathrm{~nm}$, respectively, with a cutoff wavelength of $495 \mathrm{~nm}$. At least three such FRET experiments were carried out.

Zika virus high content imaging infections assay: We utilized strains from both ZIKV lineages (African and Asian) to assess the potential for Bithionol to inhibit viral abundance. ZIKV strain DAK AR D 41525 was originally isolated from a pool of Aedes africanus mosquitoes in Senegal in 1984 (passage history: AP61\#1, C6/36\#1, Vero 3) and strain PRVABC59 was originally isolated from human sera in Puerto Rico in 2015 (passage history: Vero 6). Cells were pre-treated with Bithionol for 2 hours prior to infection. Vero E6 cells were exposed to ZIKV at an 
$\mathrm{MOI}$ of 0.5 ; astrocytes were infected with ZIKV at an MOI of 15 . Infection was terminated after 48 hours by fixing samples in formalin solution. For visualization of Zika infection cells were treated for 1 hour with anti-Flavi-virus envelop protein monoclonal antibody $4 \mathrm{G} 2$, followed by anti-mouse IgG conjugated with Dylight 488 (Thermo). Cells were stained with Hoechst (Life Technologies) for nuclei staining and with Cell Mask Red (Life technologies) for cytoplasm staining. Nuclei were stained with Draq5 (Biostatus) diluted in PBS buffer. Images were acquired on the Opera imaging plate reader (Perkin Elmer) and analyzed using Harmony and Acapella PE software. A detailed protocol is described in the supplemental file. 


\section{Supplemental}

\section{Supplemental Table}

\begin{tabular}{|c|c|c|c|c|}
\hline Drug & Cells & Virus (strain) & EC50, !M & SD, !M \\
\hline Bithionol & Vero E6 & Zika (Puerto Rico) & 6.66 & 1.15 \\
\hline Bithionol & Vero E6 & Zika (Senegal) & 5.52 & 0.29 \\
\hline Bithionol & Human Astrocytes & Zika (Senegal) & 6.28 & 0.22 \\
\hline
\end{tabular}

Table S1: The effect of Bithionol on the pathogenicity of Zika Virus in cells. The ability of Bithionol to reduce the abundance of Zika virus in host cells (Vero E6 and human astrocytes) was measured by fluorescent microscopy. The $50 \%$ effective (EC50, virus-inhibitory) concentrations were determined. 
Supplemental Figures
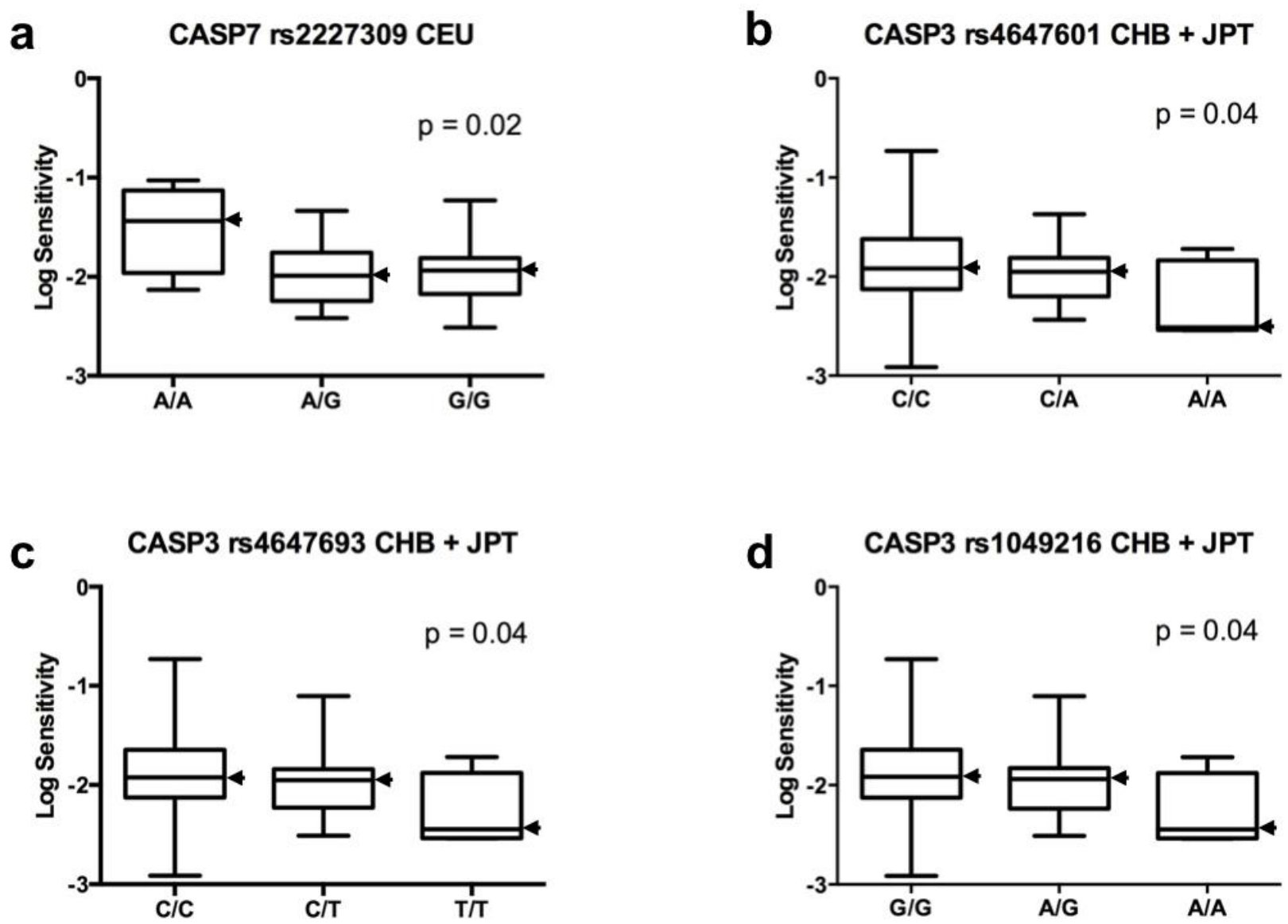

Figure S1a, 1b, 1c, 1d: Caspase-7 and Caspase-3 SNPs associate with log sensitivity of B-lymphoblastoid cells to Pseudomonas aeruginosa exotoxin $A$ in indicated populations. 


\section{Supplemental Material and Methods}

Zika virus High Content Imaging infections assay: Vero E6 cells were seeded in 384 plates (Aurora \#1052-11130) at 2,000 cells/well in 40 !I of culture media for

Zika virus infection assay. Astrocytes were lifted after culturing for 4 days using trypsin/EDTA (Lonza, \#CC-5012) neutralized after 5 min by Trypsin neutralizing solution (Lonza, \#CC-5002). Cells suspension was diluted with cultured media and plated at 20,000 cells/well in 96 well (Greiner, \#655090). After 24 hours of incubation at $37^{\circ} \mathrm{C}$ with $5 \% \mathrm{CO}_{2}$ cells were treated with Bithionol to determine its antiviral activity. Ten serial dilutions of Bithionol in quadruplicate were added directly to the Vero E6 cell cultures using the HP D300 digital dispenser (Hewlett Packard, Palo Alto, CA) in 2-fold dilution increments starting at $100 \mu \mathrm{M}$ at 2 hours prior to infection. Astrocytes were treated with 6 serial dilutions in 3-fold increment and starting at $50 \mu \mathrm{M}$. To generate Negative control column 3 in 384 well plate or row $\mathrm{H}$ in 96 well plates were treated with DMSO only (1\%). The DMSO concentration in each well was normalized to $1 \%$ using an HP D-300 digital dispenser.

The ZIKV isolates used in this study were strain DAK AR D 41525 which was originally isolated from a pool of Ae. africanus mosquitoes in Senegal in 1984 (passage history: AP61\#1, C6/36\#1, Vero 3) and strain PRVABC59 which was originally isolated from human sera in Puerto Rico in 2015 (passage history: Vero 6). Two hours after treatment with compounds Vero E6 cells were infected with Zika virus at $\mathrm{MOI}=0.5$ (calculated for 4,000 cells/well, assuming one complete round of replication of Vero E6 cells at $15 \pm 2$ hrs after cell seeding). Human 
primary astrocytes were infected with Zika at $\mathrm{MOI}=15$ calculated for seeded density of astrocytes. Column 2 in 384 well plate and row A in 96 well plates were left uninfected for positive control of inhibition. Infection was terminated after 48 hours by fixing samples in formalin solution. Antiviral assays were done using a high content imaging technique for 384 or 96 well plates to quantify virus antigen production as a measure of virus infection. After pre-incubation of the cells for 30 min with blocking solution containing 1X PBS with 3\% BSA (Sigma) supplements with $0.1 \%$ Triton X-100 (Sigma) the primary Anti-Flavi virus Group Antigen Antibody, clone D1-4G2 was diluted 1000-fold in blocking buffer (1X PBS with 3\% BSA) and added to each well of the assay plate. The assay plates were incubated for 60 minutes at room temperature. The primary antibody was removed and the cells were washed 3 times with 1X PBS. The secondary detection antibody was an anti-mouse IgG conjugated with Dylight488 (\#405310, Thermo Fisher Scientific, Waltham, MA) diluted 1,000-fold in blocking buffer and was added to each well in the assay plate. The assay plates were incubated for 60 minutes at room temperature. Nuclei were stained using Hoechst 33342 (H3570, Invitrogen), and the cytoplasm of cells was counter-stained with Cell Mask Deep Red (Cat \#C10046, Thermo Fisher Scientific, Waltham, MA) diluted in 1X PBS. Cell images were acquired using Perkin Elmer Opera confocal plate reader (Perkin Elmer, Waltham, MA) using 10X Air objective to collect five images per each well. Virusspecific antigen was quantified by measuring fluorescence emission at a $488 \mathrm{~nm}$ wavelength, the nuclei staining was quantified by measuring fluorescence emission at a $400 \mathrm{~nm}$ and cytoplasm staining with Cell Mask at $640 \mathrm{~nm}$. Analysis 
of acquired images was done using Acapella PE software. A "no virus" control (Column 2) and a "1\% DMSO" control (Column 3) were included on each plate to determine the $0 \%$ and $100 \%$ virus infection, respectively. Hoechst 33342 signal was used to generate nuclei mask and define each cell in the image. Cell Mask dye was used to better-defined area within the borders of the cells. The viralantigen signal was compartmentalized within the cell mask. The intensity of signal in the $488 \mathrm{~nm}$ channel collected from the control wells containing no virus infection was used to determine the threshold for low signal. Those cells that exhibited antigen signal higher than selected threshold were counted as positive for viral infection. Ratio of virus positive cells to total number of analyzed cells was used to determine percent of infection positive cells for each well on assay plate

$$
\% \text { Infected cells }=\frac{\text { Positive Virus Number of Objects }(s)}{\text { Number of objects }(s)} * 100
$$

Two parameters, total the number of nuclei in each well and total percent of infected cells collected for each well on the plates were exported from PE Acapella into PE Columbus Image data storage system and GeneData Screener (Genedata Inc, Lexington, MA) software for further data management and analysis.

Data normalization was done on the plate level to allow comparison of the results from different experimental tests. The percent of inhibition of viral infection (\% Activity or \% Inhibition) was used to reflect decrease in percent of virus positive cells. The median of the values from the neutral control (NC) wells containing cells 
with viral infection and treated with DMSO were used as a minimal activity of inhibitor or $0 \%$ inhibition. The median of values from Blank control wells (BC) containing cells not infected with virus were used as a threshold for the low signal and values were converted into the maximum inhibition of viral infection or $100 \%$ inhibition. (S)- samples, values from the wells treated with compounds.

$\%$ Inhibition $=\frac{\text { Median } \% \text { Virus positive }(N C)-\% \text { Virus positive }(S)}{\text { Median } \% \text { Virus positive }(N C)-\text { Median } \% \text { Virus positive }(B C)} * 100 \%$

The values of $\%$ of infection and \% of viability for each well was used in GraphPad Prism for curve fitting analysis using 2-4 parameter logistic (AC50, MAX, MIN, nHill) non-linear regression model to derive $\mathrm{EC}_{50}$ values corresponding to $50 \%$ of inhibitions. 


\section{Chapter 4 - Future Directions and Concluding Remarks}

The research has successfully unveiled the importance and significance of host oriented therapies to treat multiple infectious diseases. The research has successfuly developed multiplex drug screening method that resulted in the discovery of two host oriented drugs: Amodiaquine and Bithionol. These drugs have shown to have efficacy and potential used to treat multiple infectious diseases in animals and potentially in humans.

Our research has shown that Amodiaquine targets cathepsin $B$, a protein that plays major role in the release of the pathogenic agents into the cytoplasm. Mulltiple bacterial toxins and viruses such as anthrax toxin, diphtheria toxin, ebola, and rabies are also known to exploit cathepsin B during the infection process. The finding has been validated by testing the efficacy of Amodiaquine in vitro and in vivo. The efficacy of Amodiaquine in human has also been further tested and validated in human during 2014 ebola virus crisis in Africa. The broader application of amodiaquine are currently being evaluated through collaborations. The potential clinical trial study in Indonesia is being explored to test the potential use of amodiaquine against anthrax infection in livestock (cattle).

The research has also shown that Bithionol targets caspases, proteins that plays major role by regulating cellular death (apoptosis). Multiple bacterial toxins and viruses such as ricin, Botulinum neurotoxin A, and Zika are known to exploit 
caspases to help regulate cellular death of its host. The finding has been validated by testing the efficacy of Bithionol in vitro. Further study are still being performed, particularly to show the safety and efficacy of the drug in vivo. In addition, the broader application of Bithionol is currently being explored through collaborations. One of the collaboration that is currently being explored is to test the safety and efficacy of Bithionol to treat colic (abdominal pain) in horses.

There are still broad applications of both Amodiaquine and Bithionol that can be explored as they target host proteins that are exploited by diseases other than infectious diseases. Further safety and efficacy validations need to be assesed to bring these two drugs into human clinical trials.

The development of multiplex drug screening has successfuly helped our research to discover two drugs. Further application of multiplex drug screening still can be optimized by expanding drug library and different type of assays. These methods and technologies will help serve as a platform for many years to come to discover a fast, safe, and effective therapies against multiple diseases such as emerging and re-emerging infectious diseases. In addition, future PhD students may also utilize the method to potentially discover new proteins that play role in certain disease pathways. 


\section{References}

1 Mortality, G. B. D. \& Causes of Death, C. Global, regional, and national life expectancy, all-cause mortality, and cause-specific mortality for 249 causes of death, 1980-2015: a systematic analysis for the Global Burden of Disease Study 2015. Lancet 388, 1459-1544, doi:10.1016/S01406736(16)31012-1 (2016).

2 Smith, K. F. et al. Global rise in human infectious disease outbreaks. J R Soc Interface 11, 20140950 (2014).

3 Society, A. C. Discovery and Development of Penicillin, $<$ https://www.acs.org/content/acs/en/education/whatischemistry/landmarks /flemingpenicillin.html> (1999).

4 Diggins, F. W. The true history of the discovery of penicillin, with refutation of the misinformation in the literature. Br J Biomed Sci 56, 83-93 (1999).

5 Clatworthy, A. E., Pierson, E. \& Hung, D. T. Targeting virulence: a new paradigm for antimicrobial therapy. Nat Chem Biol 3, 541-548, doi:10.1038/nchembio.2007.24 (2007).

6 Ventola, C. L. The antibiotic resistance crisis: part 1: causes and threats. $P$ T 40, 277-283 (2015).

7 Davies, J. \& Davies, D. Origins and evolution of antibiotic resistance. Microbiol Mol Biol Rev 74, 417-433, doi:10.1128/MMBR.00016-10 (2010).

8 Aminov, R. I. A brief history of the antibiotic era: lessons learned and challenges for the future. Front Microbiol 1, 134, doi:10.3389/fmicb.2010.00134 (2010).

9 Resistance, R. o. A. Antimicrobial Resistance: Tackling a crisis for the health and wealth of nations, <https://amrreview.org/sites/default/files/AMR Review Paper - Tackling a crisis for the health and wealth of nations 1.pdf> (2014).

10 Sun, J. in Molecular Regulation of Endocytosis (ed Brian Ceresa) (2012).

11 Moayeri, M. \& Leppla, S. H. Cellular and systemic effects of anthrax lethal toxin and edema toxin. Mol Aspects Med 30, 439-455, doi:10.1016/j.mam.2009.07.003 (2009).

12 Hardes, K. et al. Novel Furin Inhibitors with Potent Anti-infectious Activity. ChemMedChem 10, 1218-1231, doi:10.1002/cmdc.201500103 (2015).

13 Gordon, V. M., Klimpel, K. R., Arora, N., Henderson, M. A. \& Leppla, S. H. Proteolytic activation of bacterial toxins by eukaryotic cells is performed by furin and by additional cellular proteases. Infect Immun 63, 82-87 (1995).

14 Tikhonov, I., Ruckwardt, T. J., Berg, S., Hatfield, G. S. \& David Pauza, C. Furin cleavage of the HIV-1 Tat protein. FEBS Lett 565, 89-92, doi:10.1016/j.febslet.2004.03.079 (2004).

15 Hoffmann, M., Gonzalez Hernandez, M., Berger, E., Marzi, A. \& Pohlmann, S. The Glycoproteins of All Filovirus Species Use the Same Host Factors for Entry into Bat and Human Cells but Entry Efficiency Is 
Species Dependent. PLoS One 11, e0149651, doi:10.1371/journal.pone.0149651 (2016).

16 Passiatore, G., Rom, S., Eletto, D. \& Peruzzi, F. HIV-1 Tat C-terminus is cleaved by calpain 1: implication for Tat-mediated neurotoxicity. Biochim Biophys Acta 1793, 378-387, doi:10.1016/j.bbamcr.2008.10.010 (2009).

17 Simonin, Y. et al. Calpain activation by hepatitis $C$ virus proteins inhibits the extrinsic apoptotic signaling pathway. Hepatology 50, 1370-1379, doi:10.1002/hep.23169 (2009).

18 Polla, B. S., Gabert, F., Peyrusse, B. M. \& Jacquier-Sarlin, M. R. Increased proteolysis of diphtheria toxin by human monocytes after heat shock: a subsidiary role for heat-shock protein 70 in antigen processing. Immunology 120, 230-241, doi:10.1111/j.1365-2567.2006.02494.x (2007).

19 Rivera, L. E., Colon, K., Cantres-Rosario, Y. M., Zenon, F. M. \& Melendez, L. M. Macrophage derived cystatin B/cathepsin B in HIV replication and neuropathogenesis. Curr HIV Res 12, 111-120 (2014).

20 Burster, T. et al. Influenza A virus elevates active cathepsin B in primary murine DC. Int Immunol 19, 645-655, doi:10.1093/intimm/dxm030 (2007).

21 Payne, A. M. et al. Caspase activation as a versatile assay platform for detection of cytotoxic bacterial toxins. Journal of clinical microbiology $\mathbf{5 1}$, 2970-2976, doi:10.1128/JCM.01161-13 (2013).

22 Komatsu, N., Oda, T. \& Muramatsu, T. Involvement of both caspase-like proteases and serine proteases in apoptotic cell death induced by ricin, modeccin, diphtheria toxin, and pseudomonas toxin. Journal of biochemistry 124, 1038-1044 (1998).

23 Cicala, C. et al. HIV-1 envelope induces activation of caspase-3 and cleavage of focal adhesion kinase in primary human CD4(+) T cells. Proc Natl Acad Sci U S A 97, 1178-1183 (2000).

24 Masuoka, H. C., Guicciardi, M. E. \& Gores, G. J. Caspase inhibitors for the treatment of hepatitis C. Clin Liver Dis 13, 467-475, doi:10.1016/j.cld.2009.05.010 (2009).

25 Morchang, A. et al. Role of cathepsin B in dengue virus-mediated apoptosis. Biochem Biophys Res Commun 438, 20-25, doi:10.1016/j.bbrc.2013.07.009 (2013).

26 Stancu, C. \& Sima, A. Statins: mechanism of action and effects. J Cell Mol Med 5, 378-387 (2001).

27 Chong, C. R. \& Sullivan, D. J., Jr. New uses for old drugs. Nature 448, 645-646, doi:10.1038/448645a (2007).

28 Bekerman, E. \& Einav, S. Infectious disease. Combating emerging viral threats. Science 348, 282-283, doi:348/6232/282 10.1126/science.aaa3778 (2015).

29 Martchenko, M., Jeong, S. Y. \& Cohen, S. N. Heterodimeric integrin complexes containing beta1-integrin promote internalization and lethality of anthrax toxin. Proc Natl Acad Sci U S A 107, 15583-15588, doi:101014510710.1073/pnas.1010145107 (2010) 
30 Chong, C. R., Chen, X., Shi, L., Liu, J. O. \& Sullivan, D. J., Jr. A clinical drug library screen identifies astemizole as an antimalarial agent. Nature chemical biology 2, 415-416, doi:10.1038/nchembio806 (2006).

31 Sandvig, K. \& van Deurs, B. Delivery into cells: lessons learned from plant and bacterial toxins. Gene Ther 12, 865-872, doi:330252510.1038/sj.gt.3302525 (2005).

32 Martchenko, M., Candille, S. I., Tang, H. \& Cohen, S. N. Human genetic variation altering anthrax toxin sensitivity. Proc Natl Acad Sci U S A 109, 2972-2977, doi:10.1073/pnas.1121006109 (2012).

33 Duesbery, N. S. et al. Proteolytic inactivation of MAP-kinase-kinase by anthrax lethal factor. Science 280, 734-737 (1998).

34 Bradley, K. A., Mogridge, J., Mourez, M., Collier, R. J. \& Young, J. A. Identification of the cellular receptor for anthrax toxin. Nature 414, 225229, doi:10.1038/n35101999 (2001).

35 Scobie, H. M., Rainey, G. J., Bradley, K. A. \& Young, J. A. Human capillary morphogenesis protein 2 functions as an anthrax toxin receptor. Proc Natl Acad Sci U S A 100, 5170-5174, doi:10.1073/pnas.0431098100 (2003).

36 Klimpel, K. R., Molloy, S. S., Thomas, G. \& Leppla, S. H. Anthrax toxin protective antigen is activated by a cell surface protease with the sequence specificity and catalytic properties of furin. Proc Natl Acad Sci U S A 89, 10277-10281 (1992).

37 Kintzer, A. F. et al. The protective antigen component of anthrax toxin forms functional octameric complexes. J Mol Biol 392, 614-629, doi:S0022-2836(09)00876-610.1016/j.jmb.2009.07.037 (2009).

38 Thoren, K. L. \& Krantz, B. A. The unfolding story of anthrax toxin translocation. $\mathrm{Mol}$ Microbiol $\mathbf{8 0}, \quad 588-595$, doi:10.1111/j.13652958.2011.07614.x (2011).

39 Checroun, C., Wehrly, T. D., Fischer, E. R., Hayes, S. F. \& Celli, J. Autophagy-mediated reentry of Francisella tularensis into the endocytic compartment after cytoplasmic replication. Proc Natl Acad Sci U S A 103, 14578-14583, doi:0601838103 (2006).

$40 \mathrm{Ha}, \mathrm{S}$. D. et al. Cathepsin B-mediated autophagy flux facilitates the anthrax toxin receptor 2-mediated delivery of anthrax lethal factor into the cytoplasm. J Biol Chem 285, 2120-2129, doi:M109.06581310.1074/jbc.M109.065813 (2010).

41 Tan, Y. K. et al. Induction of autophagy by anthrax lethal toxin. Biochem Biophys Res Commun 379, 293-297, doi:S0006-291X(08)02427310.1016/j.bbrc.2008.12.048 (2009).

42 Abrami, L., Lindsay, M., Parton, R. G., Leppla, S. H. \& van der Goot, F. G. Membrane insertion of anthrax protective antigen and cytoplasmic delivery of lethal factor occur at different stages of the endocytic pathway. $J$ Cell Biol 166, 645-651, doi:10.1083/jcb.200312072 jcb.200312072 [pii] (2004). 
43 Sobo, K. et al. Late endosomal cholesterol accumulation leads to impaired intra-endosomal trafficking. PLoS One 2, e851, doi:10.1371/journal.pone.0000851 (2007).

44 Tershak, D. R. Association of poliovirus proteins with the endoplasmic reticulum. Journal of virology 52, 777-783 (1984).

45 Wickliffe, K. E., Leppla, S. H. \& Moayeri, M. Anthrax lethal toxin-induced inflammasome formation and caspase-1 activation are late events dependent on ion fluxes and the proteasome. Cellular microbiology 10, 332-343, doi:10.1111/j.1462-5822.2007.01044.x (2008).

46 Panchal, R. G. et al. Identification of small molecule inhibitors of anthrax lethal factor. Nat Struct Mol Biol 11, 67-72, doi:10.1038/nsmb711(2004).

47 Arora, N., Klimpel, K. R., Singh, Y. \& Leppla, S. H. Fusions of anthrax toxin lethal factor to the ADP-ribosylation domain of Pseudomonas exotoxin A are potent cytotoxins which are translocated to the cytosol of mammalian cells. The Journal of biological chemistry 267, 15542-15548 (1992).

48 Miller, C. J., Elliott, J. L. \& Collier, R. J. Anthrax protective antigen: prepore-to-pore conversion. Biochemistry 38, 10432-10441, doi:10.1021/bi990792d (1999).

49 Squires, R. C., Muehlbauer, S. M. \& Brojatsch, J. Proteasomes control caspase-1 activation in anthrax lethal toxin-mediated cell killing. $J$ Biol Chem 282, 34260-34267, doi:M705687200 (2007).

50 Liu, S. \& Leppla, S. H. Cell surface tumor endothelium marker 8 cytoplasmic tail-independent anthrax toxin binding, proteolytic processing, oligomer formation, and internalization. J Biol Chem 278, 5227-5234, doi:10.1074/jbc.M210321200 (2003).

51 Mayer, M. \& Meyer, B. Group epitope mapping by saturation transfer difference NMR to identify segments of a ligand in direct contact with a protein receptor. J Am Chem Soc 123, 6108-6117, doi:ja0100120 [pii] (2001).

52 Meyer, B. \& Peters, T. NMR spectroscopy techniques for screening and identifying ligand binding to protein receptors. Angew Chem Int Ed Engl 42, 864-890, doi:10.1002/anie.200390233 (2003).

53 Mirkovic, B. et al. Novel mechanism of cathepsin B inhibition by antibiotic nitroxoline and related compounds. ChemMedChem 6, 1351-1356, doi:10.1002/cmdc.201100098 (2011).

54 Gnirss, K. et al. Cathepsins B and L activate Ebola but not Marburg virus glycoproteins for efficient entry into cell lines and macrophages independent of TMPRSS2 expression. Virology 424, 3-10, doi:S00426822(11)00568-X10.1016/j.virol.2011.11.031 (2012).

55 Sanchez, A. Analysis of filovirus entry into vero e6 cells, using inhibitors of endocytosis, endosomal acidification, structural integrity, and cathepsin (B and L) activity. J Infect Dis 196 Suppl 2, S251-258, doi:10.1086/520597 (2007). 
56 Lemichez, E. et al. Membrane translocation of diphtheria toxin fragment A exploits early to late endosome trafficking machinery. Mol Microbiol 23, 445-457 (1997).

57 Mingo, R. M. et al. Ebola virus and severe acute respiratory syndrome coronavirus display late cell entry kinetics: evidence that transport to NPC1+ endolysosomes is a rate-defining step. Journal of virology 89, 2931-2943, doi:10.1128/JVI.03398-14 (2015).

58 Colpitts, T. M., Moore, A. C., Kolokoltsov, A. A. \& Davey, R. A. Venezuelan equine encephalitis virus infection of mosquito cells requires acidification as well as mosquito homologs of the endocytic proteins Rab5 and Rab7. Virology 369, 78-91, doi:10.1016/j.virol.2007.07.012 (2007).

59 St Pierre, C. A., Leonard, D., Corvera, S., Kurt-Jones, E. A. \& Finberg, R. W. Antibodies to cell surface proteins redirect intracellular trafficking pathways. Experimental and molecular pathology 91, 723-732, doi:10.1016/j.yexmp.2011.05.011 (2011).

60 Martinez, M. G., Forlenza, M. B. \& Candurra, N. A. Involvement of cellular proteins in Junin arenavirus entry. Biotechnology journal 4, 866-870, doi:10.1002/biot.200800357 (2009).

61 Bernard, E. et al. Endocytosis of chikungunya virus into mammalian cells: role of clathrin and early endosomal compartments. PLoS One 5, e11479, doi:10.1371/journal.pone.0011479 (2010).

62 Qa'Dan, M., Spyres, L. M. \& Ballard, J. D. pH-induced conformational changes in Clostridium difficile toxin B. Infect Immun 68, 2470-2474 (2000).

63 Johannes, L. \& Decaudin, D. Protein toxins: intracellular trafficking for targeted therapy. Gene therapy 12, 1360-1368, doi:10.1038/sj.gt.3302557 (2005).

64 Jackson, M. E. et al. The KDEL retrieval system is exploited by Pseudomonas exotoxin A, but not by Shiga-like toxin-1, during retrograde transport from the Golgi complex to the endoplasmic reticulum. J Cell Sci 112 ( Pt 4), 467-475 (1999).

65 Turcotte, S., Letellier, J. \& Lippe, R. Herpes simplex virus type 1 capsids transit by the trans-Golgi network, where viral glycoproteins accumulate independently of capsid egress. Journal of virology 79, 8847-8860, doi:79/14/8847 10.1128/JVI.79.14.8847-8860.2005 (2005).

66 Haspot, F. et al. Human cytomegalovirus entry into dendritic cells occurs via a macropinocytosis-like pathway in a $\mathrm{pH}$-independent and cholesteroldependent manner. PLoS One 7, e34795, doi:10.1371/journal.pone.0034795 PONE-D-11-14831 [pii] (2012).

67 Krzyzaniak, M. A., Zumstein, M. T., Gerez, J. A., Picotti, P. \& Helenius, A. Host cell entry of respiratory syncytial virus involves macropinocytosis followed by proteolytic activation of the F protein. PLoS Pathog 9, e1003309, doi:10.1371/journal.ppat.1003309 PPATHOGENS-D-12-02762 [pii] (2013). 
68 O'Neill, P., Barton, V., Ward, S. \& Chadwick, J. 4-Aminoquinolines: Chloroquine, Amodiaquine and Next-Generation Analogues. 19-44 (Springer Basel AG, 2012).

69 Minzi, O. M., Rais, M., Svensson, J. O., Gustafsson, L. L. \& Ericsson, O. High-performance liquid chromatographic method for determination of amodiaquine, chloroquine and their monodesethyl metabolites in biological samples. Journal of chromatography. B, Analytical technologies in the biomedical and life sciences 783, 473-480 (2003).

70 Ntale, M. et al. Field-adapted sampling of whole blood to determine the levels of amodiaquine and its metabolite in children with uncomplicated malaria treated with amodiaquine plus artesunate combination. Malaria journal 8, 52, doi:1475-2875-8-52 10.1186/1475-2875-8-52 (2009).

71 Rijken, $M$. J. et al. Pharmacokinetics of amodiaquine and desethylamodiaquine in pregnant and postpartum women with Plasmodium vivax malaria. Antimicrob Agents Chemother 55, 4338-4342, doi:10.1128/AAC.00154-11 (2011).

72 Lu, Q., Wei, W., Kowalski, P. E., Chang, A. C. \& Cohen, S. N. EST-based genome-wide gene inactivation identifies ARAP3 as a host protein affecting cellular susceptibility to anthrax toxin. Proc Natl Acad Sci U S A 101, 17246-17251, doi:0407794101 10.1073/pnas.0407794101 (2004).

73 Barabasi, A. L., Gulbahce, N. \& Loscalzo, J. Network medicine: a networkbased approach to human disease. Nature reviews. Genetics 12, 56-68, doi:10.1038/nrg2918 (2011).

74 Watts, D. J. \& Strogatz, S. H. Collective dynamics of 'small-world' networks. Nature 393, 440-442, doi:10.1038/30918 (1998).

75 Zilbermintz, L. et al. Identification of agents effective against multiple toxins and viruses by host-oriented cell targeting. Scientific reports $\mathbf{5}$, 13476, doi:10.1038/srep13476 (2015).

76 Tafesse, F. G. et al. GPR107, a G-protein-coupled receptor essential for intoxication by Pseudomonas aeruginosa exotoxin A, localizes to the Golgi and is cleaved by furin. The Journal of biological chemistry 289, 2400524018, doi:10.1074/jbc.M114.589275 (2014).

77 Vidal, D. R., Garrone, P. \& Banchereau, J. Immunosuppressive effects of Pseudomonas aeruginosa exotoxin A on human B-lymphocytes. Toxicon : official journal of the International Society on Toxinology 31, 27-34 (1993).

78 Sabeti, P. C. et al. A haplotype map of the human genome. Nature 437, 1299-1320, doi:10.1038/nature04226 (2005).

79 Park, C. et al. Association between CASP7 and CASP14 genetic polymorphisms and the risk of childhood leukemia. Human immunology 73, 736-739, doi:10.1016/j.humimm.2012.04.017 (2012).

80 Garcia-Lozano, J. R. et al. Caspase 7 influences susceptibility to rheumatoid arthritis. Rheumatology (Oxford) 46, 1243-1247, doi:10.1093/rheumatology/kem096 (2007).

$81 \mathrm{Li}, \mathrm{B}$. et al. Molecular epidemiologic correlation analysis between caspase3 gene polymorphism and gastric cancer susceptibility. Cell 
biochemistry and biophysics 70, 1647-1653, doi:10.1007/s12013-0140108-0 (2014).

82 Hosgood, H. D., 3rd et al. Caspase polymorphisms and genetic susceptibility to multiple myeloma. Hematological oncology 26, 148-151, doi:10.1002/hon.852 (2008).

83 Chen, K. et al. CASP3 polymorphisms and risk of squamous cell carcinoma of the head and neck. Clinical cancer research : an official journal of the American Association for Cancer Research 14, 6343-6349, doi:10.1158/1078-0432.CCR-08-1198 (2008).

84 Lourenssen, S., Miller, K. G. \& Blennerhassett, M. G. Discrete responses of myenteric neurons to structural and functional damage by neurotoxins in vitro. American journal of physiology. Gastrointestinal and liver physiology 297, G228-239, doi:10.1152/ajpgi.90705.2008 (2009).

85 Kayagaki, N. et al. Non-canonical inflammasome activation targets caspase-11. Nature 479, 117-121, doi:10.1038/nature10558 (2011).

86 Allam, M., Bertrand, R., Zhang-Sun, G., Pappas, J. \& Viallet, J. Cholera toxin triggers apoptosis in human lung cancer cell lines. Cancer research 57, 2615-2618 (1997).

87 Monnier, P. P. et al. Involvement of caspase- 6 and caspase-8 in neuronal apoptosis and the regenerative failure of injured retinal ganglion cells. The Journal of neuroscience : the official journal of the Society for Neuroscience 31, 10494-10505, doi:10.1523/JNEUROSCI.0148-11.2011 (2011).

88 Wahome, P. G., Ahlawat, S. \& Mantis, N. J. Identification of small molecules that suppress ricin-induced stress-activated signaling pathways. PloS one 7, e49075, doi:10.1371/journal.pone.0049075 (2012).

89 Kroemer, G., Galluzzi, L. \& Brenner, C. Mitochondrial membrane permeabilization in cell death. Physiological reviews 87, 99-163, doi:10.1152/physrev.00013.2006 (2007).

90 Liu, S., Moayeri, M. \& Leppla, S. H. Anthrax lethal and edema toxins in anthrax pathogenesis. Trends in microbiology, doi:10.1016/j.tim.2014.02.012 (2014).

91 Dolly, J. O., Wang, J., Zurawski, T. H. \& Meng, J. Novel therapeutics based on recombinant botulinum neurotoxins to normalize the release of transmitters and pain mediators. The FEBS journal 278, 4454-4466, doi:10.1111/j.1742-4658.2011.08205.x (2011).

92 in The MAK-Collection for Occupational Health and Safety (Wiley-VCH Verlag $\mathrm{GmbH} \&$ Co. KGaA, 2002).

93 Boldt, G. E. et al. Synthesis, characterization and development of a highthroughput methodology for the discovery of botulinum neurotoxin a inhibitors. Journal of combinatorial chemistry 8, 513-521, doi:10.1021/cc060010h (2006).

94 Mocarski, E. S., Upton, J. W. \& Kaiser, W. J. Viral infection and the evolution of caspase 8-regulated apoptotic and necrotic death pathways. Nature reviews. Immunology 12, 79-88, doi:10.1038/nri3131 (2012). 
95 Tang, H. et al. Zika Virus Infects Human Cortical Neural Progenitors and Attenuates Their Growth. Cell stem cell, doi:10.1016/j.stem.2016.02.016 (2016).

96 Dang, J. et al. Zika Virus Depletes Neural Progenitors in Human Cerebral Organoids through Activation of the Innate Immune Receptor TLR3. Cell stem cell, doi:10.1016/j.stem.2016.04.014 (2016).

97 Wurzer, W. J. et al. Caspase 3 activation is essential for efficient influenza virus propagation. The EMBO journal 22, 2717-2728, doi:10.1093/emboj/cdg279 (2003).

98 Richard, A. \& Tulasne, D. Caspase cleavage of viral proteins, another way for viruses to make the best of apoptosis. Cell death \& disease 3, e277, doi:10.1038/cddis.2012.18 (2012).

99 Saborio, P., Lanzas, R., Arrieta, G. \& Arguedas, A. Paragonimus mexicanus pericarditis: report of two cases and review of the literature. The Journal of tropical medicine and hygiene 98, 316-318 (1995).

100 Oprea, T. I. \& Mestres, J. Drug repurposing: far beyond new targets for old drugs. The AAPS journal 14, 759-763, doi:10.1208/s12248-012-9390-1 (2012).

101 Cosme, A. et al. Sonographic findings of hepatic lesions in human fascioliasis. Journal of clinical ultrasound : JCU 31, 358-363, doi:10.1002/jcu.10189 (2003).

102 Choi, D. W. Paragonimus and paragonimiasis in Korea. Kisaengch'unghak chapchi. The Korean journal of parasitology 28 Suppl, 79-102 (1990).

103 Eleuteri, S. et al. Novel therapeutic strategy for neurodegeneration by blocking Abeta seeding mediated aggregation in models of Alzheimer's disease. Neurobiology of disease 74, 144-157, doi:10.1016/j.nbd.2014.08.017 (2015).

104 Takahashi, T., Yoshikawa, M. \& Yoshishige, S. Studies on the Distribution of Radioisotopes by Whole Body Autoradiography (XIX). Distribution of 35S-bis- (3, 5-dichloro-2-hydroxyphenyl) sulfoxide in Mice, Rats and Cockerels. Radioisotopes 18, 552-558 (1969).

105 Nwokolo, C. Endemic paragonimiasis in Africa. Bulletin of the World Health Organization 50, 569-571 (1974). 